Florida International University FIU Digital Commons

FIU Electronic Theses and Dissertations

University Graduate School

3-28-2018

\title{
On Some Ridge Regression Estimators for Logistic Regression Models
}

Ulyana P. Williams

Florida International University, uwillo02@fiu.edu

DOI: 10.25148 /etd.FIDC006547

Follow this and additional works at: https:// digitalcommons.fiu.edu/etd

Part of the Applied Statistics Commons, Other Statistics and Probability Commons, and the Statistical Methodology Commons

\section{Recommended Citation}

Williams, Ulyana P., "On Some Ridge Regression Estimators for Logistic Regression Models" (2018). FIU Electronic Theses and Dissertations. 3667.

https://digitalcommons.fiu.edu/etd/3667

This work is brought to you for free and open access by the University Graduate School at FIU Digital Commons. It has been accepted for inclusion in FIU Electronic Theses and Dissertations by an authorized administrator of FIU Digital Commons. For more information, please contact dcc@fiu.edu. 


\title{
FLORIDA INTERNATIONAL UNIVERSITY
}

Miami, Florida

ON SOME RIDGE REGRESSION ESTIMATORS FOR LOGISTIC REGRESSION MODELS

\author{
A thesis submitted in partial fulfillment \\ of the requirements for the degree of \\ MASTER OF SCIENCE \\ in \\ STATISTICS \\ by \\ Ulyana Williams
}

2018 
To: Dean Michael R. Heithaus

College of Arts, Sciences and Education

This dissertation, written by Ulyana Williams, and entitled On Some Ridge Regression Estimators for Logistic Regression Models, having been approved in respect to style and intellectual content, is referred to you for judgment.

We have read this dissertation and recommend that it be approved.

$\begin{array}{r}\hline \text { Jie Mi } \\ \hline \text { Florence George } \\ \hline \text { B.M. Golam Kibria, Major Professor }\end{array}$

Date of Defense: March 28, 2018

The dissertation of Ulyana Williams is approved.

Dean Michael R. Heithaus College of Arts, Sciences and Education

Andrés G. Gil Vice President for Research and Economic Development and Dean of the University Graduate School

Florida International University, 2018 


\section{ABSTRACT OF THE THESIS \\ ON SOME RIDGE REGRESSION ESTIMATORS FOR LOGISTIC REGRESSION MODELS}

by

Ulyana Williams

Florida International University, 2018

Miami, Florida

\section{Professor B. M. Golam Kibria, Major Professor}

The purpose of this research is to investigate the performance of some ridge regression estimators for the logistic regression model in the presence of moderate to high correlation among the explanatory variables. As a performance criterion, we use the mean square error (MSE), the mean absolute percentage error (MAPE), the magnitude of bias, and the percentage of times the ridge regression estimator produces a higher MSE than the maximum likelihood estimator.

A Monto Carlo simulation study has been executed to compare the performance of the ridge regression estimators under different experimental conditions. The degree of correlation, sample size, number of independent variables, and log odds ratio has been varied in the design of experiment.

Simulation results show that under certain conditions, the ridge regression estimators outperform the maximum likelihood estimator. Moreover, an empirical data analysis supports the main findings of this study.

This thesis proposed and recommended some good ridge regression estimators of the logistic regression model for the practitioners in the field of health, physical and social sciences. 


\section{ACKNOWLEDGMENTS}

I would like to express my sincere gratitude to my advisor Prof. B. M. Golam Kibria for the continuous support of my M.S study and related research. Also, I have to thank Prof. Kristofer Mansson for assistance with simulation study. Besides my advisor, I would like to thank the rest of my thesis committee: Prof. Jie Mi, Prof. George Florence for their contributions in the completion of this thesis. Finally, I must express my very profound gratitude to my parents and to my husband for providing me with support throughout my years of study. 


\section{TABLE OF CONTENTS}

CHAPTER

PAGE

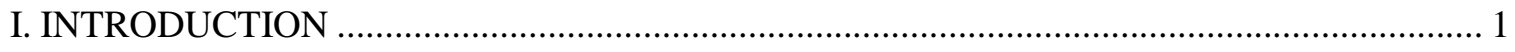

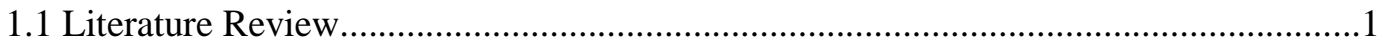

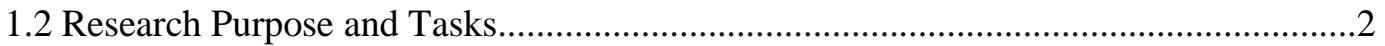

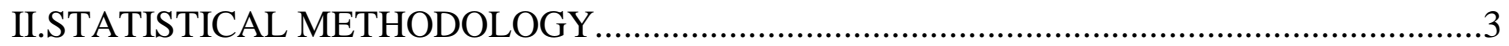

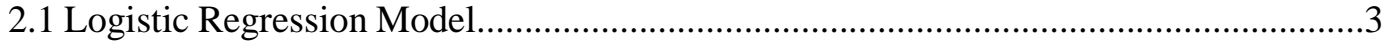

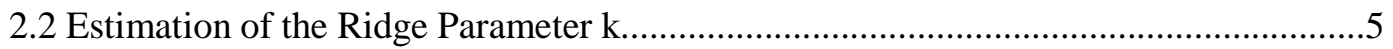

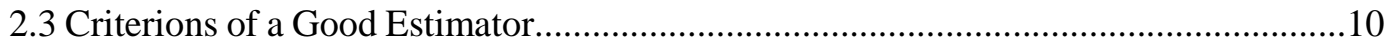

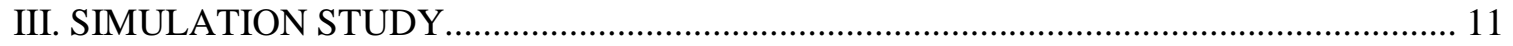

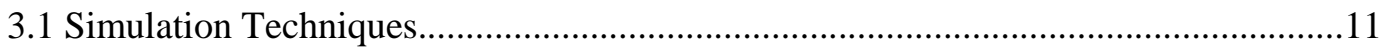

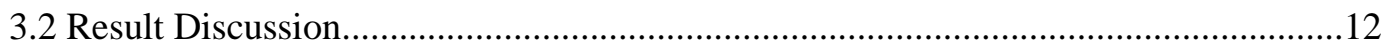

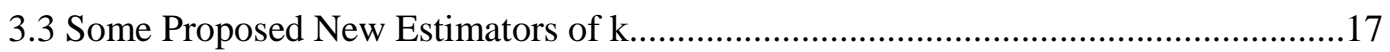

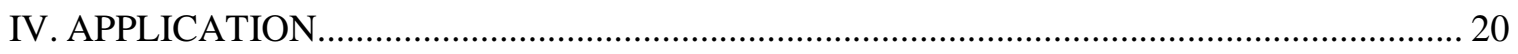

V. SUMMARY AND CORRESPONDING REMARKS........................................................22

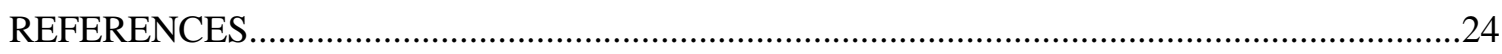

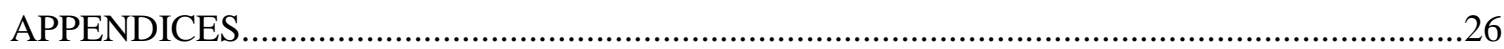




\section{LIST OF FIGURES}

FIGURE

PAGE

1. Performance of estimators as a function of sample size for $p=4, \rho=0.95$, intercept $=0 \ldots \ldots \ldots \ldots 12$

2. Performance of estimators as a function of sample size for $p=4, \rho=0.95$, intercept $=0 \ldots \ldots \ldots . .13$

3. Performance of the estimators as a function of $\rho$ when $p=4, n=100$ and intercept $=0 \ldots \ldots \ldots \ldots 14$

4. Performance of the selected estimators as a function of $\rho$ when $p=4, n=100$, intercept $=0 \ldots \ldots .14$

5. Performance of the estimators as a function of $\rho$ when $\mathrm{p}=8, \mathrm{n}=100$ and intercept $=0 \ldots \ldots \ldots \ldots 15$

6. Performance of the selected estimators as a function of $\rho$ when $p=8, n=100$, intercept $=0 \ldots \ldots .15$

7. Performance of the estimators as a function of $\mathrm{p}$ with $\rho=0.95, \mathrm{n}=100$ and intercept $=0 \ldots \ldots . .16$

8. Figure 8. Performance of the estimators as a function of the intercept

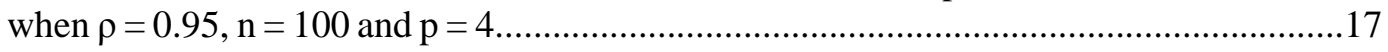

9. Performance of estimators as a function of sample size for $\mathrm{p}=4, \rho=0.95$, intercept $=0 \ldots \ldots \ldots \ldots 18$

10. Performance of estimators as a function of sample size for $\mathrm{p}=4, \rho=0.95$, intercept $=-1 \ldots \ldots .19$

11. Performance of estimators as a function of sample size for $p=4, \rho=0.95$, intercept $=1 \ldots \ldots . .19$ 


\section{CHAPTER I}

\section{INTRODUCTION}

\subsection{Literature Review}

In a multiple linear or non-linear regression model, one may deal with near- linear dependency among the explanatory variables known as a multicollinearity. If two or more explanatory variables are highly correlated with one another, methods such as the least squares and maximum likelihood (ML) for estimating the regression parameters give a very poor precision of the estimates. There is perfect multicollinearity if absolute value of the correlation coefficient between two independent variables is equal to 1 . We seldom have perfect multicollinearity in practice. In general, if simple correlation coefficient between two regressors is greater than 0.8 or 0.9 or variance inflation factor is greater than 3 , the multicollinearity will affect calculations regarding individual predictors by inflating the variance of the parameter estimates (see Mansson, 2011).

One of the many remedies for solving the multicollinearity problem, is to use the ridge regression method proposed by Hoerl and Kennard (1970). Their work is the most frequently cited in the literature and generally regarded as the seminal paper on the subject. Many authors have worked on developing estimates for ridge regression parameter for the mainly linear regression models. To mention a few, Lawless and Wang (1976), Kibria (2003), Khalaf and Shukur (2005), Alkhamisi, Grhadban and Shukur (2007), Gisela and Kibria (2009) and very recently Kibria and Banik (2016) and Asar and Genc (2017) among others. However, few researchers have been studying non-linear ridge regression model, such as the logistic ridge regression model. Among them Schaefer et al. (1984), Hoerl et al. (1975), Mansson and Shukur (2011) and very recently Månsson (2017) are notable. This thesis expands on that study by evaluating more ridge estimators and proposing some new k estimators for the logistic ridge regression model. 
Logistic regression is a widely used method for categorical data. It is a type of regression model where the response variable is a dichotomous variable and the independent variables are continuous or categorical. The logistic regression widely employed in many fields, such as epidemiological research, health science and social sciences. A very good example of this model is to investigate the occurrence of a disease as related to different characteristics of patients, such as, age, sex, food habit, calorie intake etc. The motivational example of this model is to predict the recreational trip of the registered leisure boat owners in 23 counties of East Texas using the following explanatory variables: facility's subjective quality ranking, respondent's taste for waterskiing, travel cost to Lake Conroe, travel cost to Lake Somerville, travel cost to Lake. The Texas example will be analyzed in Chapter 4 .

\subsection{Research Purpose and Tasks}

The present thesis will propose different methods for estimating the ridge parameter, $k$. In order to judge the performance of the estimators, we need to compare these estimators under different performance criterion. The main objective of my research is to investigate the performance of the popular ridge estimators for the logistic regression model in the presence of moderate to high correlation among the explanatory variables employing the following criteria:

1. Mean squared error (MSE),

2. Mean absolute percentage error (MAPE),

3. Magnitude of bias,

4. Performance of ridge regression estimator compared to the ML estimator, in terms of the percentage of times the ridge regression estimator produces a higher MSE than the ML estimator.

The organization of the thesis is as follows. We define different ridge regression estimators of $k$ in Chapter 2. A Monte Carlo simulation study is conducted in Chapter 3. In Chapter 4, the empirical application of the ridge logistic regression will be presented. Summary and concluding remarks are given in Chapter 5. 


\section{CHAPTER II}

\section{STATISTICAL METHODOLOGY}

\subsection{Logistic Regression Model}

Logistic regression is one of the most commonly used tools for applied statistics to explain the relationship between dependent binary variable and discrete and/or continuous explanatory variables. The jth value of the dependent variable $\mathbf{Y}$ of the regression model is Bernoulli random with the following parameter $\pi_{j}$ (see Mansson (2011)):

$$
\pi_{j}=\mathrm{P}\left(\mathrm{y}_{j}=1\right)=\frac{\exp \left(\mathbf{x}_{j} \boldsymbol{\beta}\right)}{1+\exp \left(\mathbf{x}_{j} \boldsymbol{\beta}\right)}, \quad \mathrm{j}=1, \ldots, \mathrm{n}
$$

where $\mathbf{x}_{j}$ is the $\mathrm{j}^{\text {th }}$ row of $\mathrm{n} \times(\mathrm{p}+1)$ data matrix $\boldsymbol{X}$ and $\boldsymbol{\beta}$ is a $(\mathrm{p}+1) \times 1$ vector of coefficients.

The most common method to estimate $\boldsymbol{\beta}$ is to apply ML method because this method does not require any restrictions on the characteristics for independent variables.

The joint PMF of $\mathrm{y}_{\mathrm{j}}$ 's is given by

$$
L(\boldsymbol{\beta} \mid \boldsymbol{X})=\prod_{j=1}^{n}\left\{\pi_{j}^{y_{j}}\left(1-\pi_{j}\right)^{1-y_{j}}\right\}
$$

and the log likelihood function by

$$
\log (L(\boldsymbol{\beta} \mid \boldsymbol{X}))=\sum_{j=1}^{n} y_{j} \log \left(\pi_{j}\right)+\sum_{j=1}^{n}\left(1-y_{j}\right) \log \left(1-\pi_{j}\right) .
$$

To find the MLE of $\boldsymbol{\beta}$ we need to take the first derivative of the above equation and solve the likelihood equation

$$
\frac{\partial \log (L(\boldsymbol{\beta} \mid \mathbf{X}))}{\partial \boldsymbol{\beta}}=\sum_{j=1}^{n} \mathrm{x}_{j}\left(y_{j}-\pi_{j}\right)=0
$$

which is nonlinear in $\boldsymbol{\beta}$. The most common method of obtaining the MLE is to apply the iteratively weighted least squares algorithm as follows (see Mansson(2011)):

$$
\hat{\beta}_{M L}=\left(X^{\prime} \widehat{W} X\right)^{-1} X^{\prime} \widehat{W} \hat{z}
$$

where $\widehat{W}=\operatorname{diag}\left(\hat{\pi}_{j}\left(1-\hat{\pi}_{j}\right)\right)$ and $\hat{z}_{j}=\log \left(\hat{\pi}_{j}\right)+\frac{y_{j}-\widehat{\pi}_{j}}{\hat{\pi}_{j}\left(1-\widehat{\pi}_{j}\right)}$ is the $j^{\text {th }}$ element of the vector $\hat{z}$. 
The asymptotic variance-covariance matrix of the ML estimator is obtained by differentiating $\log$-likelihood function second time with respect to each element of $\boldsymbol{\beta}$, denoted by $\boldsymbol{\beta}^{\prime}$ (see Mansson(2011)):

$$
\begin{aligned}
\frac{\partial^{2} \log (L(\beta \mid \mathrm{X}))}{\partial \beta \partial \beta^{\prime}} & =\frac{\partial}{\partial \beta^{\prime}} \sum_{j=1}^{n} \mathrm{x}_{j}\left(y_{j}-\pi_{j}\right) \\
& =-\frac{\partial}{\partial \beta^{\prime}} \sum_{j=1}^{n} \mathrm{x}_{j} \pi_{j} \\
& =-\sum_{j=1}^{n} \mathrm{x}_{j} \pi_{j}\left(1-\pi_{j}\right) \mathrm{x}_{j}^{\prime}=\left(X^{\prime} \widehat{W} X\right)^{-1} .
\end{aligned}
$$

One of the disadvantages of using ML method is that the ML estimator can be affected by the presence of collinearity. Because of collinearity in $X$ matrix, the elements of $\left(X^{\prime} \widehat{W} X\right)^{-1}$ will be large and consequently the variance of ML estimator become inflated. To combat the problem of multicollinearity, the ridge logistic estimator has been proposed (see Schaefer, 1986). It is defined as

$$
\hat{\beta}^{R}(k)=\left(X^{\prime} \widehat{W} X+k I\right)^{-1} X^{\prime} \widehat{W} X \hat{\beta}_{M L}=V \hat{\beta}_{M L}, \quad k>0
$$

where $V=\left(X^{\prime} \widehat{W} X+k I\right)^{-1} X^{\prime} \widehat{W} X$. The asymptotic mean square error (MSE) of the ridge estimator is obtain as follows (see Mansson (2011)):

$\operatorname{MSE}\left(\hat{\beta}^{R}(\mathrm{k})\right)=E\left[\left(V \hat{\beta}_{M L}-\beta\right)^{\prime}\left(V \hat{\beta}_{M L}-\beta\right)\right]$

$$
\left.=E\left(\left(\hat{\beta}_{M L}-\beta\right)^{\prime} V^{\prime} V\left(\hat{\beta}_{M L}-\beta\right)\right)+E\left(\beta^{\prime}(V-I)^{\prime}(V-I) \beta\right)+2 * E\left(\left(\hat{\beta}_{M L}-\beta\right)^{\prime} V^{\prime}(V-I) \beta\right)\right) \text {. }
$$

It is known that for large $n,\left(\hat{\beta}_{M L}-\beta\right) \sim \mathrm{N}\left(0,\left(X^{\prime} \widehat{W} X\right)^{-1}\right)$ (see Lee (1988)).

Therefore, $\left.E\left(\left(\hat{\beta}_{M L}-\beta\right)^{\prime} V^{\prime}(V-I) \beta\right)\right)=0$.

Then the MSE becomes as follows:

$$
\begin{aligned}
& \operatorname{MSE}\left(\hat{\beta}^{R}(\mathrm{k})\right)=E\left(\left(\hat{\beta}_{M L}-\beta\right)^{\prime} V^{\prime} V\left(\hat{\beta}_{M L}-\beta\right)\right)+E\left(\beta^{\prime}(V-I)^{\prime}(V-I) \beta\right) \\
& E\left(\left(\hat{\beta}_{M L}-\beta\right)^{\prime} V^{\prime} V\left(\hat{\beta}_{M L}-\beta\right)\right)=\operatorname{tr}\left(E\left(V\left(\hat{\beta}_{M L}-\beta\right)\left(\hat{\beta}_{M L}-\beta\right)^{\prime} V^{\prime}\right)\right)=\operatorname{tr}\left(V \operatorname{Cov}\left(\hat{\beta}_{M L}\right) V^{\prime}\right)= \\
& \operatorname{tr}\left(V\left(X^{\prime} \widehat{W} X\right)^{-1} V^{\prime}\right)=\operatorname{tr}\left(\left(X^{\prime} \widehat{W} X+k I\right)^{-2} X^{\prime} \widehat{W} X\right) . \\
& E\left(\beta^{\prime}(V-I)^{\prime}(V-I) \beta\right)=\beta^{\prime}\left(-k\left(X^{\prime} \widehat{W} X+k I\right)^{-1}\right)^{\prime}\left(-k\left(X^{\prime} \widehat{W} X+k I\right)^{-1}\right) \beta
\end{aligned}
$$


$=\beta^{\prime}\left(k^{2}\left(X^{\prime} \widehat{W} X+k I\right)^{-2}\right) \beta$

Let $\boldsymbol{C}=\boldsymbol{X}^{\prime} \widehat{\boldsymbol{W}} \boldsymbol{X}$ and $\boldsymbol{\Lambda}=\operatorname{diag}\left(\lambda_{1}, \ldots . \lambda_{p}\right)$

Suppose there exists an orthogonal matrix $\boldsymbol{P}$, such that $\boldsymbol{P}^{\prime} \boldsymbol{C P}=\boldsymbol{\Lambda}$, then

$$
\begin{aligned}
& \operatorname{tr}\left(\left(X^{\prime} \widehat{W} X+k I\right)^{-2} X^{\prime} \widehat{W} X\right)=\operatorname{tr}\left(P P^{\prime}\left(X^{\prime} \widehat{W} X+k I\right)^{-1} P P^{\prime}\left(X^{\prime} \widehat{W} X+k I\right)^{-1} P P^{\prime} X^{\prime} \widehat{W} X\right)= \\
& =\operatorname{tr}\left(P^{\prime}\left(X^{\prime} \widehat{W} X+k I\right)^{-1} P P^{\prime}\left(X^{\prime} \widehat{W} X+k I\right)^{-1} P P^{\prime} X^{\prime} \widehat{W} X P\right)= \\
& =\operatorname{tr}\left(\left(P^{\prime} X^{\prime} \widehat{W} X P+k I\right)^{-1}\left(P^{\prime} X^{\prime} \widehat{W} X P+k I\right)^{-1} P^{\prime} X^{\prime} \widehat{W} X P\right)=\operatorname{tr}\left((\Lambda+k I)^{-1}(\Lambda+k I)^{-1} \Lambda\right)= \\
& =\sum_{i=1}^{p} \frac{\lambda_{i}}{\left(\lambda_{i}+k\right)^{2}} \\
& k^{2} \beta^{\prime}\left(X^{\prime} \widehat{W} X+k I\right)^{-2} \beta=k^{2}(P \beta)^{\prime}\left(P^{\prime} X^{\prime} \widehat{W} X P+k P P^{\prime}\right)^{-2}(P \beta)=k^{2} \sum_{i=1}^{p} \frac{\alpha_{i}^{2}}{\left(\lambda_{i}+k\right)^{2}}
\end{aligned}
$$

So, $\operatorname{MSE}\left(\hat{\beta}^{R}(\mathrm{k})\right)=\operatorname{Var}\left(\hat{\beta}^{R}\right)+\left(\operatorname{Bias}\left(\hat{\beta}^{R}\right)\right)^{2}$

$$
=\sum_{i=1}^{p} \frac{\lambda_{i}}{\left(\lambda_{i}+k\right)^{2}}+k^{2} \sum_{i=1}^{p} \frac{\alpha_{i}^{2}}{\left(\lambda_{i}+k\right)^{2}},
$$

where $\lambda_{i}$ is the $\mathrm{i}^{\text {th }}$ eigenvalue of the $\mathbf{X}^{\prime} \widehat{\mathbf{W}} \mathbf{X}$ matrix and $\boldsymbol{\alpha}=\mathbf{P} \boldsymbol{\beta}$ (see Mansson (2011)).

The first term in Eq. (2.10) is a continuous, monotonically decreasing function of $k$, and the second term is a continuous, monotonically increasing function of $k$. For large value of $k$, the variance vanishes and the bias dominates the MSE. The main goal of logistic ridge regression method is to find an appropriate $k$ such that the decrease in variance of the ridge regression estimator exceeds the increase in its bias.

\subsection{Estimation of the Ridge Parameter $k$.}

The first method of choosing the biasing or ridge parameter $k$ was proposed by Hoerl and Kennard (1970) for linear regression model. It states that there always exists a k $>0$ such that MSE $\left(\hat{\beta}^{R}(\mathrm{k})\right)<\operatorname{MSE}\left(\hat{\beta}_{M L}\right)$. Schaefer (1984) followed the same principal to find the ridge parameter for 
logistic regression. To show that we minimize the mean square error of ridge estimator, the first derivative of Eq. (2.10) with respect to $k$ is

$$
\frac{\partial \operatorname{MSE}\left(\widehat{\beta}^{R}\right)}{\partial k}=-2 \sum_{i=1}^{p} \frac{\lambda_{i}}{\left(\lambda_{i}+k\right)^{3}}+2 k \sum_{i=1}^{p} \frac{\lambda_{i} \alpha_{i}^{2}}{\left(\lambda_{i}+k\right)^{3}}
$$

Since $\lambda_{i}>0$, the first derivatives of the first and second terms are always non-positive and non-negative, respectively. We note that when $k$ is equal to zero $\hat{\beta}^{R}(k)=\hat{\beta}_{M L}$ with equal variance $\sum_{i=1}^{p} \frac{1}{\lambda_{i}}$ and zero bias.

Moreover, the optimal value of any individual parameter $k_{i}$ can be found by setting Eq. (2.11) to zero and solve for $k$. Then it can be shown that

$$
k_{i}=\frac{1}{\alpha_{i}^{2}}
$$

The optimal value of $k_{i}$ fully depends on the unknown $\alpha_{i}$, which can be estimated from the data. Schaeffer et al. (1984) suggested to replace $\alpha_{i}$ by its estimator $\hat{\alpha}_{i}$. That means, the optimum value if $k$ is obtained as follows:

$$
\hat{k}_{H}=\frac{1}{\widehat{\alpha}_{i}^{2}}
$$

Schaefer (1984) showed that the optimal value of $k$ for ridge logistic regression model as follows:

$$
\hat{k}_{H 1}=\frac{1}{\widehat{\alpha}_{\max }^{2}}
$$

Hoerl et al. (1975) suggested a different estimator of $k$ taking the harmonic mean of the ridge parameter $\hat{k}_{i}$. The estimator is given as:

$$
\hat{k}_{H 2}=\frac{p}{\sum_{i=1}^{p} \widehat{\alpha}_{i}^{2}}=\frac{p}{\widehat{\alpha}^{\prime} \widehat{\alpha}}
$$

Lawless and Wang (1976) proposed the following ridge estimator for $k$ :

$$
\hat{k}_{L i}=\frac{1}{\widehat{\alpha}_{i}^{2} \lambda_{i}}
$$

and represent as a single value by taking harmonic mean of $\hat{k}_{L i}$ : 


$$
\hat{k}_{L}=\frac{p}{\sum_{i=1}^{p} \widehat{\alpha}_{i}^{2} \lambda_{i}}=\frac{p}{\widehat{\alpha}^{\prime} X^{\prime} X \widehat{\alpha}}
$$

Hocking et al. (1976) suggested the following estimator:

$$
\hat{k}_{H G}=\frac{\sum_{i=1}^{p}\left(\lambda_{i} \widehat{\alpha}_{i}\right)^{2}}{\left(\sum_{i=1}^{p} \lambda_{i} \widehat{\alpha}_{i}^{2}\right)^{2}}
$$

Batah et.al (2008) suggested the following:

$$
\hat{k}_{B H}=\frac{p}{\sum_{i=1}^{p}\left[\frac{\widehat{\alpha}_{i}^{2}}{\left(\frac{\widehat{\alpha}_{i}^{4} \lambda_{i}^{2}}{4}+\frac{6 \widehat{\alpha}_{i}^{2} \lambda_{i}}{1}\right)^{1 / 2}-\frac{\widehat{\alpha}_{i}^{2} \lambda_{i}}{2}}\right]}
$$

Noruma (1988) proposed the following estimator:

$$
\hat{k}_{N R}=\frac{p}{\sum_{i=1}^{p}\left[\frac{\hat{\alpha}_{i}^{2}}{1+\left(1+\lambda_{i}\left(\hat{\alpha}_{i}^{2}\right)^{1 / 2}\right)}\right]} .
$$

Kibria (2003) proposed new estimators for $k$ by taking the geometric mean, arithmetic mean and median $(\mathrm{p} \geq 3)$ of the ridge estimator of $\hat{k}_{i}$. These estimators are represented respectively as follows:

$$
\begin{aligned}
\hat{k}_{K 1} & =\frac{1}{\left(\prod_{i=1}^{p} \widehat{\alpha}_{i}^{2}\right)^{1 / p}} \\
\hat{k}_{K 2} & =\frac{1}{p} \sum_{i=1}^{p} \frac{1}{\widehat{\alpha}_{i}^{2}} \\
\hat{k}_{K 3} & =\operatorname{med}\left(\frac{1}{\widehat{\alpha}_{i}^{2}}\right) .
\end{aligned}
$$

Furthermore, Muniz et al $(2009,2012)$ proposed some estimators of $k$ in the following form: The square root of the geometric mean of $\hat{k}_{i}$

$$
\hat{k}_{K 4}=\prod_{i=1}^{p}\left(\sqrt{\frac{1}{\hat{\alpha}_{i}^{2}}}\right)^{1 / p}
$$

The reciprocal of the square root of the geometric mean of $\hat{k}_{i}$

$$
\hat{k}_{K 5}=\prod_{i=1}^{p}\left(\frac{1}{\sqrt{\frac{1}{\hat{\alpha}_{i}^{2}}}}\right)^{1 / p}
$$


The median of the square root of $\hat{k}_{i}$

$$
\hat{k}_{K 6}=\operatorname{med}\left(\sqrt{\frac{1}{\hat{\alpha}_{i}^{2}}}\right)
$$

The maximum of the reciprocal of the square root of $\hat{k}_{i}$

$$
\hat{k}_{K 7}=\max \left(\frac{1}{\sqrt{\frac{1}{\hat{\alpha}_{i}^{2}}}}\right)
$$

The median of the reciprocal of the square root of $\hat{k}_{i}$

$$
\hat{k}_{K 8}=\operatorname{med}\left(\frac{1}{\sqrt{\frac{1}{\widehat{\alpha}_{i}^{2}}}}\right)
$$

The maximum of the square root of $\hat{k}_{i}$

$$
\hat{k}_{K 9}=\max \left(\sqrt{\frac{1}{\widehat{\alpha}_{i}^{2}}}\right)
$$

Doruge (2013) proposed a new estimator for $k$ by multiplying the denominator with $\lambda_{\max } / 2$ :

$$
\hat{k}_{D i}=\frac{2}{\lambda_{\max } \widehat{\alpha}_{i}^{2}}
$$

Lukman et al (2017) proposed the following estimators:

$$
\begin{aligned}
& \hat{k}_{L 1}=\max \left(\frac{2}{\lambda_{\max } \widehat{\alpha}_{i}^{2}}\right) \\
& \hat{k}_{L 2}=\max \left(1 / \frac{2}{\lambda_{\max } \widehat{\alpha}_{i}^{2}}\right)
\end{aligned}
$$

Following Kibria (2003), the modification on the Doruge's estimator also have been performed:

$$
\begin{aligned}
& \hat{k}_{D 1}=\frac{2 p}{\lambda_{\max } \sum_{i=1}^{p} \widehat{\alpha}_{i}^{2}} \\
& \hat{k}_{D 2}=\operatorname{med}\left(\frac{2}{\lambda_{\max } \widehat{\alpha}_{i}^{2}}\right) \\
& \hat{k}_{D 3}=\frac{2}{\lambda_{\max }\left(\Pi_{i=1}^{p} \widehat{\alpha}_{i}^{2}\right)^{1 / p}} \\
& \hat{k}_{D 4}=\frac{2}{\lambda_{\max } p} \sum_{i=1}^{p} \frac{1}{\widehat{\alpha}_{i}^{2}}
\end{aligned}
$$


Khalaf and Shukur (2005) suggested a new estimator of $k$ as modification of $\hat{k}_{H 1}$ :

$$
\hat{k}_{K S}=\frac{\lambda_{\max }}{(n-p)+\lambda_{\max } \widehat{\alpha}_{\max }^{2}} .
$$

Kibria et al. (2012) and Alkhamisi (2006) proposed new estimators based on modifications of $q_{i}=\frac{\lambda_{\max }}{(n-p)+\lambda_{\max } \widehat{\alpha}_{i}^{2}}$ as follows:

$$
\begin{aligned}
& \hat{k}_{K S 1}=\max \left(\sqrt{q_{i}}\right) \\
& \hat{k}_{K S 2}=\max \left(\frac{1}{\sqrt{q_{i}}}\right) \\
& \hat{k}_{K S 3}=\operatorname{med}\left(\frac{1}{\sqrt{q_{i}}}\right) \\
& \hat{k}_{K S 4}=\left(\prod_{i=1}^{p} \sqrt{q_{i}}\right)^{1 / p} \\
& \hat{k}_{K S 5}=\left(\prod_{i=1}^{p} \frac{1}{\sqrt{q_{i}}}\right)^{1 / p} \\
& \hat{k}_{A l 1}=\max \left(q_{i}\right) \\
& \hat{k}_{A l 2}=\frac{1}{p} \sum_{i=1}^{p} q_{i}
\end{aligned}
$$

Alkhamisi and Shukur (2007) suggested some new estimators of $k$ as modification of $\hat{k}_{H 1}$ :

$$
\hat{k}_{A S 1}=\hat{k}_{H 1}+\frac{1}{\lambda_{\max }}
$$

and its functions as

$$
\begin{aligned}
& \hat{k}_{A S 2}=\max \left(\frac{1}{\hat{\alpha}_{i}^{2}}+\frac{1}{\lambda_{\max }}\right) \\
& \hat{k}_{A S 3}=\operatorname{med}\left(\frac{1}{\hat{\alpha}_{i}^{2}}+\frac{1}{\lambda_{\max }}\right) \\
& \hat{k}_{A S 4}=\frac{1}{p} \sum_{i=1}^{p} \frac{1}{\hat{\alpha}_{i}^{2}}+\frac{1}{\lambda_{\max }}
\end{aligned}
$$

Furthermore, Alkhamisi and Shukur (2007) proposed new estimator based on Lawless and Wang (1976):

$$
\hat{k}_{A S 5}=\hat{k}_{L}+\frac{1}{\lambda_{\max }}
$$


Since, just a few estimators of $k$ have been studied for the ridge logistic regression in literature, all proposed estimators of $k$ are under consideration.

\subsection{Criterion of a Good Estimator}

In the current study we employed different criteria to evaluate the performance of ridge parameter, $k$. The main criterion is to investigate the performance of the estimators is the mean square error (MSE). It defines as follows:

$$
\text { Average MSE }=\frac{\sum_{r=1}^{2000}(\widehat{\beta}-\beta)^{\prime}(\widehat{\beta}-\beta)}{2000}, \text { at } r^{\text {th }} \text { step of the simulation }
$$

In case of equal MSEs for any two estimators, we will prefer the estimator with smaller bias. Therefore, the average bias has been calculated for each proposed estimator as follows

$$
\text { Average Bias }=\frac{\sum_{r=1}^{2000} \operatorname{bias}(\widehat{\beta})}{2000} \text {, at } r^{\text {th }} \text { step of the simulation }
$$

where $\operatorname{bias}(\hat{\beta})=-\hat{k} U \beta, \quad U=\left(X^{\prime} \widehat{W} X+\hat{k} I\right)^{-1}$.

Another interesting criteria of performance of the estimators is the Mean Absolute Percent Error (MAPE) which measures the size of the error in percentage terms. It defines as

$$
\text { Average MAPE }=\frac{\sum_{r=1}^{2000} M A P E(\widehat{\beta})}{2000}, \text { at } r^{\text {th }} \text { step of the simulation }
$$

where $\operatorname{MAPE}(\hat{\beta})=\frac{1}{p} \sum_{i=1}^{p} \frac{|\widehat{\beta}-\beta|}{|\beta|}$.

In addition, the proportion of replication (out of 2000) for which ML estimator had a smaller MSE than the proposed ridge regression estimator has been presented. 


\section{CHAPTER III}

\section{SIMULATION STUDY}

Since a theoretical comparison among the estimators is not possible, a Monte Carlo simulation study has been conducted to compare the performance of the estimators in Chapter Three. We use R-3.2.2 software to complete the simulation study.

\subsection{Simulation Techniques}

The main factor in the design of the experiment is the degree of correlation between the regressors. To vary the strength of the correlation, following Kibria (2003) we generate the datasets by using

$$
x_{j i}=\left(1-\rho^{2}\right)^{1 / 2} z_{j i}+\rho z_{j p} \quad i=1,2, \ldots, p \quad j=1,2, \ldots, n
$$

where $z_{j i}$ are independent standard normal pseudo-random numbers and $\rho$ is specified such that the correlation between two explanatory variables is given by $\rho^{2}$. The main restriction in simulation study without loss of generality is that the parameter values of $\boldsymbol{\beta}$ are equal and chosen so that $\sum_{i=1}^{p} \beta_{i}^{2}=1$ (see Kibria 2003). For given $\mathrm{X}$ matrix and $\boldsymbol{\beta}$, the $\mathrm{n}$ observations for dependent variable $y$ was obtained from $\operatorname{Be}\left(\pi_{j}\right)$ distribution, where

$$
\pi_{j}=\mathrm{P}\left(\mathrm{y}_{j}=1\right)=\frac{\exp \left(\mathrm{x}_{j} \boldsymbol{\beta}\right)}{1+\exp \left(\mathrm{x}_{j} \boldsymbol{\beta}\right)}, \quad \mathrm{j}=1, \ldots, \mathrm{n}
$$

In the simulation technique, four different values of $\rho$ as $0.75,0.85,0.95,0.99$ are used. To investigate the effect of the sample sizes on the performance of the estimator, we will set sample size $n$ as 70, 100, 200. Also, we consider $p=4$ and $p=8$ explanatory variables. Another consideration is taken to the value of the intercept since it represents the average value of the log odds ratio. In the simulation study we set the value of intercept be $-1,0$, and 1 .

For given values $n, \rho, p$, and intercept, the set of explanatory variables was generated. Then the experiment is replicated 2000 times and the MSE, MAPE, bias, and proportion of replication for which ML estimator had a smaller MSE was calculated for 35 estimators. 


\subsection{Results Discussion}

Here in the results from Monte Carlo study concerning the performance of the different estimators of $k$ and the ML estimate are summarized. The outputs of the estimators except the proposed one are presented for different values of $n, p$ and $\rho$ in Tables A1 - A3 for intercept

$-1,0$ and 1 respectively. The output for all estimators including proposed estimators are presented in Table A.4.

\subsubsection{Results as a function of $n$}

Overall, increasing the sample size has a positive effect on all estimators of $k$. Results show that mean square error decreases as the number of observations increases. Graphical illustration of the performance based on MSE for different sample sizes with fixed $p=4$, correlation coefficient 0.95 and intercept 0 is presented in the Figure 3.1.

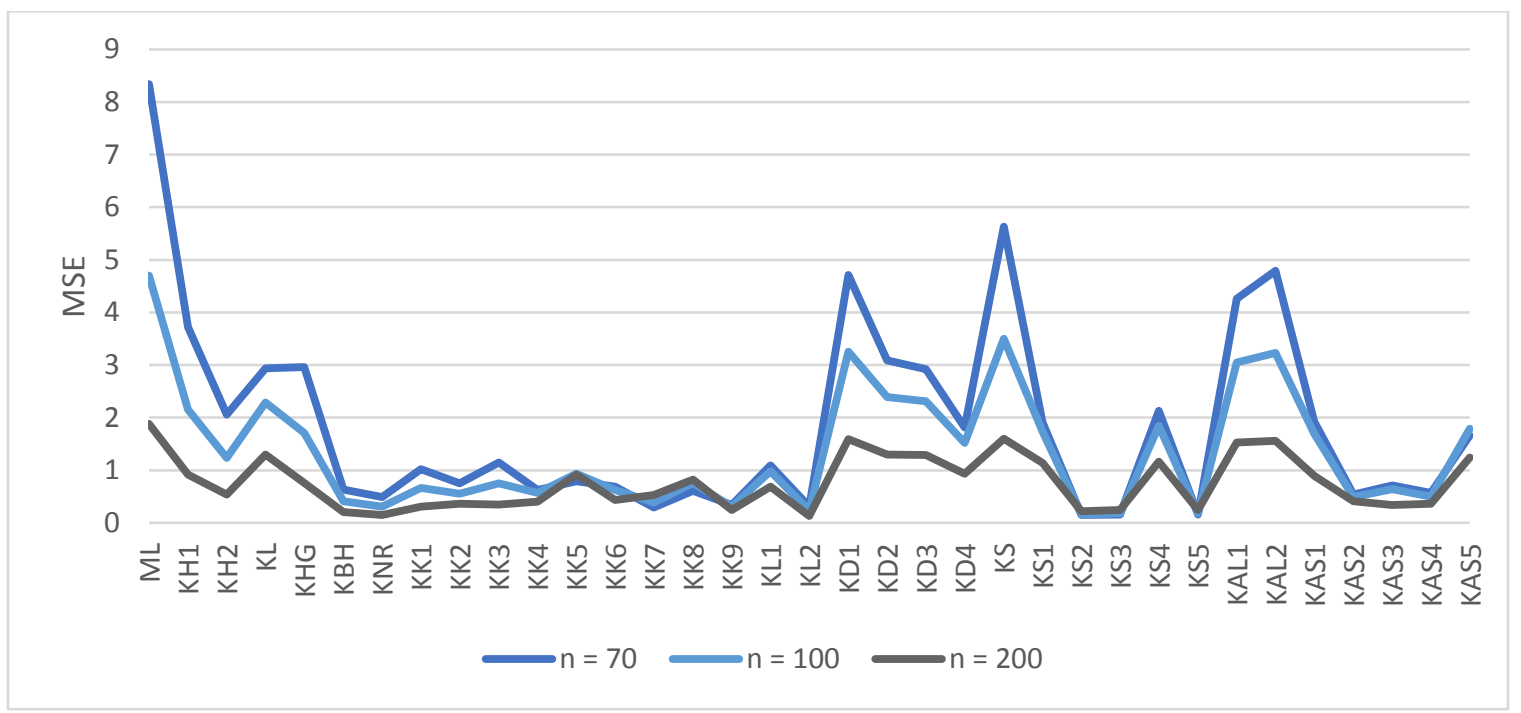

Figure 3.1.Performance of estimators as a function of sample size for $p=4, \rho=0.95$, intercept $=0$

Figure 3.1 shows that all RR estimators outperform the ML estimator in the sense of smaller MSE for different sample sizes and it is evident the advantage of using logistic ridge regression estimators over ML estimator when explanatory variables are correlated. 
Furthermore, increasing sample size has a positive effect on the mean absolute percent error (MAPE). In general, MAPE decreases as the number of observation increase with a few exceptions. Graphical illustration of the performance based on MAPE for different sample sizes with fixed $\mathrm{p}=4$, correlation coefficient 0.95 and intercept 0 is presented in the Figure 3.2.

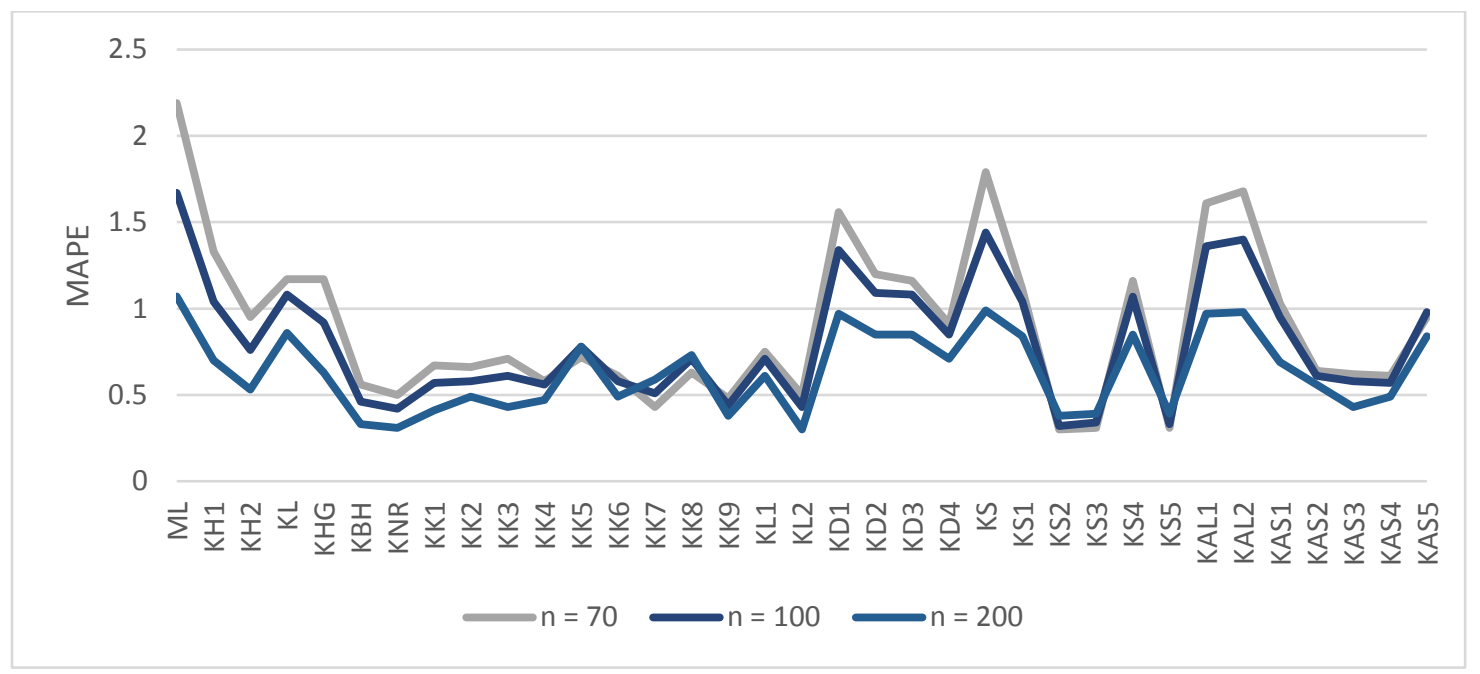

Figure 3.2. Performance of estimators as a function sample size for $p=4, \rho=0.95$, intercept $=0$

Figure 3.2 shows that all RR estimators outperform the ML estimator in terms of MAPE for different sample sizes and it shows the advantage of using logistic ridge regression estimators over ML estimator. The best RR estimators in terms of MAPE achieved when sample size is large, in this case when $\mathrm{n}$ is 200 .

\subsubsection{Results as a function of $\rho$}

It is easy to see that MSEs for estimators of $k$ increases as correlation coefficient increases. For smaller correlation coefficient $(\rho=0.75$ and $\rho=0.85)$, the MSEs are almost the same for any sample size, an intercept and number of parameters. For given $n=100$ and intercept 0 , performance of estimators as a function of the correlation between the explanatory variables for $p=4$ and $p=8$ is provided in Figure 3.3 - 3.4 and Figure 3.5 - 3.6, respectively. 


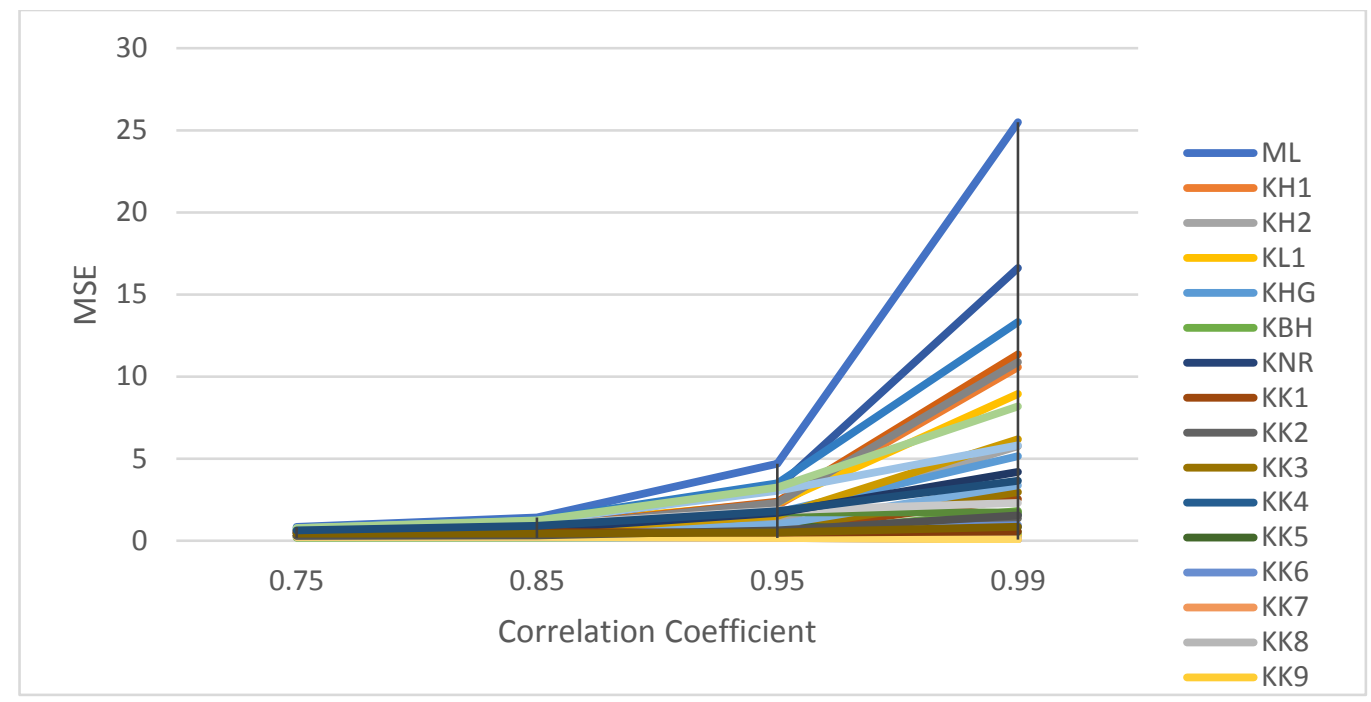

Figure 3.3. Performance of the estimators as a function of $\rho$ when $p=4, n=100$ and intercept $=0$

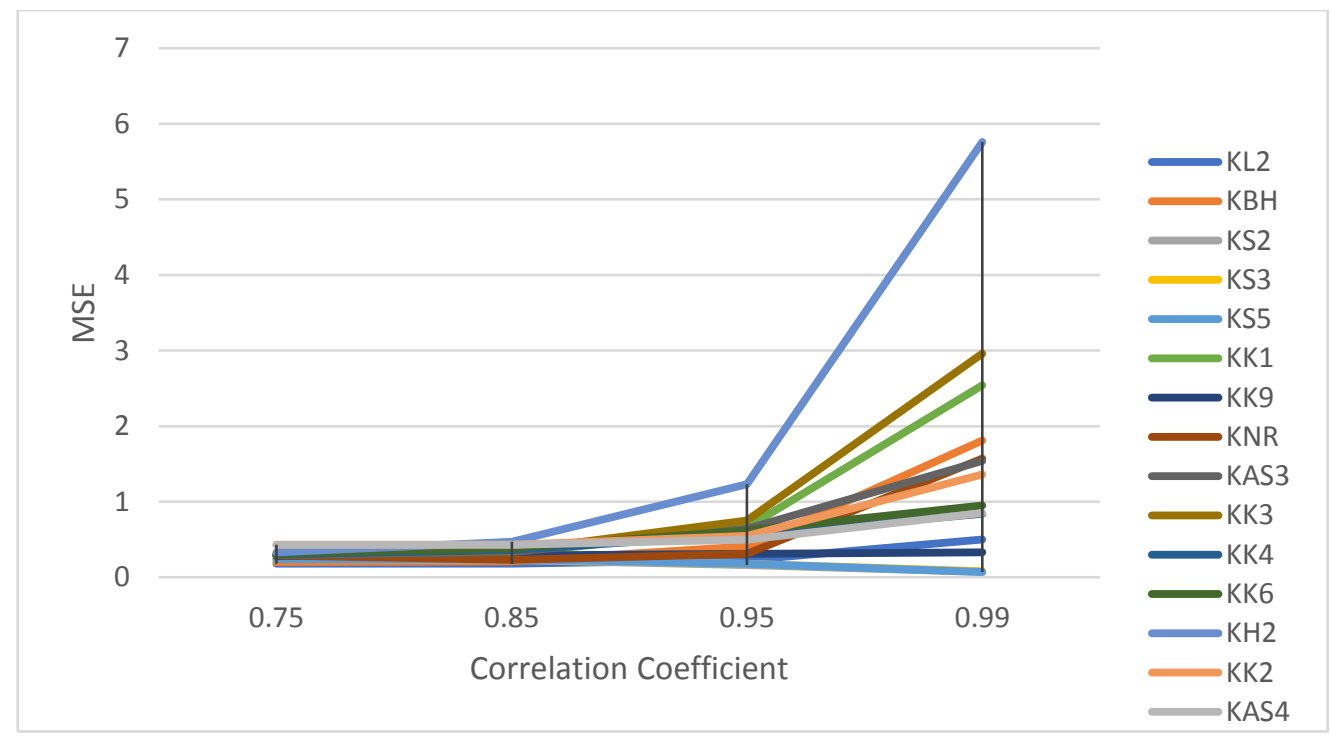

Figure 3.4.Performance of the selected estimators as a function of $\rho$ when $p=4, n=100$,intercept $=0$ 


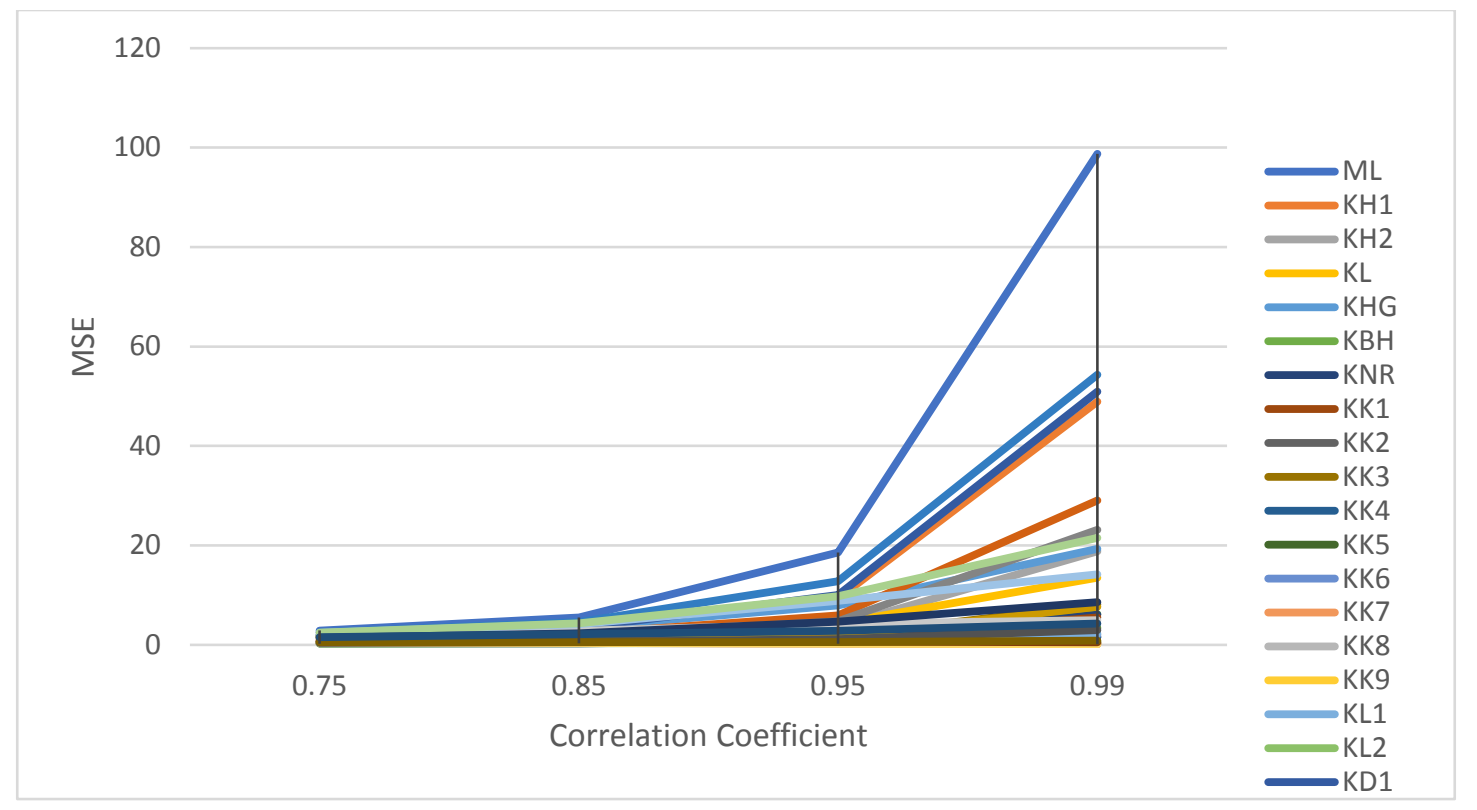

Figure 3.5. Performance of the estimators as a function of $\rho$ when $p=8, n=100$ and intercept $=0$

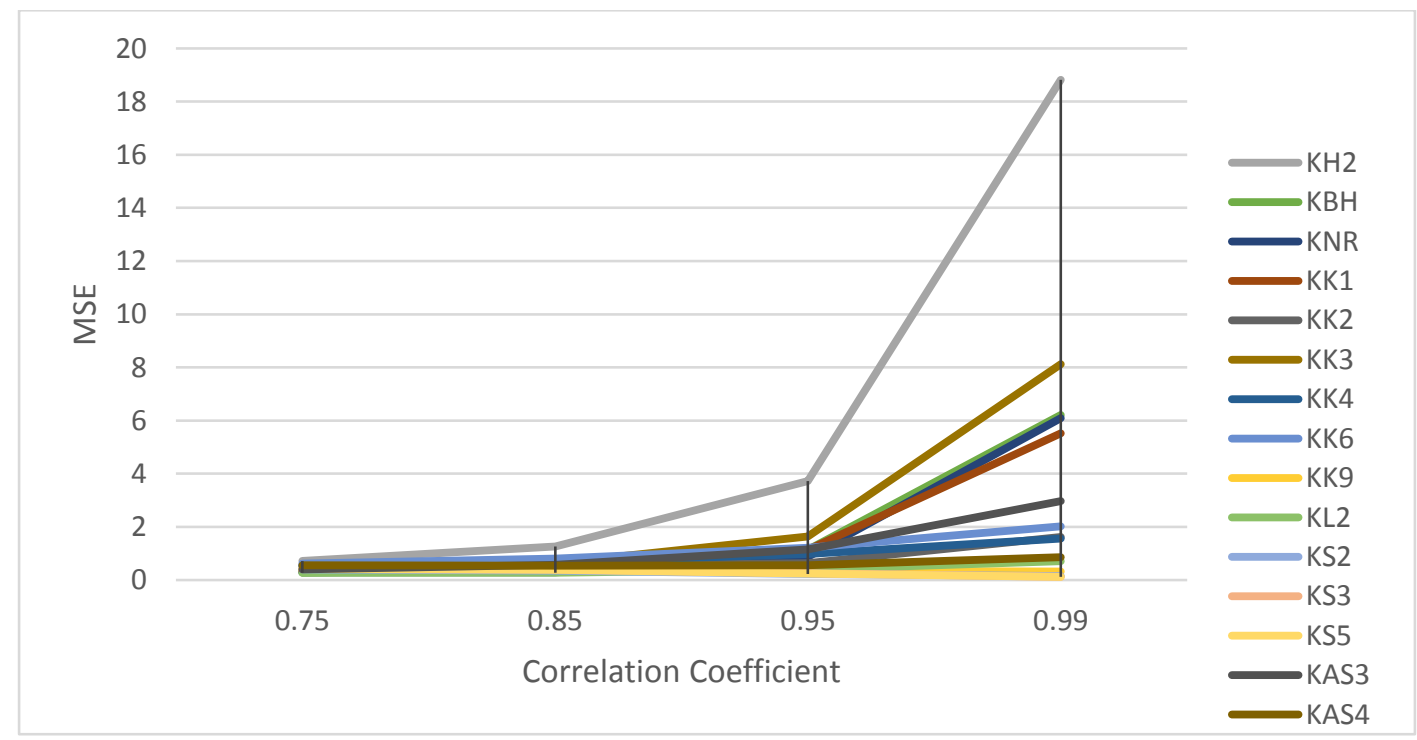

Figure 3.6. Performance of the selected estimators as a function of $\rho$ when $p=8, n=100$ and intercept $=0$ 
These figures show that as correlation increases the MSE also increases. Also, MSE of ML estimator increases rapidly as correlation coefficient increase from 0.85 to 0.99 . All the RR estimators have smaller MSE compared with ML and they don't change as rapidly as ML estimator.

\subsubsection{Results as a function of $p$}

Overall, the MSE increases when more explanatory variables are included, disregarding the fact that changing the number of explanatory variables from 4 to 8 the number of observations is also changes. For given $n=100$, intercept 0 , and correlation coefficients 0.95 , performance of estimators as a function of the number of explanatory variables for $\mathrm{p}=4$ and $\mathrm{p}=8$ is provided in Figure 3.7.

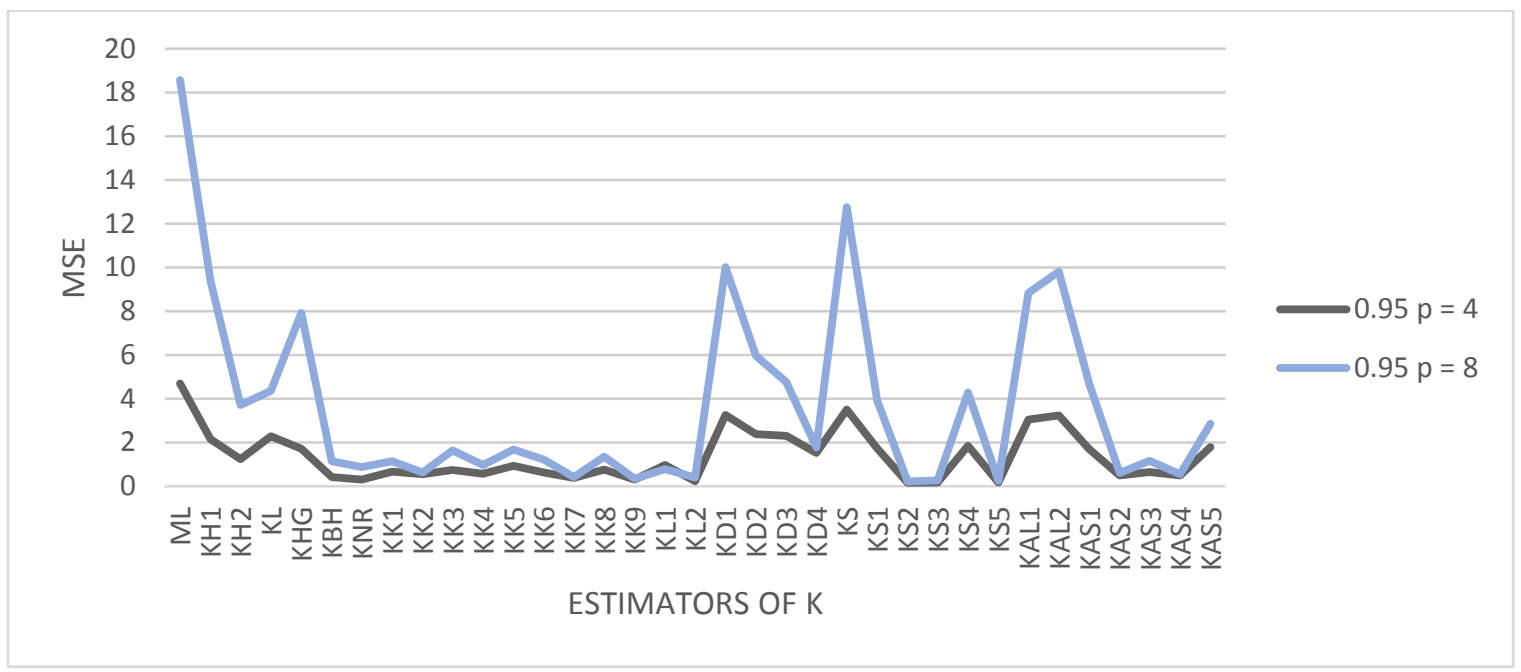

Figure 3.7.Performance of the estimators as a function of $p$ with $\rho=0.95, n=100$ and intercept $=0$

From this figure 3.8, we observe that as the number of explanatory variables increases from 4 to 8 , the MSE also increases. Also, as the number of explanatory variables increases proportion for which ML estimator has bigger MSE than the other estimator decreases.

\subsubsection{Results as function of the intercept}

Since the value of the intercept is equal to the average value of the log odds ratio, then with intercept equal to zero there is an equal probability of obtaining ones and zeros. With intercept equal to 1 there is a greater probability of obtaining ones than zeros. Also, with intercept equal to 
-1 there is a greater probability of obtaining zeros than ones. For given $n=100, p=4$, and correlation coefficients 0.95 , performance of estimators as a function of the log odds ratio is provided in Figure 3.8.

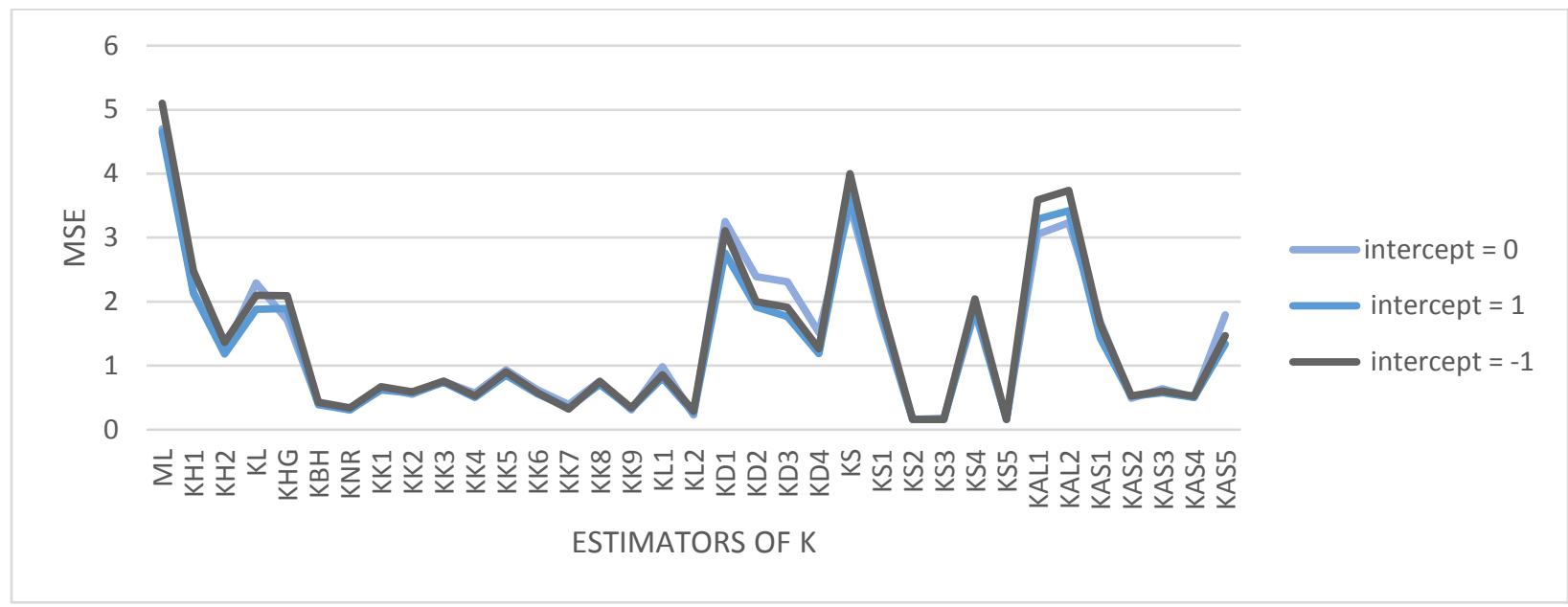

Figure 3.8. Performance of the estimators as a function of the intercept when $\rho=0.95, \mathrm{n}=100$ and $\mathrm{p}=4$.

From Figure 3.8, we observe that changing the log odds from zero to 1 or -1 MSE increases for the ML and the KD1 - KD3 and KAL1, KAL2. The MSEs for the other estimators are the same or slightly decreases. Hence, these estimators are more robust to changes of the log odd ratio than ML and the KD1 - KD3 and KAL1, KAL2.

\subsection{Some Proposed New Estimators of k.}

From the results analysis in section 3.2, it is evident that the following estimators: KHB, KNR, KK2, KK4, KK6, KK7, KK9, KK12, KS2, KS5 are performing better than the rest of the estimators. Thus, the following new estimators of $k$ are proposed in this section:

1. $\mathrm{KN} 1$ = Maximum $(\mathrm{KHB}, \mathrm{KNR}, \mathrm{KK} 2, \mathrm{KK} 4, \mathrm{KK} 6, \mathrm{KK} 7, \mathrm{KK} 9, \mathrm{KK} 12, \mathrm{KS} 2, \mathrm{KS} 5)$

2. $\mathrm{KN} 2=$ Arithmetic mean of $(\mathrm{KHB}, \mathrm{KNR}, \mathrm{KK} 2, \mathrm{KK} 4, \mathrm{KK} 6, \mathrm{KK} 7, \mathrm{KK} 9, \mathrm{KK} 12, \mathrm{KS} 2, \mathrm{KS} 5)$

3. $\mathrm{KN} 3=$ Median $(\mathrm{KHB}, \mathrm{KNR}, \mathrm{KK} 2, \mathrm{KK} 4, \mathrm{KK} 6, \mathrm{KK} 7, \mathrm{KK} 9, \mathrm{KK} 12, \mathrm{KS} 2, \mathrm{KS} 5)$

4. $\mathrm{KN} 4=$ Harmonic mean $(\mathrm{KHB}, \mathrm{KNR}, \mathrm{KK} 2, \mathrm{KK} 4, \mathrm{KK} 6, \mathrm{KK} 7, \mathrm{KK}$, KK12, KS2, KS5) 
The MSEs values for $\mathrm{n}=70,100$, and 200, $\rho=0.95$ and $\mathrm{p}=4$ are reported for different values of intercept in table A4. Also, performance of estimators including new estimators as a function of sample size are plotted in Figures 3.9-3.11.

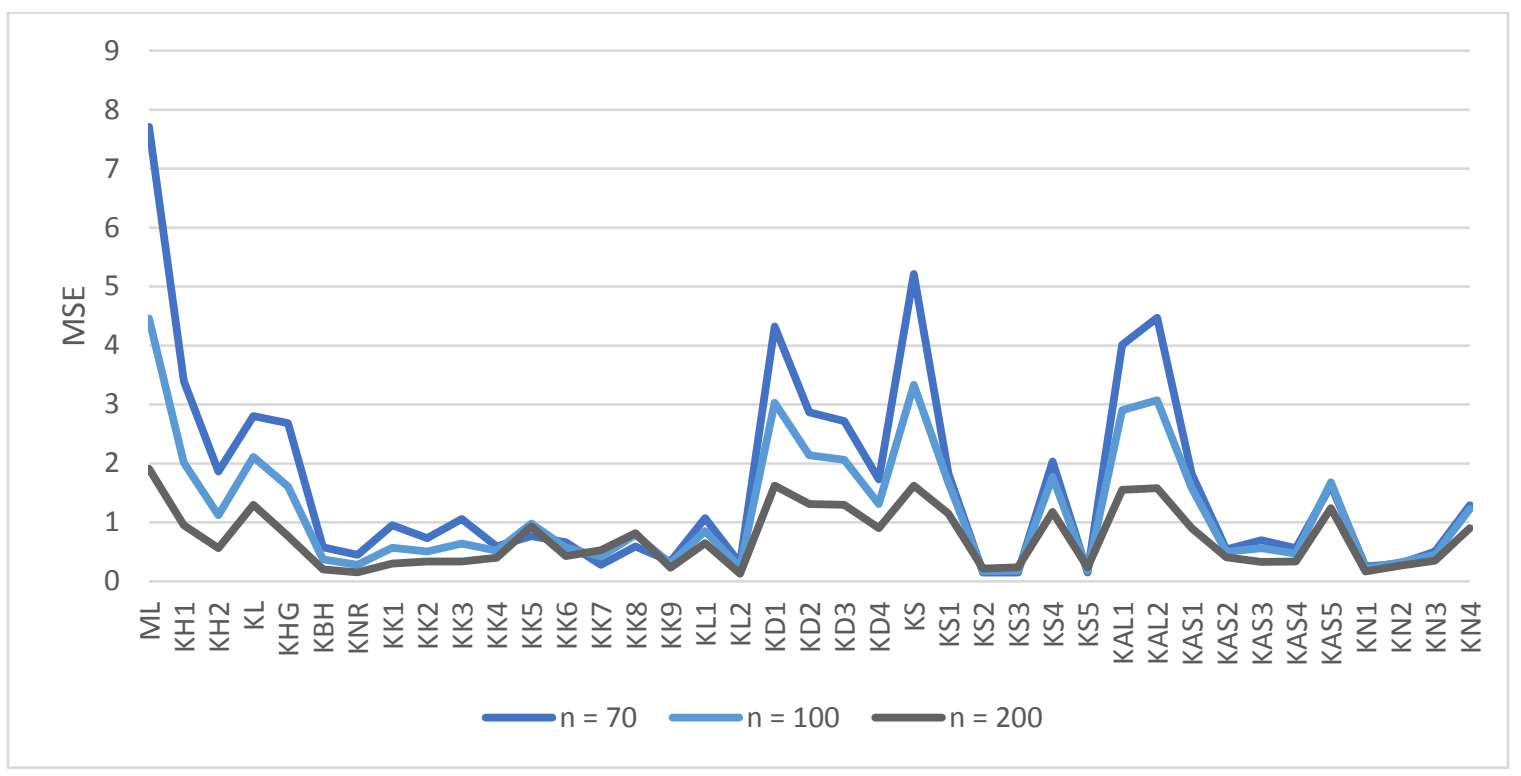

Figure 3.9. Performance of estimators as a function of sample size for $p=4, \rho=0.95$, intercept $=0$

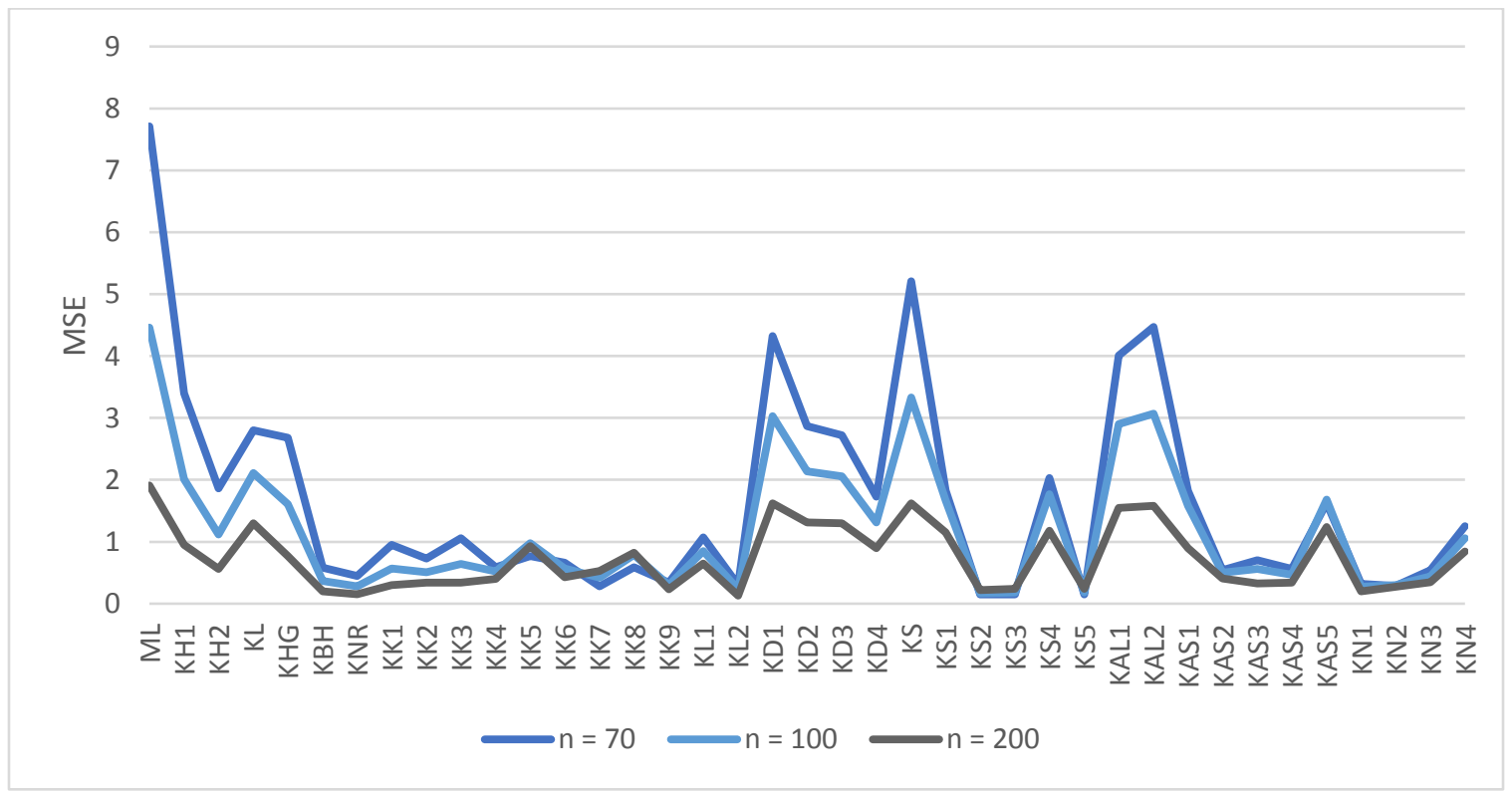

Figure 3.10.Performance of estimators as a function of sample size for $p=4, \rho=0.95$,intercept $=1$ 


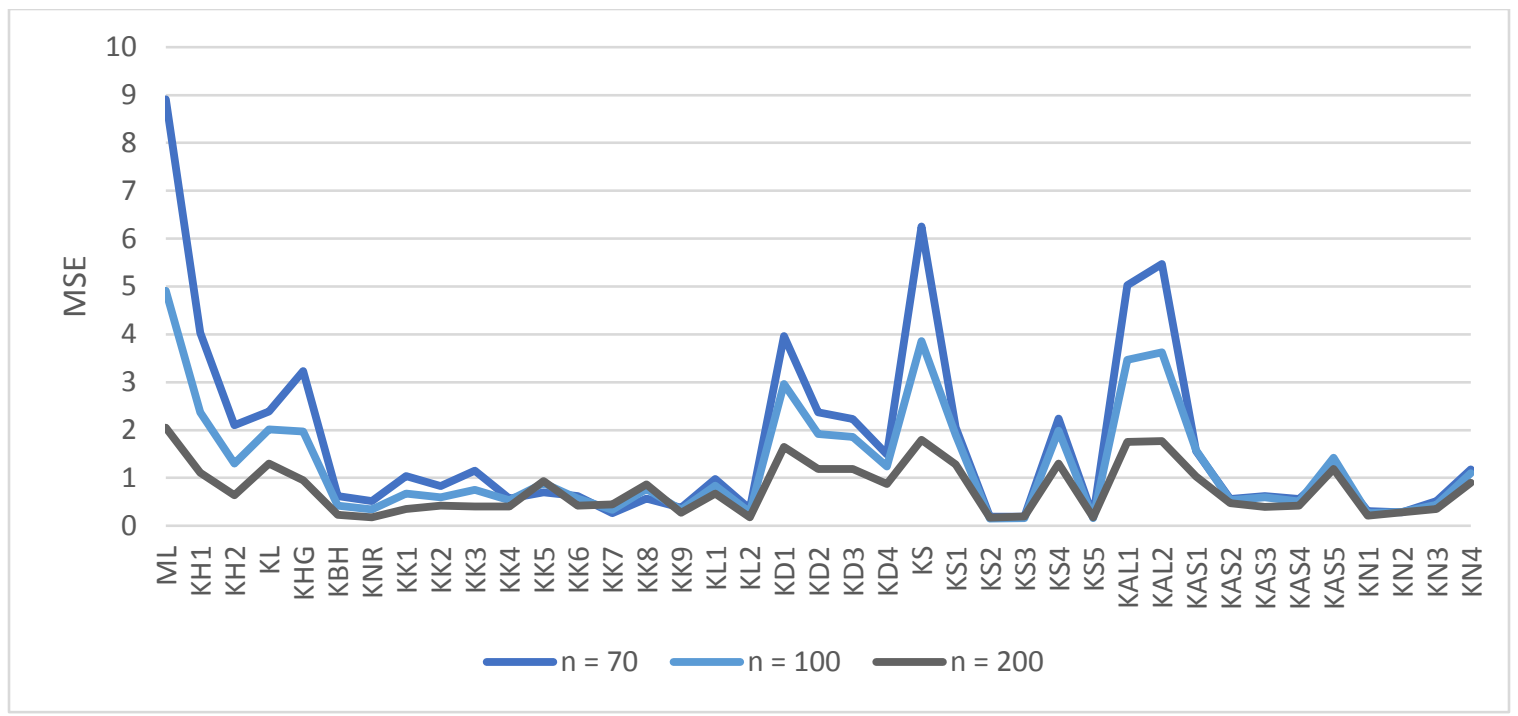

Figure 3.11.Performance of estimators as a function of sample size for $p=4, \rho=0.95$, intercept $=-1$ It appears from Figures $3.9-3.11$ and Tables in A.4, that all new proposed estimators performed better in the sense of smaller MSE compare to the rest of the estimators. The estimator, $\mathrm{KN} 3$ performed the best among proposed five and rest of the estimators. 


\section{CHAPTER IV}

\section{APPLICATION}

To illustrate the findings of this thesis, we consider the data, which have been taken from survey of 659 registered leisure boat owners in 23 counties of East Texas collected by Sellar, Stoll and Chavas (1985). We consider the following logistic regression model

$$
Y=\frac{\exp \left(\beta_{0}+X_{1} \beta_{1}+X_{2} \beta_{2}+X_{3} \beta_{3}+X_{4} \beta_{4}+X_{5} \beta_{5}\right)}{1+\exp \left(\beta_{0}+X_{1} \beta_{1}+X_{2} \beta_{2}+X_{3} \beta_{3}+X_{4} \beta_{4}+X_{5} \beta_{5}\right)},
$$

where $\mathrm{Y}$ is defined as 0 , if survey participant has not taken a recreational trip and 1 , otherwise. $\mathrm{X}_{1}$ is the facility's subjective quality ranking, $\mathrm{X}_{2}$ is the respondent's taste for water-skiing, $\mathrm{X}_{3}$ is travel cost to Lake Conroe, $\mathrm{X}_{4}$ is travel cost to Lake Somerville, $\mathrm{X}_{5}$ is travel cost to Lake Houston. The correlation matrix of the variables in model (4.1) is presented in Table 4.1 (see Shiferaw Gurmu, 1996)

Table 4.1. Correlation among the variables with corresponding VIF

\begin{tabular}{|c|c|c|c|c|c|}
\hline & $\mathrm{X}_{1}$ & $\mathrm{X}_{2}$ & $\mathrm{X}_{3}$ & $\mathrm{X}_{4}$ & $\mathrm{X}_{5}$ \\
\hline $\mathrm{X}_{1}$ & 1.000 & 0.136 & 0.077 & 0.003 & 0.090 \\
\hline $\mathrm{X}_{2}$ & 0.126 & 0.028 & 0.161 & 0.155 & 0.144 \\
\hline $\mathrm{X}_{3}$ & 0.077 & 0.009 & 1.000 & 0.977 & 0.986 \\
\hline $\mathrm{X}_{4}$ & 0.003 & -0.034 & 0.977 & 1.000 & 0.965 \\
\hline $\mathrm{X}_{5}$ & 0.090 & 0.016 & 0.986 & 0.965 & 1.000 \\
\hline $\mathrm{VIF}$ & 1.052 & 1.120 & 81.462 & 31.932 & 50.722 \\
\hline
\end{tabular}

It is observed from Table 4.1 that the explanatory variables $\mathrm{X}_{3}, \mathrm{X}_{4}, \mathrm{X}_{5}$ are highly correlated. Also, variance inflation factors for $\mathrm{X}_{3}, \mathrm{X}_{4}, \mathrm{X}_{5}$ are 81,31 , and 50 respectively. It implies the existence of multicollinearity problem in the data set. The estimated predicted proba bility along with the ridge regression coefficients of the estimators are presented in Table 4.2. I als o provided the $\mathrm{p}$-values for testing the significance of regression parameters of the following estim ators: ML, KH1, KH2 and KNR. From Table 4.2, we observed that all ridge regression estimators have higher prediction accuracy than that of ML estimator, which supported our findings from sim ulation study in Chapter 3. 
Table 4.2. The MSEs along with the ridge regression coefficients of the estimators

\begin{tabular}{|c|c|c|c|c|c|c|c|}
\hline & $\hat{\beta}_{0}$ & $\hat{\beta}_{1}$ & $\hat{\beta}_{2}$ & $\hat{\beta}_{3}$ & $\hat{\beta}_{4}$ & $\hat{\beta}_{5}$ & Accuracy \\
\hline ML & -2.88 & 1.44 & 0.41 & 0.01 & -0.08 & 0.07 & 0.89 \\
\hline P-values & & 0.00 & 0.21 & 0.76 & 0.00 & 0.00 & \\
\hline KH1 & -2.84 & 1.43 & 0.40 & 0.01 & -0.08 & 0.07 & 0.91 \\
\hline P-values & & 0.00 & 0.20 & 0.75 & 0.00 & 0.00 & \\
\hline $\mathrm{KH} 2$ & -2.87 & 1.44 & 0.40 & 0.01 & -0.08 & 0.07 & 0.91 \\
\hline P-values & & 0.00 & 0.22 & 0.75 & 0.0 & 0.11 & \\
\hline $\mathrm{KL}$ & -2.88 & 1.44 & 0.41 & 0.01 & -0.08 & 0.07 & 0.91 \\
\hline KNR & -1.38 & 1.23 & 0.21 & 0.03 & -0.08 & 0.05 & 0.91 \\
\hline P-values & & 0.00 & 0.52 & 0.21 & 0.00 & 0.03 & \\
\hline $\mathrm{KHG}$ & -2.88 & 1.44 & 0.41 & 0.01 & -0.08 & 0.07 & 0.91 \\
\hline $\mathrm{KBH}$ & -2.87 & 1.44 & 0.40 & 0.01 & -0.08 & 0.07 & 0.91 \\
\hline KK1 & -0.63 & 1.05 & 0.11 & 0.05 & -0.08 & 0.03 & 0.91 \\
\hline KK2 & 0.00 & 0.06 & 0.00 & 0.02 & -0.04 & 0.01 & 0.90 \\
\hline KK3 & -0.94 & 1.14 & 0.15 & 0.04 & -0.08 & 0.04 & 0.91 \\
\hline KK4 & -1.57 & 1.26 & 0.24 & 0.03 & -0.08 & 0.05 & 0.91 \\
\hline KK5 & -2.75 & 1.42 & 0.39 & 0.01 & -0.08 & 0.07 & 0.91 \\
\hline KK6 & -1.76 & 1.29 & 0.26 & 0.03 & -0.08 & 0.05 & 0.91 \\
\hline KK7 & -1.62 & 1.27 & 0.24 & 0.03 & -0.08 & 0.05 & 0.91 \\
\hline KK8 & -2.71 & 1.42 & 0.38 & 0.01 & -0.08 & 0.07 & 0.91 \\
\hline KK9 & -0.11 & 0.60 & 0.03 & 0.05 & -0.08 & 0.02 & 0.91 \\
\hline KL1 & -1.32 & 1.21 & 0.20 & 0.03 & -0.08 & 0.05 & 0.91 \\
\hline KL2 & 0.00 & 0.00 & 0.00 & 0.00 & -0.01 & 0.00 & 0.90 \\
\hline KD1 & -2.88 & 1.44 & 0.41 & 0.01 & -0.08 & 0.07 & 0.91 \\
\hline KD2 & -2.88 & 1.44 & 0.41 & 0.01 & -0.08 & 0.07 & 0.91 \\
\hline KD3 & -2.88 & 1.44 & 0.41 & 0.01 & -0.08 & 0.07 & 0.91 \\
\hline KD4 & -2.36 & 1.37 & 0.34 & 0.02 & -0.08 & 0.06 & 0.91 \\
\hline $\mathrm{KS}$ & -2.88 & 1.44 & 0.41 & 0.01 & -0.08 & 0.07 & 0.91 \\
\hline KS1 & -1.99 & 1.32 & 0.29 & 0.02 & -0.08 & 0.06 & 0.91 \\
\hline KS2 & -0.69 & 1.07 & 0.11 & 0.04 & -0.08 & 0.03 & 0.91 \\
\hline KS3 & -2.27 & 1.36 & 0.33 & 0.02 & -0.08 & 0.06 & 0.91 \\
\hline KS4 & -2.59 & 1.40 & 0.37 & 0.01 & -0.08 & 0.07 & 0.91 \\
\hline KS5 & -2.22 & 1.35 & 0.32 & 0.02 & -0.08 & 0.06 & 0.91 \\
\hline KAL1 & -1.45 & 1.24 & 0.22 & 0.03 & -0.08 & 0.05 & 0.91 \\
\hline KAL2 & -2.18 & 1.35 & 0.32 & 0.02 & -0.08 & 0.06 & 0.91 \\
\hline KAS1 & -2.84 & 1.43 & 0.40 & 0.01 & -0.08 & 0.07 & 0.91 \\
\hline KAS2 & 0.00 & 0.01 & 0.00 & 0.01 & -0.02 & 0.01 & 0.83 \\
\hline KAS3 & -0.94 & 1.14 & 0.15 & 0.04 & -0.08 & 0.04 & 0.91 \\
\hline KAS4 & 0.00 & 0.06 & 0.00 & 0.02 & -0.04 & 0.01 & 0.90 \\
\hline KAS5 & -2.88 & 1.44 & 0.41 & 0.01 & -0.08 & 0.07 & 0.91 \\
\hline KN1 & -0.69 & 1.07 & 0.11 & 0.04 & -0.08 & 0.03 & 0.91 \\
\hline KN2 & -1.71 & 1.28 & 0.25 & 0.03 & -0.08 & 0.05 & 0.91 \\
\hline KN3 & -1.96 & 1.32 & 0.29 & 0.02 & -0.08 & 0.06 & 0.91 \\
\hline KN4 & -2.88 & 1.44 & 0.41 & 0.01 & -0.08 & 0.07 & 0.91 \\
\hline
\end{tabular}




\section{CHAPTER V}

\section{SUMMARY AND CORRESPONDING REMARKS}

In this thesis, we investigated some ridge regression (RR) estimators for estimating the ridge regression parameter $k$ for logistic regression model when the explanatory variables are highly correlated. Since a theoretical comparison among the estimators is not possible, a Monto Carlo simulation study has been conducted to compare the performance of the proposed ridge regression estimators. In simulation, we evaluated proposed estimators of $k$ for different experimental conditions: the degree of correlation, sample size, the number of independent variables, and the log odds ratio. For each combination of parameters, we performed 2000 replications. The evaluation of the performance of these estimators has been done by using the MSE, MAPE, the magnitude of bias, and the proportion of times the ML outperforms the RR estimators.

The simulation results show that the increase of the correlation among the explanatory variables and the number of independent variables have a negative effect on the performance of the estimators, the MSE and MAPE increases. In most of the cases, RR estimators outperform ML estimator even when the correlation between the explanatory variables are large. When the sample size increases the MSEs as well as MAPE decreases for all estimators including ML estimator. The analysis of the log odds ratio reveals that majority of estimators are robust to changes of the $\log$ odds ratio with few exceptions. The top ten estimators of $k$ from our simulation study are KHB, KNR, KK2, KK4, KK6, KK7, KK9, KK12, KS2, KS5. Also, new proposed estimators based on top ten estimators have performed well compared to other estimators. Furthermore, the analysis from real data supported the results from simulation study to some extent. 
The following estimators KBH, KNR, KK2, KK6, KK7, KL2, KS2, KS5, KN1, KN2, KN3 are recommending for the practitioners for using them when they analysis data with multicollinearity problem.

We have considered the logistic regression model. As a future research, this can further be extended for the following models:

(i) Two parameters logistic regression model. That means, a model with both ridge regression estimator and Liu (1993) estimator.

(ii) Ridge Regression Based on Some Robust Estimators (see Samkar and Alpu, 2010).

(iii) Ridge regression estimators for the restricted linear model.

(iv) Restricted ridge regression estimators for a semiparametric regression model. 


\section{REFERENCES}

1. Alkhamisi M.A., G. Shukur.A. (2007). "Monte Carlo study of recent ridge parameters". Communications in Statistics - Simulation and Computation, 36 (3), pp. 535-547.

2. Alkhamisi M.A., Mahdi \& Khalaf, Ghadban \& Shukur, Ghazi. (2006). "Some Modifications for Choosing Ridge Parameters". Communications in Statistics. Theory and Methods. 35(11), pp. 2005-2020.

3. Asar, Y and Genc, A. (2017). "A note on some new modifications of ridge estimators". Kuwait J. Sci. 44 (3) pp. 75-82.

4. Batah, F. S.M., Ramanathan, T.V., Gore, S.D. (2008). "The efficiency of modified Jack-knife and ridge type regression estimators: a comparison". Surveys in Mathematics and its Applications. 3,pp. $111-122$.

5. Dorugade A.V. (2013). "New ridge parameters for ridge regression". Journal of the Association of Arab Universities for Basic and Applied Sciences. 15, 94-99.

6. Hocking R.R., F.M. Speed, M.J. Lynn. (1976) “A class of biased estimators in linear regression". Technometrics, 18 (4), pp 425-437.

7. Hoerl, Arthur E., and Robert W. Kennard (1970). "Ridge regression: Biased Estimation for Nonorthogonal Problems". Technometrics. 12(1), pp. 55 - 67.

8. Hoerl, Arthur E., Robert W. Kannard \& Kent F. Baldwin. (1975) "Ridge regression:some simulations." Communications in Statistics . 4(2), pp. $105-123$.

9. Kibria B. M. G. (2003). "Performance of Some New Ridge Regression Estimators" . Communications in Statistics- Theory and Methods. 32(2), pp. $419-435$.

10. Kibria, B. M. Golam and Banik, Shipra (2016). "Some Ridge Regression Estimators and Their Performances.” Journal of Modern Applied Statistical Methods. 15(1), Article 12, pp. 206-238.

11. Lawless, J. F., Wang, P. (1976). "A simulation study of ridge and other regression estimators". Communications in Statistics-Theory and Methods. 5, pp. 307-323.

12. A. H. Lee \& M. J. Silvapulle (1998). "Ridge estimation in logistic regression". Communications in Statistics - Simulation and Computation, 17(4), pp.1231-1257

13. Liu, K. (1993). "A new class of biased estimate in linear regression". Communications in Statistics: Theory and Methods. 22, pp. 393-402. 
14. Lukman, A. F., Ayinde, K., \& Ajiboye, A. S. (2017). "Monte Carlo study of some classificationbased ridge parameter estimators". Journal of Modern Applied Statistical Methods, 16(1), pp. 428451.

15. Månsson K., Shukur G. (2011).” On Ridge Parameters in Logistic Regression”. Communications in Statistics - Theory and Methods . 40(18), pp. 3366-3381.

16. Månsson, K, Shukur, G. and Kibria, B. M. G. (2017). "Performance of Some Ridge Regression Estimators for the Multinomial Logit Model". Communications in Statistics-Theory and Methods.

17. Muniz, Gisela and Kibria, B.M. Golam (2009). "On Some Ridge Regression Estimators: An Empirical Comparisons". Communications in Statistics- Theory and Methods. 38 (3), pp. 621 - 630

18. Muniz, Gisela; Kibria, B.M. Goam; and Shukur, Ghazi. (2012). "On Developing Ridge Regression Parameters: A Graphical investigation”. Department of Mathematics and Statistics. 10, pp. 1-25.

19. Nomura M.(1988) “ On the almost unbiased ridge regression estimator". Communications in Statistics - Simulation and Computation . 17(3), pp. $729-743$.

20. Sellar, C., Stoll, J. R., and Chavas, J. P. (1985), "Validation of Empirical Measures of Welfare Change: A Comparison of Nonmarket Techniques." Land Economics, 61, 156-175.

21. Samkar, Hatice and Alpu, Ozlem (2010) "Ridge Regression Based on Some Robust Estimators," Journal of Modern Applied Statistical Methods. 9(2),Article 17, pp. 495-501

22. Schaefer R.L., L.D. Roi \& R.A. Wolfe (1984).“A ridge logistic estimator”. Communications in Statistics - Theory and Methods . 1391). pp. 100-112

23. Shiferaw Gurmu and Pravin K. Trivedi (1996). "Excess Zeros in Count Models for Recreational Trips. Journal of Business \& Economic Statistics".14(4), pp. 469-47. 


\section{APPENDICES}

Table A1. Estimated MSEs, MAPEs, Bias and proportion of times in simulation when the ridge

regression estimator produces a higher MSE than the ML estimator of the proposed estimators

with intercept $=0$ for the following cases:

$$
p=4, \rho=0.75
$$

\begin{tabular}{|c|c|c|c|c|c|c|c|c|c|c|c|c|}
\hline & \multicolumn{4}{|c|}{$\mathrm{n}=70$} & \multicolumn{4}{|c|}{$\mathrm{n}=100$} & \multicolumn{4}{|c|}{$\mathrm{n}=200$} \\
\hline & MSE & Bias & MAPE & Pr. & MSE & Bias & MAPE & Pr. & MSE & Bias & MAPE & Pr. \\
\hline ML & 1.40 & 0.00 & 0.91 & 0.00 & 0.84 & 0.00 & 0.72 & 0.00 & 0.36 & 0.00 & 0.48 & 0.00 \\
\hline KH1 & 0.75 & 0.20 & 0.65 & 0.02 & 0.49 & 0.16 & 0.54 & 0.03 & 0.26 & 0.10 & 0.40 & 0.04 \\
\hline KH2 & 0.47 & 0.37 & 0.52 & 0.04 & 0.33 & 0.31 & 0.45 & 0.05 & 0.19 & 0.20 & 0.34 & 0.07 \\
\hline KL & 0.92 & 0.11 & 0.73 & 0.01 & 0.67 & 0.06 & 0.64 & 0.02 & 0.34 & 0.02 & 0.46 & 0.02 \\
\hline KHG & 0.85 & 0.15 & 0.70 & 0.01 & 0.56 & 0.12 & 0.58 & 0.03 & 0.28 & 0.07 & 0.42 & 0.03 \\
\hline KBH & 0.24 & 0.68 & 0.42 & 0.09 & 0.20 & 0.63 & 0.38 & 0.12 & 0.13 & 0.50 & 0.30 & 0.17 \\
\hline KNR & 0.31 & 0.98 & 0.51 & 0.09 & 0.29 & 0.99 & 0.50 & 0.12 & 0.26 & 0.96 & 0.48 & 0.17 \\
\hline KK1 & 0.35 & 0.69 & 0.49 & 0.11 & 0.28 & 0.62 & 0.44 & 0.14 & 0.17 & 0.46 & 0.34 & 0.18 \\
\hline KK2 & 0.48 & 1.09 & 0.62 & 0.23 & 0.43 & 1.05 & 0.59 & 0.31 & 0.34 & 0.90 & 0.50 & 0.43 \\
\hline KK3 & 0.39 & 0.68 & 0.51 & 0.11 & 0.30 & 0.61 & 0.45 & 0.14 & 0.19 & 0.45 & 0.36 & 0.18 \\
\hline KK4 & 0.35 & 0.37 & 0.47 & 0.03 & 0.30 & 0.30 & 0.43 & 0.04 & 0.19 & 0.18 & 0.35 & 0.05 \\
\hline KK5 & 0.73 & 0.10 & 0.69 & 0.01 & 0.61 & 0.06 & 0.62 & 0.01 & 0.32 & 0.02 & 0.45 & 0.02 \\
\hline KK6 & 0.38 & 0.36 & 0.48 & 0.03 & 0.31 & 0.28 & 0.44 & 0.04 & 0.20 & 0.17 & 0.35 & 0.05 \\
\hline KK7 & 0.45 & 0.21 & 0.55 & 0.01 & 0.44 & 0.12 & 0.54 & 0.02 & 0.28 & 0.05 & 0.42 & 0.02 \\
\hline KK8 & 0.67 & 0.12 & 0.66 & 0.01 & 0.57 & 0.07 & 0.61 & 0.02 & 0.31 & 0.03 & 0.45 & 0.02 \\
\hline KK9 & 0.33 & 0.78 & 0.49 & 0.12 & 0.28 & 0.69 & 0.45 & 0.16 & 0.19 & 0.50 & 0.36 & 0.19 \\
\hline KL1 & 0.52 & 0.92 & 0.62 & 0.18 & 0.44 & 0.78 & 0.56 & 0.22 & 0.29 & 0.50 & 0.44 & 0.23 \\
\hline KL2 & 0.22 & 0.60 & 0.39 & 0.02 & 0.18 & 0.50 & 0.34 & 0.03 & 0.12 & 0.40 & 0.28 & 0.09 \\
\hline KD1 & 0.94 & 0.11 & 0.74 & 0.01 & 0.67 & 0.06 & 0.64 & 0.02 & 0.34 & 0.02 & 0.46 & 0.02 \\
\hline KD2 & 0.68 & 0.28 & 0.63 & 0.04 & 0.53 & 0.18 & 0.56 & 0.04 & 0.30 & 0.06 & 0.43 & 0.04 \\
\hline KD3 & 0.65 & 0.27 & 0.61 & 0.03 & 0.51 & 0.17 & 0.55 & 0.03 & 0.30 & 0.06 & 0.43 & 0.03 \\
\hline KD4 & 0.56 & 0.63 & 0.60 & 0.12 & 0.46 & 0.51 & 0.55 & 0.13 & 0.29 & 0.30 & 0.43 & 0.14 \\
\hline KS & 1.23 & 0.03 & 0.86 & 0.01 & 0.77 & 0.02 & 0.69 & 0.01 & 0.35 & 0.01 & 0.47 & 0.02 \\
\hline KS1 & 0.92 & 0.08 & 0.75 & 0.01 & 0.65 & 0.05 & 0.64 & 0.02 & 0.32 & 0.02 & 0.45 & 0.02 \\
\hline KS2 & 0.23 & 0.43 & 0.38 & 0.02 & 0.24 & 0.30 & 0.39 & 0.03 & 0.19 & 0.15 & 0.35 & 0.04 \\
\hline KS3 & 0.24 & 0.41 & 0.39 & 0.02 & 0.24 & 0.29 & 0.40 & 0.03 & 0.19 & 0.14 & 0.35 & 0.04 \\
\hline KS4 & 0.93 & 0.08 & 0.76 & 0.01 & 0.66 & 0.05 & 0.64 & 0.02 & 0.32 & 0.02 & 0.45 & 0.02 \\
\hline KS5 & 0.24 & 0.41 & 0.39 & 0.02 & 0.24 & 0.29 & 0.39 & 0.03 & 0.19 & 0.14 & 0.35 & 0.04 \\
\hline KAL1 & 1.19 & 0.03 & 0.85 & 0.01 & 0.76 & 0.02 & 0.69 & 0.01 & 0.35 & 0.01 & 0.47 & 0.02 \\
\hline KAL2 & 1.21 & 0.03 & 0.85 & 0.01 & 0.77 & 0.02 & 0.69 & 0.01 & 0.35 & 0.01 & 0.47 & 0.02 \\
\hline KAS1 & 0.65 & 0.22 & 0.61 & 0.02 & 0.47 & 0.17 & 0.53 & 0.03 & 0.25 & 0.10 & 0.40 & 0.04 \\
\hline KAS2 & 0.59 & 1.38 & 0.72 & 0.32 & 0.56 & 1.35 & 0.69 & 0.43 & 0.48 & 1.21 & 0.63 & 0.60 \\
\hline KAS3 & 0.37 & 0.69 & 0.50 & 0.11 & 0.29 & 0.61 & 0.45 & 0.14 & 0.19 & 0.45 & 0.36 & 0.18 \\
\hline KAS4 & 0.48 & 1.09 & 0.62 & 0.23 & 0.43 & 1.05 & 0.58 & 0.31 & 0.34 & 0.90 & 0.50 & 0.43 \\
\hline KAS5 & 0.79 & 0.14 & 0.69 & 0.01 & 0.63 & 0.07 & 0.62 & 0.02 & 0.34 & 0.02 & 0.46 & 0.02 \\
\hline
\end{tabular}




$$
p=4, \rho=0.85
$$

\begin{tabular}{|c|c|c|c|c|c|c|c|c|c|c|c|c|}
\hline & \multicolumn{4}{|c|}{$\mathrm{n}=70$} & \multicolumn{4}{|c|}{$\mathrm{n}=100$} & \multicolumn{4}{|c|}{$\mathrm{n}=200$} \\
\hline & MSE & Bias & MAPE & Pr. & MSE & Bias & MAPE & Pr. & MSE & Bias & MAPE & Pr. \\
\hline ML & 2.37 & 0.00 & 1.17 & 0.00 & 1.42 & 0.00 & 0.93 & 0.00 & 0.60 & 0.00 & 0.61 & 0.00 \\
\hline KH1 & 1.18 & 0.16 & 0.78 & 0.01 & 0.76 & 0.14 & 0.65 & 0.01 & 0.37 & 0.10 & 0.47 & 0.02 \\
\hline KH2 & 0.67 & 0.31 & 0.59 & 0.02 & 0.47 & 0.26 & 0.51 & 0.02 & 0.25 & 0.19 & 0.39 & 0.03 \\
\hline$\overline{\mathrm{KL}}$ & 1.26 & 0.13 & 0.83 & 0.00 & 0.98 & 0.07 & 0.76 & 0.01 & 0.53 & 0.02 & 0.57 & 0.01 \\
\hline KHG & 1.25 & 0.14 & 0.81 & 0.00 & 0.82 & 0.12 & 0.68 & 0.01 & 0.40 & 0.08 & 0.49 & 0.01 \\
\hline KBH & 0.26 & 0.54 & 0.41 & 0.03 & 0.21 & 0.50 & 0.37 & 0.04 & 0.13 & 0.42 & 0.30 & 0.08 \\
\hline KNR & 0.27 & 0.80 & 0.46 & 0.03 & 0.23 & 0.79 & 0.43 & 0.04 & 0.19 & 0.77 & 0.40 & 0.08 \\
\hline KK1 & 0.40 & 0.60 & 0.50 & 0.06 & 0.31 & 0.54 & 0.45 & 0.07 & 0.18 & 0.40 & 0.35 & 0.08 \\
\hline KK2 & 0.49 & 1.02 & 0.61 & 0.14 & 0.43 & 0.97 & 0.58 & 0.20 & 0.32 & 0.84 & 0.49 & 0.28 \\
\hline KK3 & 0.46 & 0.60 & 0.53 & 0.06 & 0.35 & 0.53 & 0.47 & 0.08 & 0.21 & 0.40 & 0.36 & 0.09 \\
\hline KK4 & 0.40 & 0.34 & 0.49 & 0.01 & 0.36 & 0.27 & 0.46 & 0.02 & 0.25 & 0.16 & 0.39 & 0.02 \\
\hline KK5 & 0.87 & 0.12 & 0.75 & 0.00 & 0.80 & 0.06 & 0.72 & 0.01 & 0.49 & 0.02 & 0.56 & 0.01 \\
\hline KK6 & 0.43 & 0.33 & 0.51 & 0.01 & 0.39 & 0.25 & 0.48 & 0.02 & 0.26 & 0.15 & 0.40 & 0.02 \\
\hline KK7 & 0.45 & 0.23 & 0.54 & 0.00 & 0.50 & 0.13 & 0.57 & 0.0 & 0.39 & 0.05 & 0.50 & 0.01 \\
\hline KK8 & 0.76 & 0.13 & 0.71 & 0.00 & 0.72 & 0.08 & 0.69 & 0.01 & 0.47 & 0.03 & 0.55 & 0.01 \\
\hline KK9 & 0.32 & 0.73 & 0.48 & 0.06 & 0.29 & 0.64 & 0.45 & 0.08 & 0.20 & 0.46 & 0.36 & 0.09 \\
\hline KL1 & 0.57 & 0.88 & 0.63 & 0.11 & 0.50 & 0.73 & 0.59 & 0.1 & 0.34 & 0.45 & 0.47 & 0.13 \\
\hline KL2 & 0.23 & 0.66 & 0.40 & 0.01 & 0.18 & 0.55 & 0.34 & 0.01 & 0.12 & 0.41 & 0.28 & 0.04 \\
\hline KD1 & 1.45 & 0.10 & 0.90 & 0.00 & 1.07 & 0.06 & 0.79 & 0.01 & 0.54 & 0.02 & 0.58 & 0.01 \\
\hline KD2 & 0.98 & 0.25 & 0.72 & 0.01 & 0.81 & 0.16 & 0.68 & 0.0 & 0.47 & 0.06 & 0.53 & 0.01 \\
\hline KD3 & 0.90 & 0.24 & 0.70 & 0.01 & 0.78 & 0.15 & 0.66 & 0.01 & 0.46 & 0.05 & 0.53 & 0.01 \\
\hline KD4 & 0.68 & 0.60 & 0.64 & 0.07 & 0.60 & 0.48 & 0.61 & 0.08 & 0.38 & 0.26 & 0.48 & 0.07 \\
\hline KS & 1.96 & 0.02 & 1.07 & 0.00 & 1.25 & 0.02 & 0.87 & 0.01 & 0.56 & 0.01 & 0.59 & 0.01 \\
\hline KS1 & 1.23 & 0.08 & 0.88 & 0.00 & 0.95 & 0.05 & 0.77 & 0.01 & 0.50 & 0.02 & 0.56 & 0.01 \\
\hline KS2 & 0.21 & 0.43 & 0.36 & 0.00 & 0.23 & 0.30 & 0.38 & 0.01 & 0.23 & 0.15 & 0.38 & 0.01 \\
\hline KS3 & 0.22 & 0.41 & 0.37 & 0.00 & 0.24 & 0.29 & 0.39 & 0.01 & 0.23 & 0.15 & 0.39 & 0.01 \\
\hline KS4 & 1.27 & 0.07 & 0.89 & 0.00 & 0.97 & 0.05 & 0.77 & 0.01 & 0.50 & 0.02 & 0.56 & 0.01 \\
\hline KS5 & 0.22 & 0.41 & 0.37 & 0.00 & 0.24 & 0.29 & 0.39 & 0.01 & 0.23 & 0.15 & 0.39 & 0.01 \\
\hline KAL1 & 1.83 & 0.03 & 1.04 & 0.00 & 1.22 & 0.02 & 0.86 & 0.01 & 0.56 & 0.01 & 0.59 & 0.01 \\
\hline KAL2 & 1.88 & 0.03 & 1.05 & 0.00 & 1.23 & 0.02 & 0.87 & 0.01 & 0.56 & 0.01 & 0.59 & 0.01 \\
\hline KAS1 & 0.90 & 0.19 & 0.71 & 0.01 & 0.70 & 0.15 & 0.63 & 0.01 & 0.37 & 0.10 & 0.47 & 0.02 \\
\hline KAS2 & 0.57 & 1.32 & 0.70 & 0.20 & 0.53 & 1.27 & 0.67 & 0.28 & 0.45 & 1.16 & 0.61 & 0.43 \\
\hline KAS3 & 0.40 & 0.61 & 0.51 & 0.06 & 0.33 & 0.53 & 0.46 & 0.08 & 0.20 & 0.40 & 0.36 & 0.10 \\
\hline KAS4 & 0.47 & 1.03 & 0.61 & 0.14 & 0.43 & 0.97 & 0.58 & 0.20 & 0.32 & 0.84 & 0.49 & 0.28 \\
\hline KAS5 & 1.00 & 0.15 & 0.76 & 0.00 & 0.90 & 0.08 & 0.73 & 0.01 & 0.52 & 0.02 & 0.57 & 0.01 \\
\hline
\end{tabular}




$$
p=4, \rho=0.95
$$

\begin{tabular}{|c|c|c|c|c|c|c|c|c|c|c|c|c|}
\hline & \multicolumn{4}{|c|}{$\mathrm{n}=70$} & \multicolumn{4}{|c|}{$\mathrm{n}=100$} & \multicolumn{4}{|c|}{$\mathrm{n}=200$} \\
\hline & MSE & Bias & MAPE & Pr. & MSE & Bias & MAPE & Pr. & MSE & Bias & MAPE & Pr. \\
\hline ML & 8.34 & 0.00 & 2.19 & 0.00 & 4.70 & 0.00 & 1.67 & 0.00 & 1.88 & 0.00 & 1.07 & 0.00 \\
\hline KH1 & 3.72 & 0.09 & 1.33 & 0.00 & 2.15 & 0.08 & 1.04 & 0.00 & 0.92 & 0.07 & 0.70 & 0.00 \\
\hline $\mathrm{KH} 2$ & 2.06 & 0.17 & 0.95 & 0.00 & 1.23 & 0.16 & 0.76 & 0.01 & 0.54 & 0.13 & 0.53 & 0.00 \\
\hline KL & 2.94 & 0.12 & 1.17 & 0.00 & 2.29 & 0.08 & 1.08 & 0.00 & 1.30 & 0.03 & 0.86 & 0.00 \\
\hline KHG & 2.96 & 0.12 & 1.17 & 0.00 & 1.71 & 0.11 & 0.92 & 0.00 & 0.76 & 0.09 & 0.63 & 0.00 \\
\hline KBH & 0.63 & 0.28 & 0.56 & 0.00 & 0.41 & 0.27 & 0.46 & 0.01 & 0.20 & 0.24 & 0.33 & 0.01 \\
\hline KNR & 0.49 & 0.43 & 0.50 & 0.00 & 0.31 & 0.44 & 0.42 & 0.01 & 0.15 & 0.43 & 0.31 & 0.01 \\
\hline KK1 & 1.02 & 0.37 & 0.67 & 0.01 & 0.66 & 0.35 & 0.57 & 0.02 & 0.31 & 0.31 & 0.41 & 0.02 \\
\hline KK2 & 0.75 & 0.77 & 0.66 & 0.03 & 0.55 & 0.73 & 0.58 & 0.05 & 0.36 & 0.70 & 0.49 & 0.10 \\
\hline KK3 & 1.15 & 0.37 & 0.71 & 0.01 & 0.75 & 0.37 & 0.61 & 0.02 & 0.35 & 0.32 & 0.43 & 0.02 \\
\hline KK4 & 0.62 & 0.24 & 0.58 & 0.00 & 0.57 & 0.19 & 0.56 & 0.00 & 0.40 & 0.13 & 0.47 & 0.00 \\
\hline KK5 & 0.79 & 0.15 & 0.72 & 0.00 & 0.93 & 0.09 & 0.78 & 0.00 & 0.92 & 0.03 & 0.78 & 0.00 \\
\hline KK6 & 0.69 & 0.23 & 0.61 & 0.00 & 0.62 & 0.19 & 0.58 & 0.00 & 0.43 & 0.13 & 0.49 & 0.00 \\
\hline KK7 & 0.29 & 0.28 & 0.43 & 0.00 & 0.39 & 0.17 & 0.51 & 0.00 & 0.53 & 0.06 & 0.59 & 0.00 \\
\hline KK8 & 0.61 & 0.18 & 0.63 & 0.00 & 0.76 & 0.10 & 0.71 & 0.00 & 0.82 & 0.04 & 0.73 & 0.00 \\
\hline KK9 & 0.34 & 0.59 & 0.48 & 0.01 & 0.31 & 0.50 & 0.44 & 0.02 & 0.24 & 0.39 & 0.38 & 0.02 \\
\hline KL1 & 1.09 & 0.68 & 0.75 & 0.02 & 0.98 & 0.54 & 0.71 & 0.04 & 0.69 & 0.39 & 0.61 & 0.04 \\
\hline KL2 & 0.31 & 0.93 & 0.50 & 0.00 & 0.23 & 0.77 & 0.43 & 0.00 & 0.13 & 0.55 & 0.30 & 0.01 \\
\hline KD1 & 4.71 & 0.06 & 1.56 & 0.00 & 3.25 & 0.04 & 1.34 & 0.00 & 1.59 & 0.01 & 0.97 & 0.00 \\
\hline KD2 & 3.09 & 0.15 & 1.20 & 0.00 & 2.39 & 0.11 & 1.09 & 0.00 & 1.30 & 0.05 & 0.85 & 0.00 \\
\hline KD3 & 2.92 & 0.14 & 1.16 & 0.00 & 2.31 & 0.09 & 1.08 & 0.00 & 1.29 & 0.04 & 0.85 & 0.00 \\
\hline KD4 & 1.81 & 0.45 & 0.91 & 0.01 & 1.52 & 0.33 & 0.85 & 0.02 & 0.93 & 0.23 & 0.71 & 0.02 \\
\hline KS & 5.63 & 0.02 & 1.79 & 0.00 & 3.50 & 0.02 & 1.44 & 0.00 & 1.60 & 0.01 & 0.99 & 0.00 \\
\hline KS1 & 1.91 & 0.07 & 1.11 & 0.00 & 1.73 & 0.05 & 1.04 & 0.00 & 1.14 & 0.02 & 0.84 & 0.00 \\
\hline KS2 & 0.15 & 0.44 & 0.30 & 0.00 & 0.16 & 0.30 & 0.32 & 0.00 & 0.22 & 0.14 & 0.38 & 0.00 \\
\hline KS3 & 0.16 & 0.40 & 0.31 & 0.00 & 0.18 & 0.28 & 0.34 & 0.00 & 0.24 & 0.14 & 0.39 & 0.00 \\
\hline KS4 & 2.13 & 0.07 & 1.16 & 0.00 & 1.84 & 0.05 & 1.07 & 0.00 & 1.16 & 0.02 & 0.85 & 0.00 \\
\hline KS5 & 0.16 & 0.41 & 0.31 & 0.00 & 0.18 & 0.28 & 0.33 & 0.00 & 0.24 & 0.14 & 0.39 & 0.00 \\
\hline KAL1 & 4.26 & 0.03 & 1.61 & 0.00 & 3.05 & 0.02 & 1.36 & 0.00 & 1.53 & 0.01 & 0.97 & 0.00 \\
\hline KAL2 & 4.79 & 0.03 & 1.68 & 0.00 & 3.23 & 0.02 & 1.40 & 0.00 & 1.56 & 0.01 & 0.98 & 0.00 \\
\hline KAS1 & 1.92 & 0.12 & 1.03 & 0.00 & 1.69 & 0.09 & 0.95 & 0.00 & 0.89 & 0.07 & 0.69 & 0.00 \\
\hline KAS2 & 0.54 & 1.07 & 0.64 & 0.04 & 0.49 & 1.03 & 0.61 & 0.08 & 0.41 & 0.99 & 0.56 & 0.16 \\
\hline KAS3 & 0.71 & 0.39 & 0.62 & 0.01 & 0.64 & 0.37 & 0.58 & 0.02 & 0.34 & 0.32 & 0.43 & 0.02 \\
\hline KAS4 & 0.57 & 0.78 & 0.61 & 0.03 & 0.50 & 0.73 & 0.57 & 0.05 & 0.36 & 0.70 & 0.49 & 0.10 \\
\hline KAS5 & 1.66 & 0.15 & 0.95 & 0.00 & 1.79 & 0.09 & 0.98 & 0.00 & 1.24 & 0.03 & 0.84 & 0.00 \\
\hline
\end{tabular}




$$
p=4, \rho=0.99
$$

\begin{tabular}{|c|c|c|c|c|c|c|c|c|c|c|c|c|}
\hline & \multicolumn{4}{|c|}{$\mathrm{n}=70$} & \multicolumn{4}{|c|}{$\mathrm{n}=100$} & \multicolumn{4}{|c|}{$\mathrm{n}=200$} \\
\hline & MSE & Bias & MAPE & Pr. & MSE & Bias & MAPE & Pr. & MSE & Bias & MAPE & Pr. \\
\hline ML & 40.12 & 0.00 & 4.76 & 0.00 & 25.49 & 0.00 & 3.88 & 0.00 & 10.39 & 0.00 & 2.49 & 0.00 \\
\hline KH1 & 16.51 & 0.03 & 2.69 & 0.00 & 10.57 & 0.03 & 2.22 & 0.00 & 4.42 & 0.03 & 1.44 & 0.00 \\
\hline $\mathrm{KH} 2$ & 8.91 & 0.06 & 1.89 & 0.00 & 5.76 & 0.05 & 1.57 & 0.00 & 2.46 & 0.05 & 1.03 & 0.00 \\
\hline KL & 10.20 & 0.09 & 1.97 & 0.00 & 8.94 & 0.05 & 1.95 & 0.00 & 5.28 & 0.03 & 1.60 & 0.00 \\
\hline KHG & 7.72 & 0.09 & 1.68 & 0.00 & 5.15 & 0.08 & 1.41 & 0.00 & 2.11 & 0.08 & 0.92 & 0.00 \\
\hline KBH & 2.74 & 0.08 & 1.11 & 0.00 & 1.81 & 0.07 & 0.92 & 0.00 & 0.82 & 0.08 & 0.62 & 0.00 \\
\hline KNR & 2.54 & 0.15 & 0.98 & 0.00 & 1.57 & 0.14 & 0.79 & 0.00 & 0.62 & 0.15 & 0.51 & 0.00 \\
\hline KK1 & 4.00 & 0.15 & 1.18 & 0.00 & 2.54 & 0.14 & 0.98 & 0.00 & 1.14 & 0.14 & 0.67 & 0.00 \\
\hline KK2 & 2.23 & 0.46 & 0.87 & 0.00 & 1.36 & 0.45 & 0.74 & 0.00 & 0.70 & 0.44 & 0.56 & 0.01 \\
\hline KK3 & 4.64 & 0.16 & 1.27 & 0.00 & 2.96 & 0.16 & 1.05 & 0.00 & 1.26 & 0.15 & 0.71 & 0.00 \\
\hline KK4 & 0.88 & 0.13 & 0.67 & 0.00 & 0.84 & 0.10 & 0.66 & 0.00 & 0.70 & 0.07 & 0.59 & 0.00 \\
\hline KK5 & 0.22 & 0.23 & 0.36 & 0.00 & 0.34 & 0.14 & 0.44 & 0.00 & 0.71 & 0.05 & 0.67 & 0.00 \\
\hline KK6 & 1.02 & 0.12 & 0.72 & 0.00 & 0.95 & 0.10 & 0.70 & 0.00 & 0.77 & 0.07 & 0.62 & 0.00 \\
\hline KK7 & 0.12 & 0.43 & 0.28 & 0.00 & 0.10 & 0.27 & 0.25 & 0.00 & 0.21 & 0.10 & 0.37 & 0.00 \\
\hline KK8 & 0.16 & 0.27 & 0.31 & 0.00 & 0.23 & 0.17 & 0.36 & 0.00 & 0.51 & 0.06 & 0.57 & 0.00 \\
\hline KK9 & 0.36 & 0.40 & 0.45 & 0.00 & 0.33 & 0.34 & 0.43 & 0.00 & 0.28 & 0.27 & 0.38 & 0.00 \\
\hline KL1 & 3.66 & 0.41 & 1.10 & 0.00 & 3.37 & 0.34 & 1.11 & 0.00 & 2.62 & 0.24 & 1.02 & 0.00 \\
\hline KL2 & 0.57 & 1.41 & 0.73 & 0.00 & 0.50 & 1.32 & 0.67 & 0.00 & 0.31 & 1.01 & 0.52 & 0.00 \\
\hline KD1 & 21.40 & 0.02 & 3.24 & 0.00 & 16.61 & 0.01 & 2.95 & 0.00 & 8.37 & 0.01 & 2.15 & 0.00 \\
\hline KD2 & 13.48 & 0.06 & 2.43 & 0.00 & 11.35 & 0.04 & 2.29 & 0.00 & 6.52 & 0.02 & 1.82 & 0.00 \\
\hline KD3 & 12.58 & 0.05 & 2.35 & 0.00 & 10.88 & 0.03 & 2.26 & 0.00 & 6.46 & 0.02 & 1.82 & 0.00 \\
\hline KD4 & 6.99 & 0.25 & 1.58 & 0.00 & 6.18 & 0.20 & 1.56 & 0.00 & 4.13 & 0.14 & 1.35 & 0.00 \\
\hline $\mathrm{KS}$ & 19.62 & 0.01 & 3.16 & 0.00 & 13.32 & 0.01 & 2.70 & 0.00 & 6.38 & 0.01 & 1.92 & 0.00 \\
\hline KS1 & 1.47 & 0.06 & 0.97 & 0.00 & 1.71 & 0.04 & 1.05 & 0.00 & 1.88 & 0.02 & 1.09 & 0.00 \\
\hline KS2 & 0.12 & 0.51 & 0.30 & 0.00 & 0.07 & 0.35 & 0.22 & 0.00 & 0.09 & 0.15 & 0.24 & 0.00 \\
\hline KS3 & 0.10 & 0.43 & 0.26 & 0.00 & 0.08 & 0.29 & 0.21 & 0.00 & 0.11 & 0.13 & 0.27 & 0.00 \\
\hline KS4 & 2.17 & 0.05 & 1.15 & 0.00 & 2.30 & 0.03 & 1.20 & 0.00 & 2.19 & 0.02 & 1.16 & 0.00 \\
\hline KS5 & 0.10 & 0.43 & 0.26 & 0.00 & 0.07 & 0.30 & 0.21 & 0.00 & 0.11 & 0.13 & 0.26 & 0.00 \\
\hline KAL1 & 6.46 & 0.02 & 1.95 & 0.00 & 5.81 & 0.02 & 1.90 & 0.00 & 4.33 & 0.01 & 1.64 & 0.00 \\
\hline KAL2 & 10.06 & 0.02 & 2.38 & 0.00 & 8.18 & 0.01 & 2.20 & 0.00 & 5.10 & 0.01 & 1.75 & 0.00 \\
\hline KAS1 & 3.14 & 0.05 & 1.34 & 0.00 & 4.19 & 0.04 & 1.52 & 0.00 & 3.53 & 0.03 & 1.32 & 0.00 \\
\hline KAS2 & 0.57 & 0.71 & 0.59 & 0.01 & 0.56 & 0.69 & 0.58 & 0.01 & 0.45 & 0.68 & 0.51 & 0.02 \\
\hline KAS3 & 1.35 & 0.18 & 0.82 & 0.00 & 1.54 & 0.16 & 0.84 & 0.00 & 1.10 & 0.15 & 0.68 & 0.00 \\
\hline KAS4 & 0.80 & 0.48 & 0.65 & 0.00 & 0.85 & 0.45 & 0.65 & 0.00 & 0.64 & 0.45 & 0.55 & 0.01 \\
\hline KAS5 & 2.40 & 0.11 & 1.10 & 0.00 & 3.65 & 0.06 & 1.36 & 0.00 & 4.12 & 0.03 & 1.44 & 0.00 \\
\hline
\end{tabular}




$$
p=8, \rho=0.75
$$

\begin{tabular}{|c|c|c|c|c|c|c|c|c|c|c|c|c|}
\hline & \multicolumn{4}{|c|}{$\mathrm{n}=70$} & \multicolumn{4}{|c|}{$\mathrm{n}=100$} & \multicolumn{4}{|c|}{$\mathrm{n}=200$} \\
\hline & MSE & Bias & MAPE & Pr. & $\begin{array}{c}\text { MS } \\
\text { E }\end{array}$ & $\begin{array}{c}\text { Bia } \\
\text { s }\end{array}$ & MAPE & Pr. & MSE & Bias & MAPE & Pr. \\
\hline $\mathrm{ML}$ & 208.80 & 0.00 & 2.22 & 0.00 & 2.87 & 0.00 & 1.29 & 0.00 & 1.04 & 0.00 & 0.80 & 0.00 \\
\hline KH1 & 3.38 & 0.20 & 1.28 & 0.00 & 1.62 & 0.18 & 0.95 & 0.00 & 0.70 & 0.13 & 0.65 & 0.00 \\
\hline KH2 & 1.21 & 0.47 & 0.80 & 0.00 & 0.72 & 0.43 & 0.64 & 0.00 & 0.38 & 0.33 & 0.48 & 0.00 \\
\hline KL & 2.43 & 0.22 & 1.17 & 0.00 & 1.74 & 0.13 & 1.01 & 0.00 & 0.89 & 0.04 & 0.74 & 0.00 \\
\hline KHG & 4.10 & 0.13 & 1.45 & 0.00 & 2.01 & 0.10 & 1.07 & 0.00 & 0.83 & 0.07 & 0.71 & 0.00 \\
\hline KBH & 0.39 & 0.82 & 0.49 & 0.00 & 0.28 & 0.81 & 0.43 & 0.00 & 0.18 & 0.72 & 0.35 & 0.01 \\
\hline KNR & 0.35 & 1.13 & 0.51 & 0.00 & 0.29 & 1.20 & 0.48 & 0.00 & 0.25 & 1.26 & 0.46 & 0.01 \\
\hline KK1 & 0.47 & 0.96 & 0.55 & 0.00 & 0.35 & 0.92 & 0.49 & 0.01 & 0.23 & 0.77 & 0.39 & 0.02 \\
\hline KK2 & 0.61 & 1.85 & 0.73 & 0.03 & 0.56 & 1.83 & 0.69 & 0.07 & 0.48 & 1.71 & 0.64 & 0.23 \\
\hline KK3 & 0.62 & 0.81 & 0.60 & 0.00 & 0.43 & 0.78 & 0.52 & 0.00 & 0.26 & 0.64 & 0.41 & 0.01 \\
\hline KK4 & 0.57 & 0.58 & 0.60 & 0.00 & 0.52 & 0.47 & 0.57 & 0.00 & 0.39 & 0.30 & 0.49 & 0.00 \\
\hline KK5 & 1.71 & 0.23 & 1.05 & 0.00 & 1.60 & 0.11 & 1.01 & 0.00 & 0.89 & 0.03 & 0.75 & 0.00 \\
\hline KK6 & 0.69 & 0.52 & 0.65 & 0.00 & 0.62 & 0.42 & 0.62 & 0.00 & 0.44 & 0.26 & 0.52 & 0.00 \\
\hline KK7 & 0.70 & 0.49 & 0.67 & 0.00 & 0.83 & 0.27 & 0.74 & 0.00 & 0.69 & 0.09 & 0.67 & 0.00 \\
\hline KK8 & 1.49 & 0.27 & 0.98 & 0.00 & 1.46 & 0.13 & 0.96 & 0.00 & 0.87 & 0.04 & 0.74 & 0.00 \\
\hline KK9 & 0.45 & 1.49 & 0.61 & 0.01 & 0.39 & 1.36 & 0.56 & 0.02 & 0.29 & 1.07 & 0.46 & 0.06 \\
\hline KL1 & 0.65 & 1.92 & 0.76 & 0.03 & 0.59 & 1.74 & 0.70 & 0.06 & 0.45 & 1.32 & 0.59 & 0.16 \\
\hline KL2 & 0.36 & 1.22 & 0.53 & 0.00 & 0.27 & 0.93 & 0.44 & 0.00 & 0.19 & 0.61 & 0.36 & 0.00 \\
\hline KD1 & 2.95 & 0.18 & 1.28 & 0.00 & 1.93 & 0.11 & 1.06 & 0.00 & 0.92 & 0.04 & 0.75 & 0.00 \\
\hline KD2 & 1.72 & 0.36 & 0.96 & 0.00 & 1.33 & 0.24 & 0.87 & 0.00 & 0.78 & 0.10 & 0.69 & 0.00 \\
\hline KD3 & 1.29 & 0.44 & 0.84 & 0.00 & 1.10 & 0.30 & 0.79 & 0.00 & 0.72 & 0.12 & 0.66 & 0.00 \\
\hline KD4 & 0.69 & 1.29 & 0.70 & 0.01 & 0.63 & 1.10 & 0.66 & 0.03 & 0.48 & 0.72 & 0.56 & 0.06 \\
\hline KS & 8.47 & 0.05 & 1.69 & 0.00 & 2.52 & 0.03 & 1.22 & 0.00 & 0.99 & 0.01 & 0.78 & 0.00 \\
\hline KS1 & 2.39 & 0.16 & 1.23 & 0.00 & 1.84 & 0.09 & 1.06 & 0.00 & 0.89 & 0.04 & 0.74 & 0.00 \\
\hline KS2 & 0.37 & 0.75 & 0.49 & 0.00 & 0.40 & 0.51 & 0.50 & 0.00 & 0.41 & 0.25 & 0.51 & 0.00 \\
\hline KS3 & 0.39 & 0.70 & 0.50 & 0.00 & 0.43 & 0.49 & 0.52 & 0.00 & 0.42 & 0.24 & 0.52 & 0.00 \\
\hline KS4 & 2.48 & 0.16 & 1.25 & 0.00 & 1.86 & 0.09 & 1.07 & 0.00 & 0.89 & 0.04 & 0.74 & 0.00 \\
\hline KS5 & 0.39 & 0.70 & 0.50 & 0.00 & 0.42 & 0.49 & 0.52 & 0.00 & 0.42 & 0.24 & 0.52 & 0.00 \\
\hline KAL1 & 7.47 & 0.07 & 1.60 & 0.00 & 2.43 & 0.04 & 1.20 & 0.00 & 0.98 & 0.01 & 0.78 & 0.00 \\
\hline KAL2 & 7.69 & 0.06 & 1.62 & 0.00 & 2.46 & 0.03 & 1.20 & 0.00 & 0.98 & 0.01 & 0.78 & 0.00 \\
\hline KAS1 & 1.91 & 0.26 & 1.06 & 0.00 & 1.42 & 0.20 & 0.91 & 0.00 & 0.69 & 0.13 & 0.64 & 0.00 \\
\hline KAS2 & 0.78 & 2.36 & 0.86 & 0.04 & 0.75 & 2.35 & 0.85 & 0.11 & 0.71 & 2.29 & 0.82 & 0.41 \\
\hline KAS3 & 0.51 & 0.84 & 0.57 & 0.00 & 0.40 & 0.79 & 0.51 & 0.00 & 0.26 & 0.65 & 0.41 & 0.01 \\
\hline KAS4 & 0.60 & 1.86 & 0.72 & 0.03 & 0.56 & 1.83 & 0.69 & 0.07 & 0.48 & 1.71 & 0.64 & 0.23 \\
\hline KAS5 & 1.72 & 0.27 & 1.02 & 0.00 & 1.55 & 0.15 & 0.97 & 0.00 & 0.88 & 0.05 & 0.73 & 0.00 \\
\hline
\end{tabular}




$$
p=8, \rho=0.85
$$

\begin{tabular}{|c|c|c|c|c|c|c|c|c|c|c|c|c|}
\hline & \multicolumn{4}{|c|}{$\mathrm{n}=70$} & \multicolumn{4}{|c|}{$\mathrm{n}=100$} & \multicolumn{4}{|c|}{$\mathrm{n}=200$} \\
\hline & MSE & Bias & MAPE & Pr. & MSE & Bias & MAPE & Pr. & MSE & Bias & MAPE & Pr. \\
\hline ML & 4369.38 & 0.00 & 5.59 & 0.00 & 5.53 & 0.00 & 1.77 & 0.00 & 1.82 & 0.00 & 1.05 & 0.00 \\
\hline KH1 & 6.19 & 0.15 & 1.70 & 0.00 & 2.96 & 0.13 & 1.27 & 0.00 & 1.12 & 0.10 & 0.81 & 0.00 \\
\hline KH2 & 2.17 & 0.34 & 1.03 & 0.00 & 1.26 & 0.31 & 0.82 & 0.00 & 0.54 & 0.26 & 0.56 & 0.00 \\
\hline $\mathrm{KL}$ & 3.16 & 0.23 & 1.31 & 0.00 & 2.59 & 0.14 & 1.22 & 0.00 & 1.36 & 0.05 & 0.90 & 0.00 \\
\hline KHG & 7.20 & 0.11 & 1.87 & 0.00 & 3.49 & 0.09 & 1.40 & 0.00 & 1.29 & 0.07 & 0.88 & 0.00 \\
\hline KBH & 0.62 & 0.58 & 0.59 & 0.00 & 0.40 & 0.58 & 0.49 & 0.00 & 0.21 & 0.54 & 0.36 & 0.00 \\
\hline$\overline{\text { KNR }}$ & 0.45 & 0.79 & 0.53 & 0.00 & 0.29 & 0.85 & 0.44 & 0.00 & $\begin{array}{l}0.18 \\
\end{array}$ & 0.92 & 0.37 & 0.00 \\
\hline KK1 & 0.75 & 0.72 & 0.64 & 0.00 & 0.47 & 0.72 & 0.53 & 0.00 & 0.25 & 0.65 & 0.40 & 0.00 \\
\hline KK2 & 0.62 & 1.58 & 0.70 & 0.01 & 0.55 & 1.65 & 0.67 & 0.02 & 0.46 & 1.58 & 0.61 & 0.08 \\
\hline KK3 & 1.06 & 0.61 & 0.73 & 0.00 & 0.63 & 0.60 & 0.59 & 0.00 & 0.31 & 0.55 & 0.44 & 0.00 \\
\hline KK4 & 0.72 & 0.48 & 0.66 & 0.00 & 0.67 & 0.39 & 0.64 & 0.00 & 0.49 & 0.26 & 0.55 & 0.00 \\
\hline KK5 & 1.68 & 0.28 & 1.04 & 0.00 & 1.99 & 0.13 & 1.13 & 0.00 & 1.37 & 0.04 & 0.92 & 0.00 \\
\hline KK6 & 0.88 & 0.43 & 0.73 & 0.00 & 0.81 & 0.35 & 0.70 & 0.00 & 0.56 & 0.23 & 0.58 & 0.00 \\
\hline KK7 & 0.58 & 0.55 & 0.61 & 0.00 & 0.81 & 0.30 & 0.72 & 0.00 & 0.88 & 0.11 & 0.76 & 0.00 \\
\hline KK8 & 1.42 & 0.31 & 0.95 & 0.00 & 1.75 & 0.15 & 1.06 & 0.00 & 1.30 & 0.05 & 0.90 & 0.00 \\
\hline KK9 & 0.43 & 1.32 & 0.58 & 0.00 & 0.38 & 1.24 & 0.54 & 0.01 & 0.28 & 0.99 & 0.46 & 0.02 \\
\hline KL1 & 0.67 & 1.72 & 0.74 & 0.01 & 0.61 & 1.62 & 0.70 & 0.02 & 0.49 & 1.24 & 0.60 & 0.06 \\
\hline KL2 & 0.40 & 1.38 & 0.58 & 0.00 & 0.28 & 1.08 & 0.47 & 0.00 & 0.17 & 0.69 & 0.34 & 0.00 \\
\hline KD1 & 4.95 & 0.15 & 1.63 & 0.00 & 3.43 & 0.09 & 1.39 & 0.00 & 1.53 & 0.03 & 0.96 & 0.00 \\
\hline KD2 & 2.83 & 0.29 & 1.21 & 0.00 & 2.22 & 0.20 & 1.10 & 0.00 & 1.22 & 0.09 & 0.85 & 0.00 \\
\hline KD3 & 2.12 & 0.35 & 1.05 & 0.00 & 1.80 & 0.24 & 0.99 & 0.00 & 1.11 & 0.11 & 0.81 & 0.00 \\
\hline KD4 & 0.96 & 1.10 & 0.76 & 0.00 & 0.84 & 0.99 & 0.71 & 0.01 & 0.63 & 0.67 & 0.62 & 0.02 \\
\hline $\mathrm{KS}$ & 18.95 & 0.05 & 2.31 & 0.00 & 4.55 & 0.03 & 1.62 & 0.00 & 1.68 & 0.01 & 1.01 & 0.00 \\
\hline KS1 & 3.05 & 0.16 & 1.40 & 0.00 & 2.72 & 0.09 & 1.30 & 0.00 & 1.40 & 0.04 & 0.93 & 0.00 \\
\hline KS2 & 0.33 & 0.78 & 0.47 & 0.00 & 0.36 & 0.51 & 0.48 & 0.00 & 0.45 & 0.25 & 0.54 & 0.00 \\
\hline KS3 & 0.35 & 0.71 & 0.48 & 0.00 & 0.40 & 0.48 & 0.50 & 0.00 & 0.47 & 0.24 & 0.55 & 0.00 \\
\hline KS4 & 3.25 & 0.15 & 1.44 & 0.00 & 2.80 & 0.09 & 1.32 & 0.00 & 1.41 & 0.04 & 0.93 & 0.00 \\
\hline KS5 & 0.35 & 0.72 & 0.48 & 0.00 & 0.39 & 0.48 & 0.50 & 0.00 & 0.47 & 0.24 & 0.55 & 0.00 \\
\hline KAL1 & 16.33 & 0.06 & 2.09 & 0.00 & 4.19 & 0.03 & 1.57 & 0.00 & 1.65 & 0.01 & 1.00 & 0.00 \\
\hline KAL2 & 16.93 & 0.06 & 2.15 & 0.00 & 4.30 & 0.03 & 1.59 & 0.00 & 1.66 & 0.01 & 1.00 & 0.00 \\
\hline KAS1 & 2.60 & 0.22 & 1.25 & 0.00 & 2.33 & 0.15 & 1.16 & 0.00 & 1.09 & 0.11 & 0.80 & 0.00 \\
\hline KAS2 & 0.71 & 2.17 & 0.82 & 0.01 & 0.71 & 2.23 & 0.82 & 0.03 & 0.67 & 2.19 & 0.79 & 0.17 \\
\hline KAS3 & 0.70 & 0.65 & 0.65 & 0.00 & 0.57 & 0.61 & 0.57 & 0.00 & 0.31 & 0.55 & 0.44 & 0.00 \\
\hline KAS4 & 0.57 & 1.60 & 0.68 & 0.01 & 0.54 & 1.66 & 0.67 & 0.02 & 0.46 & 1.58 & 0.61 & 0.08 \\
\hline KAS5 & 1.88 & 0.28 & 1.06 & 0.00 & 2.13 & 0.16 & 1.12 & 0.00 & 1.31 & 0.06 & 0.89 & 0.00 \\
\hline
\end{tabular}




$$
p=8, \rho=0.95
$$

\begin{tabular}{|c|c|c|c|c|c|c|c|c|c|c|c|c|}
\hline & \multicolumn{4}{|c|}{$\mathrm{n}=70$} & \multicolumn{4}{|c|}{$\mathrm{n}=100$} & \multicolumn{4}{|c|}{$\mathrm{n}=200$} \\
\hline & MSE & Bias & MAPE & Pr. & MSE & Bias & MAPE & Pr. & MSE & Bias & MAPE & Pr. \\
\hline ML & 39212.14 & 0.00 & 18.34 & 0 & 18.57 & 0.00 & 3.14 & 0 & 6.05 & 0.00 & 1.87 & 0.00 \\
\hline KH1 & 24.00 & 0.07 & 3.03 & 0 & 9.39 & 0.06 & 2.14 & 0 & 3.31 & 0.05 & 1.34 & 0.00 \\
\hline $\mathrm{KH} 2$ & 7.65 & 0.16 & 1.81 & 0 & 3.72 & 0.14 & 1.34 & 0 & 1.45 & 0.13 & 0.88 & 0.00 \\
\hline KL & 5.04 & 0.19 & 1.56 & 0 & 4.37 & 0.12 & 1.49 & 0 & 2.92 & 0.06 & 1.28 & 0.00 \\
\hline KHG & 20.44 & 0.08 & 2.80 & 0 & 7.92 & 0.06 & 2.00 & 0 & 2.92 & 0.06 & 1.28 & 0.00 \\
\hline $\mathrm{KBH}$ & 3.83 & 0.25 & 1.04 & 0 & 1.14 & 0.25 & 0.78 & 0 & 0.50 & 0.24 & 0.53 & 0.00 \\
\hline KNR & 1.92 & 0.34 & 0.88 & 0 & 0.87 & 0.36 & 0.65 & 0 & 0.30 & 0.39 & 0.41 & 0.00 \\
\hline KK1 & 2.51 & 0.36 & 0.96 & 0 & 1.14 & 0.38 & 0.73 & 0 & 0.51 & 0.36 & 0.51 & 0.00 \\
\hline KK2 & 1.12 & 1.18 & 0.73 & 0 & 0.63 & 1.25 & 0.65 & 0 & 0.42 & 1.20 & 0.55 & 0.01 \\
\hline KK3 & 3.50 & 0.30 & 1.16 & 0 & 1.64 & 0.31 & 0.87 & 0 & 0.71 & 0.29 & 0.60 & 0.00 \\
\hline KK4 & 1.01 & 0.31 & 0.77 & 0 & 0.98 & 0.25 & 0.75 & 0 & 0.79 & 0.17 & 0.68 & 0.00 \\
\hline KK5 & 1.04 & 0.35 & 0.79 & 0 & 1.68 & 0.16 & 1.03 & 0 & 2.20 & 0.05 & 1.20 & 0.00 \\
\hline KK6 & 1.27 & 0.28 & 0.86 & 0 & 1.21 & 0.22 & 0.83 & 0 & 0.95 & 0.15 & 0.75 & 0.00 \\
\hline KK7 & 0.32 & 0.70 & 0.47 & 0 & 0.42 & 0.39 & 0.51 & 0 & 0.87 & 0.13 & 0.75 & 0.00 \\
\hline KK8 & 0.83 & 0.39 & 0.71 & 0 & 1.35 & 0.19 & 0.92 & 0 & 1.93 & 0.06 & 1.12 & 0.00 \\
\hline KK9 & 0.39 & 1.07 & 0.55 & 0 & 0.35 & 1.00 & 0.50 & 0 & 0.27 & 0.77 & 0.42 & 0.00 \\
\hline KL1 & 0.77 & 1.40 & 0.73 & 0 & 0.78 & 1.29 & 0.70 & 0 & 0.68 & 0.94 & 0.63 & 0.00 \\
\hline KL2 & 0.55 & 1.86 & 0.72 & 0 & 0.40 & 1.54 & 0.60 & 0 & 0.20 & 1.06 & 0.41 & 0.00 \\
\hline KD1 & 14.24 & 0.09 & 2.71 & 0 & 10.02 & 0.04 & 2.30 & 0 & 4.79 & 0.02 & 1.65 & 0.00 \\
\hline KD2 & 7.41 & 0.15 & 1.92 & 0 & 5.96 & 0.10 & 1.75 & 0 & 3.60 & 0.05 & 1.41 & 0.00 \\
\hline KD3 & 5.58 & 0.18 & 1.65 & 0 & 4.77 & 0.12 & 1.56 & 0 & 3.18 & 0.05 & 1.32 & 0.00 \\
\hline KD4 & 1.87 & 0.81 & 0.93 & 0 & 1.77 & 0.72 & 0.91 & 0 & 1.44 & 0.46 & 0.84 & 0.00 \\
\hline KS & 65.93 & 0.03 & 3.88 & 0 & 12.77 & 0.02 & 2.62 & 0 & 4.99 & 0.01 & 1.71 & 0.00 \\
\hline KS1 & 3.57 & 0.14 & 1.53 & 0 & 3.93 & 0.08 & 1.58 & 0 & 2.97 & 0.04 & 1.36 & 0.00 \\
\hline KS2 & 0.27 & 0.86 & 0.44 & 0 & 0.22 & 0.55 & 0.37 & 0 & 0.36 & 0.24 & 0.48 & 0.00 \\
\hline KS3 & 0.27 & 0.72 & 0.42 & 0 & 0.26 & 0.47 & 0.40 & 0 & 0.42 & 0.22 & 0.52 & 0.00 \\
\hline KS4 & 4.18 & 0.13 & 1.65 & 0 & 4.29 & 0.07 & 1.65 & 0 & 3.05 & 0.03 & 1.38 & 0.00 \\
\hline KS5 & 0.26 & 0.74 & 0.42 & 0 & 0.25 & 0.48 & 0.39 & 0 & 0.41 & 0.22 & 0.51 & 0.00 \\
\hline KAL1 & 48.20 & 0.05 & 2.95 & 0 & 8.83 & 0.03 & 2.30 & 0 & 4.53 & 0.01 & 1.65 & 0.00 \\
\hline KAL2 & 51.21 & 0.04 & 3.21 & 0 & 9.81 & 0.03 & 2.40 & 0 & 4.66 & 0.01 & 1.66 & 0.00 \\
\hline KAS1 & 3.98 & 0.16 & 1.56 & 0 & 4.68 & 0.09 & 1.65 & 0 & 2.98 & 0.05 & 1.29 & 0.00 \\
\hline KAS2 & 0.62 & 1.83 & 0.74 & 0 & 0.61 & 1.88 & 0.73 & 0 & 0.56 & 1.87 & 0.70 & 0.01 \\
\hline KAS3 & 1.18 & 0.36 & 0.81 & 0 & 1.16 & 0.33 & 0.77 & 0 & 0.68 & 0.30 & 0.59 & 0.00 \\
\hline KAS4 & 0.59 & 1.21 & 0.65 & 0 & 0.55 & 1.26 & 0.63 & 0 & 0.41 & 1.20 & 0.55 & 0.01 \\
\hline KAS5 & 2.06 & 0.25 & 1.08 & 0 & 2.86 & 0.14 & 1.26 & 0 & 2.67 & 0.06 & 1.24 & 0.00 \\
\hline
\end{tabular}




$$
p=8, \rho=0.99
$$

\begin{tabular}{|c|c|c|c|c|c|c|c|c|c|c|c|c|}
\hline & & $\mathrm{n}=7$ & & & & $\mathrm{n}=$ & 100 & & & & 200 & \\
\hline & MSE & Bias & MAPE & Pr. & MSE & Bias & MAPE & Pr. & MSE & Bias & MAPE & Pr. \\
\hline ML & 8808478.4 & 0.00 & 99.20 & 0 & 98.75 & 0.00 & 7.17 & 0 & 34.74 & 0.00 & 4.35 & 0 \\
\hline KH1 & 305.57 & 0.04 & 7.37 & 0 & 48.91 & 0.01 & 4.81 & 0 & 17.19 & 0.01 & 3.01 & 0 \\
\hline $\mathrm{KH} 2$ & 58.17 & 0.06 & 4.30 & 0 & 18.82 & 0.03 & 2.98 & 0 & 7.07 & 0.03 & 1.91 & 0 \\
\hline KL & 16.21 & 0.13 & 2.40 & 0 & 13.51 & 0.07 & 2.37 & 0 & 9.58 & 0.03 & 2.17 & 0 \\
\hline KHG & 51.95 & 0.06 & 4.19 & 0 & 19.31 & 0.04 & 2.98 & 0 & 7.15 & 0.04 & 1.89 & 0 \\
\hline KBH & 29.70 & 0.07 & 2.56 & 0 & 6.21 & 0.06 & 1.80 & 0 & 2.59 & 0.06 & 1.19 & 0 \\
\hline KNR & 16.32 & 0.10 & 2.40 & 0 & 6.09 & 0.08 & 1.65 & 0 & 2.13 & 0.08 & 1.02 & 0 \\
\hline KK1 & 16.63 & 0.12 & 2.18 & 0 & 5.52 & 0.10 & 1.53 & 0 & 2.20 & 0.10 & 1.00 & 0 \\
\hline KK2 & 6.29 & 0.65 & 1.05 & 0 & 1.62 & 0.67 & 0.79 & 0 & 0.71 & 0.70 & 0.58 & 0 \\
\hline KK3 & 23.13 & 0.10 & 2.63 & 0 & 8.12 & 0.08 & 1.86 & 0 & 3.17 & 0.08 & 1.21 & 0 \\
\hline KK4 & 1.60 & 0.17 & 0.95 & 0 & 1.56 & 0.11 & 0.93 & 0 & 1.42 & 0.08 & 0.89 & 0 \\
\hline KK5 & 0.26 & 0.58 & 0.42 & 0 & 0.37 & 0.26 & 0.46 & 0 & 1.22 & 0.08 & 0.86 & 0 \\
\hline KK6 & 2.06 & 0.15 & 1.08 & 0 & 2.02 & 0.10 & 1.06 & 0 & 1.81 & 0.07 & 1.00 & 0 \\
\hline KK7 & 0.30 & 1.13 & 0.50 & 0 & 0.15 & 0.64 & 0.33 & 0 & 0.19 & 0.22 & 0.34 & 0 \\
\hline KK8 & 0.24 & 0.65 & 0.41 & 0 & 0.28 & 0.30 & 0.40 & 0 & 0.90 & 0.09 & 0.74 & 0 \\
\hline KK9 & 0.36 & 0.72 & 0.49 & 0 & 0.32 & 0.62 & 0.44 & 0 & 0.26 & 0.51 & 0.39 & 0 \\
\hline KL1 & 2.34 & 0.87 & 0.89 & 0 & 2.24 & 0.74 & 0.89 & 0 & 2.03 & 0.56 & 0.88 & 0 \\
\hline KL2 & 0.83 & 2.49 & 0.90 & 0 & 0.71 & 2.29 & 0.83 & 0 & 0.52 & 1.94 & 0.70 & 0 \\
\hline KD1 & 83.71 & 0.05 & 6.21 & 0 & 50.93 & 0.01 & 5.11 & 0 & 24.70 & 0.00 & 3.70 & 0 \\
\hline KD2 & 38.61 & 0.07 & 4.25 & 0 & 29.05 & 0.02 & 3.83 & 0 & 17.37 & 0.01 & 3.09 & 0 \\
\hline KD3 & 29.58 & 0.08 & 3.69 & 0 & 23.14 & 0.03 & 3.41 & 0 & 15.23 & 0.01 & 2.89 & 0 \\
\hline KD4 & 9.07 & 0.44 & 1.69 & 0 & 7.66 & 0.33 & 1.65 & 0 & 5.95 & 0.25 & 1.57 & 0 \\
\hline $\mathrm{KS}$ & 389.18 & 0.01 & 8.38 & 0 & 54.33 & 0.01 & 5.23 & 0 & 20.94 & 0.01 & 3.44 & 0 \\
\hline KS1 & 2.36 & 0.12 & 1.23 & 0 & 3.44 & 0.06 & 1.48 & 0 & 4.58 & 0.03 & 1.71 & 0 \\
\hline KS2 & 0.31 & 1.19 & 0.52 & 0 & 0.15 & 0.72 & 0.34 & 0 & 0.11 & 0.29 & 0.26 & 0 \\
\hline KS3 & 0.22 & 0.86 & 0.42 & 0 & 0.12 & 0.50 & 0.29 & 0 & 0.17 & 0.21 & 0.32 & 0 \\
\hline KS4 & 4.13 & 0.10 & 1.62 & 0 & 4.96 & 0.05 & 1.77 & 0 & 5.38 & 0.02 & 1.85 & 0 \\
\hline KS5 & 0.23 & 0.89 & 0.43 & 0 & 0.12 & 0.52 & 0.29 & 0 & 0.16 & 0.22 & 0.31 & 0 \\
\hline KAL1 & 91.95 & 0.03 & 3.56 & 0 & 14.18 & 0.02 & 2.98 & 0 & 11.47 & 0.01 & 2.70 & 0 \\
\hline KAL2 & 106.92 & 0.02 & 4.65 & 0 & 21.52 & 0.02 & 3.60 & 0 & 13.65 & 0.01 & 2.91 & 0 \\
\hline KAS1 & 4.46 & 0.13 & 1.63 & 0 & 8.59 & 0.04 & 2.30 & 0 & 10.82 & 0.02 & 2.52 & 0 \\
\hline KAS2 & 0.51 & 1.24 & 0.62 & 0 & 0.52 & 1.26 & 0.60 & 0 & 0.43 & 1.30 & 0.56 & 0 \\
\hline KAS3 & 2.00 & 0.18 & 1.05 & 0 & 2.97 & 0.10 & 1.25 & 0 & 2.63 & 0.08 & 1.12 & 0 \\
\hline KAS4 & 0.73 & 0.71 & 0.65 & 0 & 0.86 & 0.68 & 0.66 & 0 & 0.65 & 0.70 & 0.56 & 0 \\
\hline KAS5 & 2.10 & 0.20 & 1.03 & 0 & 4.29 & 0.09 & 1.48 & 0 & 6.92 & 0.04 & 1.91 & 0 \\
\hline
\end{tabular}


Table A2. Estimated MSEs, MAPEs, Bias and Proportion of times in simulation when the ridge regression estimator produces a higher MSE than the ML estimator of the proposed estimators with intercept $=1$ for the following cases:

$$
p=4, \rho=0.75
$$

\begin{tabular}{|c|c|c|c|c|c|c|c|c|c|c|c|c|}
\hline & \multicolumn{4}{|c|}{$\mathrm{n}=70$} & \multicolumn{4}{|c|}{$\mathrm{n}=100$} & \multicolumn{4}{|c|}{$\mathrm{n}=200$} \\
\hline & MSE & Bias & MAPE & Pr. & MSE & Bias & MAPE & Pr. & MSE & Bias & MAPE & Pr. \\
\hline ML & 1.67 & 0.00 & 0.99 & 0.00 & 0.96 & 0.00 & 0.77 & 0.00 & 0.41 & 0.00 & 0.50 & 0.00 \\
\hline KH1 & 0.95 & 0.15 & 0.73 & 0.02 & 0.59 & 0.12 & 0.59 & 0.02 & 0.30 & 0.07 & 0.43 & 0.04 \\
\hline KH2 & 0.58 & 0.29 & 0.57 & 0.04 & 0.39 & 0.24 & 0.48 & 0.05 & 0.22 & 0.16 & 0.37 & 0.07 \\
\hline KL & 1.03 & 0.10 & 0.78 & 0.01 & 0.74 & 0.06 & 0.67 & 0.02 & 0.38 & 0.02 & 0.48 & 0.03 \\
\hline KHG & 1.07 & 0.11 & 0.78 & 0.02 & 0.67 & 0.09 & 0.63 & 0.02 & 0.33 & 0.05 & 0.45 & 0.03 \\
\hline $\mathrm{KBH}$ & 0.29 & 0.57 & 0.46 & 0.09 & 0.23 & 0.53 & 0.40 & 0.12 & 0.16 & 0.42 & 0.33 & 0.19 \\
\hline KNR & 0.35 & 0.83 & 0.54 & 0.09 & 0.32 & 0.83 & 0.52 & 0.12 & 0.29 & 0.82 & 0.51 & 0.19 \\
\hline KK1 & 0.42 & 0.62 & 0.54 & 0.12 & 0.32 & 0.56 & 0.48 & 0.16 & 0.21 & 0.44 & 0.39 & 0.23 \\
\hline KK2 & 0.55 & 1.05 & 0.68 & 0.24 & 0.49 & 1.01 & 0.63 & 0.32 & 0.41 & 0.90 & 0.57 & 0.48 \\
\hline KK3 & 0.45 & 0.64 & 0.56 & 0.13 & 0.36 & 0.58 & 0.50 & 0.17 & 0.24 & 0.48 & 0.41 & 0.26 \\
\hline KK4 & 0.37 & 0.36 & 0.48 & 0.04 & 0.31 & 0.28 & 0.44 & 0.05 & 0.21 & 0.18 & 0.36 & 0.07 \\
\hline KK5 & 0.72 & 0.12 & 0.69 & 0.01 & 0.61 & 0.07 & 0.63 & 0.01 & 0.35 & 0.03 & 0.47 & 0.03 \\
\hline KK6 & 0.39 & 0.35 & 0.49 & 0.04 & 0.32 & 0.28 & 0.45 & 0.05 & 0.21 & 0.18 & 0.36 & 0.07 \\
\hline KK7 & 0.40 & 0.25 & 0.51 & 0.02 & 0.39 & 0.16 & 0.50 & 0.02 & 0.28 & 0.07 & 0.42 & 0.04 \\
\hline KK8 & 0.65 & 0.14 & 0.65 & 0.01 & 0.56 & 0.08 & 0.61 & 0.02 & 0.34 & 0.03 & 0.46 & 0.03 \\
\hline KK9 & 0.38 & 0.76 & 0.55 & 0.13 & 0.33 & 0.68 & 0.50 & 0.18 & 0.23 & 0.51 & 0.41 & 0.26 \\
\hline KL1 & 0.58 & 0.99 & 0.68 & 0.22 & 0.50 & 0.85 & 0.62 & 0.26 & 0.35 & 0.60 & 0.50 & 0.31 \\
\hline KL2 & 0.30 & 0.63 & 0.47 & 0.04 & 0.23 & 0.54 & 0.41 & 0.07 & 0.16 & 0.45 & 0.34 & 0.17 \\
\hline KD1 & 1.01 & 0.11 & 0.76 & 0.01 & 0.72 & 0.06 & 0.66 & 0.02 & 0.37 & 0.02 & 0.48 & 0.03 \\
\hline KD2 & 0.67 & 0.33 & 0.63 & 0.05 & 0.53 & 0.23 & 0.57 & 0.06 & 0.31 & 0.11 & 0.44 & 0.06 \\
\hline KD3 & 0.64 & 0.30 & 0.61 & 0.04 & 0.51 & 0.20 & 0.55 & 0.04 & 0.31 & 0.08 & 0.43 & 0.04 \\
\hline KD4 & 0.59 & 0.71 & 0.64 & 0.14 & 0.48 & 0.58 & 0.58 & 0.17 & 0.32 & 0.38 & 0.47 & 0.20 \\
\hline KS & 1.47 & 0.02 & 0.93 & 0.01 & 0.89 & 0.01 & 0.74 & 0.01 & 0.39 & 0.01 & 0.50 & 0.03 \\
\hline KS1 & 1.02 & 0.07 & 0.80 & 0.01 & 0.72 & 0.05 & 0.67 & 0.01 & 0.36 & 0.02 & 0.48 & 0.03 \\
\hline KS2 & 0.25 & 0.47 & 0.40 & 0.03 & 0.21 & 0.34 & 0.37 & 0.04 & 0.17 & 0.18 & 0.33 & 0.06 \\
\hline KS3 & 0.25 & 0.45 & 0.40 & 0.03 & 0.22 & 0.33 & 0.37 & 0.04 & 0.18 & 0.18 & 0.34 & 0.06 \\
\hline KS4 & 1.04 & 0.07 & 0.80 & 0.01 & 0.73 & 0.05 & 0.68 & 0.01 & 0.36 & 0.02 & 0.48 & 0.03 \\
\hline KS5 & 0.25 & 0.45 & 0.40 & 0.03 & 0.22 & 0.33 & 0.37 & 0.04 & 0.18 & 0.18 & 0.33 & 0.06 \\
\hline KAL1 & 1.42 & 0.02 & 0.92 & 0.01 & 0.87 & 0.02 & 0.73 & 0.01 & 0.39 & 0.01 & 0.49 & 0.03 \\
\hline KAL2 & 1.44 & 0.02 & 0.92 & 0.01 & 0.88 & 0.01 & 0.74 & 0.01 & 0.39 & 0.01 & 0.49 & 0.03 \\
\hline KAS1 & 0.72 & 0.18 & 0.65 & 0.02 & 0.54 & 0.13 & 0.57 & 0.02 & 0.30 & 0.07 & 0.43 & 0.04 \\
\hline KAS2 & 0.64 & 1.34 & 0.76 & 0.32 & 0.61 & 1.30 & 0.74 & 0.43 & 0.54 & 1.21 & 0.69 & 0.63 \\
\hline KAS3 & 0.41 & 0.65 & 0.55 & 0.13 & 0.35 & 0.59 & 0.50 & 0.17 & 0.24 & 0.48 & 0.41 & 0.26 \\
\hline KAS4 & 0.54 & 1.06 & 0.67 & 0.24 & 0.49 & 1.01 & 0.63 & 0.32 & 0.41 & 0.91 & 0.57 & 0.48 \\
\hline KAS5 & 0.80 & 0.14 & 0.70 & 0.01 & 0.67 & 0.07 & 0.64 & 0.02 & 0.37 & 0.02 & 0.48 & 0.03 \\
\hline
\end{tabular}




$$
p=4, \rho=0.85
$$

\begin{tabular}{|c|c|c|c|c|c|c|c|c|c|c|c|c|}
\hline & \multicolumn{4}{|c|}{$\mathrm{n}=70$} & \multicolumn{4}{|c|}{$\mathrm{n}=100$} & \multicolumn{4}{|c|}{$\mathrm{n}=200$} \\
\hline & MSE & Bias & MAPE & Pr. & MSE & Bias & MAPE & Pr. & MSE & Bias & MAPE & Pr. \\
\hline $\mathrm{ML}$ & 2.80 & 0.00 & 1.27 & 0.00 & 1.60 & 0.00 & 0.98 & 0.00 & 0.67 & 0.00 & 0.64 & 0.00 \\
\hline KH1 & 1.44 & 0.13 & 0.86 & 0.00 & 0.92 & 0.11 & 0.71 & 0.01 & 0.44 & 0.06 & 0.52 & 0.02 \\
\hline KH2 & 0.81 & 0.25 & 0.65 & 0.01 & 0.56 & 0.21 & 0.55 & 0.02 & 0.30 & 0.14 & 0.42 & 0.03 \\
\hline KL & 1.35 & 0.12 & 0.86 & 0.00 & 1.06 & 0.07 & 0.78 & 0.01 & 0.58 & 0.02 & 0.60 & 0.01 \\
\hline KHG & 1.58 & 0.11 & 0.91 & 0.00 & 1.00 & 0.09 & 0.75 & 0.01 & 0.48 & 0.05 & 0.54 & 0.02 \\
\hline $\mathrm{KBH}$ & 0.31 & 0.47 & 0.45 & 0.03 & 0.25 & 0.43 & 0.40 & 0.06 & 0.16 & 0.35 & 0.33 & 0.08 \\
\hline KNR & 0.32 & 0.68 & 0.49 & 0.03 & 0.27 & 0.67 & 0.47 & 0.06 & 0.22 & 0.65 & 0.43 & 0.08 \\
\hline KK1 & 0.49 & 0.56 & 0.56 & 0.06 & 0.38 & 0.50 & 0.49 & 0.09 & 0.23 & 0.38 & 0.40 & 0.12 \\
\hline KK2 & 0.57 & 0.97 & 0.67 & 0.14 & 0.49 & 0.92 & 0.62 & 0.20 & 0.39 & 0.81 & 0.55 & 0.33 \\
\hline KK3 & 0.54 & 0.57 & 0.59 & 0.06 & 0.42 & 0.52 & 0.52 & 0.10 & 0.26 & 0.43 & 0.42 & 0.15 \\
\hline KK4 & 0.42 & 0.33 & 0.50 & 0.01 & 0.37 & 0.26 & 0.47 & 0.02 & 0.27 & 0.16 & 0.40 & 0.03 \\
\hline KK5 & 0.84 & 0.13 & 0.74 & 0.00 & 0.78 & 0.07 & 0.71 & 0.01 & 0.52 & 0.03 & 0.57 & 0.01 \\
\hline KK6 & 0.45 & 0.32 & 0.52 & 0.01 & 0.39 & 0.26 & 0.48 & 0.03 & 0.27 & 0.17 & 0.41 & 0.04 \\
\hline KK7 & 0.38 & 0.26 & 0.50 & 0.00 & 0.42 & 0.16 & 0.53 & 0.01 & 0.38 & 0.07 & 0.49 & 0.02 \\
\hline KK8 & 0.74 & 0.15 & 0.69 & 0.00 & 0.72 & 0.08 & 0.69 & 0.01 & 0.50 & 0.03 & 0.56 & 0.01 \\
\hline KK9 & 0.39 & 0.72 & 0.54 & 0.08 & 0.33 & 0.61 & 0.49 & 0.11 & 0.25 & 0.45 & 0.42 & 0.16 \\
\hline KL1 & 0.64 & 0.94 & 0.69 & 0.14 & 0.54 & 0.78 & 0.63 & 0.17 & 0.41 & 0.53 & 0.53 & 0.22 \\
\hline KL2 & 0.28 & 0.65 & 0.46 & 0.02 & 0.23 & 0.55 & 0.41 & 0.03 & 0.16 & 0.44 & 0.34 & 0.08 \\
\hline KD1 & 1.48 & 0.11 & 0.89 & 0.00 & 1.11 & 0.06 & 0.80 & 0.01 & 0.59 & 0.02 & 0.60 & 0.01 \\
\hline KD2 & 0.93 & 0.32 & 0.71 & 0.02 & 0.77 & 0.21 & 0.65 & 0.03 & 0.47 & 0.10 & 0.53 & 0.03 \\
\hline KD3 & 0.88 & 0.29 & 0.68 & 0.02 & 0.75 & 0.19 & 0.64 & 0.03 & 0.47 & 0.07 & 0.53 & 0.02 \\
\hline KD4 & 0.73 & 0.68 & 0.69 & 0.09 & 0.61 & 0.53 & 0.62 & 0.11 & 0.43 & 0.34 & 0.53 & 0.13 \\
\hline KS & 2.36 & 0.02 & 1.17 & 0.00 & 1.44 & 0.01 & 0.93 & 0.01 & 0.63 & 0.01 & 0.63 & 0.01 \\
\hline KS1 & 1.41 & 0.07 & 0.94 & 0.00 & 1.07 & 0.05 & 0.81 & 0.01 & 0.56 & 0.02 & 0.59 & 0.01 \\
\hline KS2 & 0.23 & 0.47 & 0.39 & 0.01 & 0.21 & 0.34 & 0.36 & 0.02 & 0.20 & 0.18 & 0.35 & 0.03 \\
\hline KS3 & 0.23 & 0.45 & 0.39 & 0.01 & 0.22 & 0.33 & 0.37 & 0.02 & 0.21 & 0.18 & 0.36 & 0.03 \\
\hline KS4 & 1.45 & 0.07 & 0.95 & 0.00 & 1.09 & 0.04 & 0.82 & 0.01 & 0.56 & 0.02 & 0.59 & 0.01 \\
\hline KS5 & 0.23 & 0.46 & 0.39 & 0.01 & 0.21 & 0.33 & 0.37 & 0.02 & 0.20 & 0.18 & 0.36 & 0.03 \\
\hline KAL1 & 2.21 & 0.02 & 1.15 & 0.00 & 1.40 & 0.02 & 0.92 & 0.01 & 0.63 & 0.01 & 0.63 & 0.01 \\
\hline KAL2 & 2.26 & 0.02 & 1.15 & 0.00 & 1.42 & 0.01 & 0.92 & 0.01 & 0.63 & 0.01 & 0.63 & 0.01 \\
\hline KAS1 & 0.93 & 0.17 & 0.73 & 0.00 & 0.78 & 0.12 & 0.67 & 0.01 & 0.43 & 0.07 & 0.51 & 0.02 \\
\hline KAS2 & 0.61 & 1.25 & 0.73 & 0.20 & 0.57 & 1.21 & 0.71 & 0.26 & 0.50 & 1.10 & 0.65 & 0.45 \\
\hline KAS3 & 0.44 & 0.59 & 0.55 & 0.06 & 0.39 & 0.53 & 0.51 & 0.10 & 0.26 & 0.43 & 0.42 & 0.15 \\
\hline KAS4 & 0.53 & 0.98 & 0.65 & 0.14 & 0.48 & 0.92 & 0.61 & 0.20 & 0.39 & 0.81 & 0.55 & 0.33 \\
\hline KAS5 & 0.94 & 0.16 & 0.74 & 0.00 & 0.90 & 0.09 & 0.73 & 0.01 & 0.56 & 0.02 & 0.59 & 0.01 \\
\hline
\end{tabular}




$$
p=4, \rho=0.95
$$

\begin{tabular}{|c|c|c|c|c|c|c|c|c|c|c|c|c|}
\hline & \multicolumn{4}{|c|}{$\mathrm{n}=70$} & \multicolumn{4}{|c|}{$\mathrm{n}=100$} & \multicolumn{4}{|c|}{$\mathrm{n}=200$} \\
\hline & MSE & Bias & MAPE & Pr. & MSE & Bias & MAPE & Pr. & MSE & Bias & MAPE & Pr. \\
\hline $\mathrm{ML}$ & 9.05 & 0.00 & 2.25 & 0.00 & 4.65 & 0.00 & 1.66 & 0.00 & 2.08 & 0.00 & 1.13 & 0.00 \\
\hline KH1 & 3.99 & 0.08 & 1.37 & 0.00 & 2.13 & 0.08 & 1.04 & 0.00 & 1.07 & 0.05 & 0.77 & 0.00 \\
\hline KH2 & 2.19 & 0.16 & 0.98 & 0.00 & 1.18 & 0.15 & 0.75 & 0.00 & 0.65 & 0.11 & 0.58 & 0.00 \\
\hline $\mathrm{KL}$ & 2.67 & 0.14 & 1.11 & 0.00 & 1.88 & 0.09 & 0.98 & 0.00 & 1.37 & 0.03 & 0.89 & 0.00 \\
\hline KHG & 3.45 & 0.10 & 1.26 & 0.00 & 1.89 & 0.09 & 0.97 & 0.00 & 0.98 & 0.06 & 0.74 & 0.00 \\
\hline KBH & 0.65 & 0.26 & 0.57 & 0.00 & 0.39 & 0.25 & 0.46 & 0.00 & 0.23 & 0.21 & 0.36 & 0.01 \\
\hline$\overline{\text { KNR }}$ & 0.54 & 0.38 & 0.53 & 0.00 & 0.31 & 0.39 & 0.44 & 0.00 & 0.18 & 0.37 & 0.35 & 0.01 \\
\hline KK1 & 1.11 & 0.36 & 0.71 & 0.01 & 0.62 & 0.35 & 0.57 & 0.02 & 0.39 & 0.29 & 0.47 & 0.03 \\
\hline KK2 & 0.84 & 0.73 & 0.70 & 0.03 & 0.57 & 0.72 & 0.62 & 0.06 & 0.46 & 0.67 & 0.56 & 0.11 \\
\hline KK3 & 1.34 & 0.36 & 0.76 & 0.02 & 0.74 & 0.36 & 0.62 & 0.02 & 0.45 & 0.32 & 0.50 & 0.04 \\
\hline KK4 & 0.60 & 0.24 & 0.58 & 0.00 & 0.50 & 0.20 & 0.53 & 0.00 & 0.43 & 0.13 & 0.49 & 0.00 \\
\hline KK5 & 0.72 & 0.16 & 0.67 & 0.00 & 0.85 & 0.09 & 0.74 & 0.00 & 0.90 & 0.04 & 0.77 & 0.00 \\
\hline KK6 & 0.69 & 0.23 & 0.61 & 0.00 & 0.56 & 0.19 & 0.56 & 0.00 & 0.45 & 0.13 & 0.50 & 0.00 \\
\hline KK7 & 0.27 & 0.30 & 0.41 & 0.00 & 0.34 & 0.18 & 0.46 & 0.00 & 0.47 & 0.08 & 0.56 & 0.00 \\
\hline KK8 & 0.57 & 0.18 & 0.59 & 0.00 & 0.71 & 0.10 & 0.68 & 0.00 & 0.82 & 0.04 & 0.74 & 0.00 \\
\hline KK9 & 0.38 & 0.57 & 0.51 & 0.02 & 0.33 & 0.50 & 0.47 & 0.02 & 0.29 & 0.38 & 0.43 & 0.04 \\
\hline KL1 & 0.99 & 0.73 & 0.75 & 0.03 & 0.81 & 0.63 & 0.69 & 0.04 & 0.77 & 0.45 & 0.67 & 0.07 \\
\hline KL2 & 0.35 & 0.83 & 0.55 & 0.00 & 0.26 & 0.68 & 0.47 & 0.00 & 0.18 & 0.52 & 0.38 & 0.01 \\
\hline KD1 & 4.17 & 0.07 & 1.43 & 0.00 & 2.76 & 0.05 & 1.22 & 0.00 & 1.66 & 0.02 & 0.99 & 0.00 \\
\hline KD2 & 2.74 & 0.20 & 1.10 & 0.01 & 1.92 & 0.15 & 0.97 & 0.01 & 1.29 & 0.07 & 0.84 & 0.01 \\
\hline KD3 & 2.43 & 0.19 & 1.04 & 0.01 & 1.77 & 0.13 & 0.93 & 0.00 & 1.27 & 0.06 & 0.83 & 0.00 \\
\hline KD4 & 1.59 & 0.50 & 0.86 & 0.02 & 1.19 & 0.41 & 0.79 & 0.03 & 0.98 & 0.28 & 0.74 & 0.04 \\
\hline $\mathrm{KS}$ & 6.35 & 0.02 & 1.89 & 0.00 & 3.63 & 0.01 & 1.47 & 0.00 & 1.82 & 0.01 & 1.06 & 0.00 \\
\hline KS1 & 2.13 & 0.06 & 1.17 & 0.00 & 1.81 & 0.04 & 1.07 & 0.00 & 1.29 & 0.02 & 0.90 & 0.00 \\
\hline KS2 & 0.20 & 0.47 & 0.37 & 0.00 & 0.16 & 0.33 & 0.31 & 0.00 & 0.17 & 0.17 & 0.33 & 0.00 \\
\hline KS3 & 0.19 & 0.44 & 0.36 & 0.00 & 0.16 & 0.31 & 0.32 & 0.00 & 0.19 & 0.17 & 0.34 & 0.00 \\
\hline KS4 & 2.33 & 0.06 & 1.21 & 0.00 & 1.90 & 0.04 & 1.09 & 0.00 & 1.31 & 0.02 & 0.91 & 0.00 \\
\hline KS5 & 0.19 & 0.45 & 0.36 & 0.00 & 0.16 & 0.32 & 0.32 & 0.00 & 0.18 & 0.17 & 0.34 & 0.00 \\
\hline KAL1 & 5.14 & 0.02 & 1.75 & 0.00 & 3.29 & 0.02 & 1.41 & 0.00 & 1.77 & 0.01 & 1.05 & 0.00 \\
\hline KAL2 & 5.63 & 0.02 & 1.81 & 0.00 & 3.42 & 0.01 & 1.44 & 0.00 & 1.79 & 0.01 & 1.05 & 0.00 \\
\hline KAS1 & 1.60 & 0.12 & 0.95 & 0.00 & 1.43 & 0.09 & 0.89 & 0.00 & 0.99 & 0.06 & 0.75 & 0.00 \\
\hline KAS2 & 0.56 & 1.01 & 0.67 & 0.05 & 0.52 & 1.00 & 0.65 & 0.07 & 0.48 & 0.93 & 0.61 & 0.16 \\
\hline KAS3 & 0.68 & 0.39 & 0.62 & 0.02 & 0.58 & 0.37 & 0.57 & 0.02 & 0.43 & 0.32 & 0.49 & 0.04 \\
\hline KAS4 & 0.57 & 0.75 & 0.63 & 0.03 & 0.50 & 0.73 & 0.60 & 0.06 & 0.45 & 0.67 & 0.56 & 0.11 \\
\hline KAS5 & 1.28 & 0.17 & 0.83 & 0.00 & 1.34 & 0.11 & 0.86 & 0.00 & 1.26 & 0.04 & 0.86 & 0.00 \\
\hline
\end{tabular}




$$
p=4, \rho=0.99
$$

\begin{tabular}{|c|c|c|c|c|c|c|c|c|c|c|c|c|}
\hline & \multicolumn{4}{|c|}{$\mathrm{n}=70$} & \multicolumn{4}{|c|}{$\mathrm{n}=100$} & \multicolumn{4}{|c|}{$\mathrm{n}=200$} \\
\hline & MSE & Bias & MAPE & Pr. & MSE & Bias & MAPE & Pr. & MSE & Bias & MAPE & Pr. \\
\hline ML & 44.96 & 0.00 & 5.00 & 0.00 & 27.30 & 0.00 & 4.00 & 0.00 & 11.67 & 0.00 & 2.65 & 0.00 \\
\hline KH1 & 18.66 & 0.03 & 2.86 & 0.00 & 11.55 & 0.03 & 2.33 & 0.00 & 5.12 & 0.02 & 1.58 & 0.00 \\
\hline KH2 & 10.07 & 0.06 & 2.01 & 0.00 & 6.36 & 0.05 & 1.65 & 0.00 & 2.96 & 0.05 & 1.15 & 0.00 \\
\hline KL & 8.95 & 0.09 & 1.81 & 0.00 & 7.60 & 0.07 & 1.77 & 0.00 & 5.16 & 0.03 & 1.56 & 0.00 \\
\hline KHG & 9.59 & 0.07 & 1.89 & 0.00 & 5.86 & 0.07 & 1.54 & 0.00 & 2.62 & 0.06 & 1.06 & 0.00 \\
\hline KBH & 3.01 & 0.08 & 1.16 & 0.00 & 1.97 & 0.07 & 0.95 & 0.00 & 0.96 & 0.07 & 0.67 & 0.00 \\
\hline KNR & 2.83 & 0.14 & 1.04 & 0.00 & 1.75 & 0.13 & 0.84 & 0.00 & 0.76 & 0.13 & 0.57 & 0.00 \\
\hline KK1 & 4.71 & 0.14 & 1.29 & 0.00 & 2.91 & 0.13 & 1.03 & 0.00 & 1.52 & 0.13 & 0.78 & 0.00 \\
\hline KK2 & 2.64 & 0.42 & 0.96 & 0.01 & 1.65 & 0.41 & 0.80 & 0.00 & 0.97 & 0.41 & 0.66 & 0.01 \\
\hline KK3 & 5.55 & 0.15 & 1.39 & 0.00 & 3.43 & 0.15 & 1.13 & 0.00 & 1.82 & 0.14 & 0.85 & 0.00 \\
\hline KK4 & 0.89 & 0.13 & 0.67 & 0.00 & 0.85 & 0.10 & 0.66 & 0.00 & 0.80 & 0.07 & 0.63 & 0.00 \\
\hline KK5 & 0.22 & 0.25 & 0.36 & 0.00 & 0.30 & 0.15 & 0.41 & 0.00 & 0.62 & 0.05 & 0.61 & 0.00 \\
\hline KK6 & 1.03 & 0.12 & 0.72 & 0.00 & 0.99 & 0.10 & 0.71 & 0.00 & 0.92 & 0.07 & 0.67 & 0.00 \\
\hline KK7 & 0.16 & 0.45 & 0.35 & 0.00 & 0.11 & 0.29 & 0.27 & 0.00 & 0.17 & 0.11 & 0.32 & 0.00 \\
\hline KK8 & 0.18 & 0.29 & 0.34 & 0.00 & 0.22 & 0.17 & 0.36 & 0.00 & 0.47 & 0.06 & 0.53 & 0.00 \\
\hline KK9 & 0.40 & 0.37 & 0.48 & 0.00 & 0.36 & 0.32 & 0.45 & 0.00 & 0.34 & 0.25 & 0.43 & 0.00 \\
\hline KL1 & 3.29 & 0.44 & 1.05 & 0.01 & 3.04 & 0.37 & 1.04 & 0.00 & 2.84 & 0.27 & 1.06 & 0.01 \\
\hline KL2 & 0.59 & 1.31 & 0.74 & 0.00 & 0.51 & 1.19 & 0.69 & 0.00 & 0.35 & 0.91 & 0.56 & 0.00 \\
\hline KD1 & 19.24 & 0.03 & 3.01 & 0.00 & 15.51 & 0.02 & 2.80 & 0.00 & 8.78 & 0.01 & 2.19 & 0.00 \\
\hline KD2 & 12.19 & 0.08 & 2.21 & 0.00 & 10.25 & 0.05 & 2.13 & 0.00 & 6.87 & 0.03 & 1.85 & 0.00 \\
\hline KD3 & 10.97 & 0.07 & 2.11 & 0.00 & 9.49 & 0.04 & 2.06 & 0.00 & 6.62 & 0.02 & 1.81 & 0.00 \\
\hline KD4 & 6.32 & 0.27 & 1.47 & 0.00 & 5.62 & 0.22 & 1.44 & 0.00 & 4.48 & 0.15 & 1.38 & 0.00 \\
\hline KS & 23.06 & 0.01 & 3.43 & 0.00 & 15.18 & 0.01 & 2.90 & 0.00 & 7.67 & 0.01 & 2.13 & 0.00 \\
\hline KS1 & 1.77 & 0.05 & 1.06 & 0.00 & 2.07 & 0.04 & 1.15 & 0.00 & 2.31 & 0.02 & 1.21 & 0.00 \\
\hline KS2 & 0.19 & 0.56 & 0.41 & 0.00 & 0.11 & 0.39 & 0.29 & 0.00 & 0.07 & 0.18 & 0.21 & 0.00 \\
\hline KS3 & 0.16 & 0.48 & 0.36 & 0.00 & 0.10 & 0.33 & 0.26 & 0.00 & 0.08 & 0.16 & 0.22 & 0.00 \\
\hline KS4 & 2.46 & 0.04 & 1.23 & 0.00 & 2.65 & 0.03 & 1.29 & 0.00 & 2.62 & 0.02 & 1.28 & 0.00 \\
\hline KS5 & 0.16 & 0.48 & 0.37 & 0.00 & 0.10 & 0.34 & 0.27 & 0.00 & 0.08 & 0.16 & 0.22 & 0.00 \\
\hline KAL1 & 9.51 & 0.02 & 2.35 & 0.00 & 8.00 & 0.01 & 2.22 & 0.00 & 5.79 & 0.01 & 1.90 & 0.00 \\
\hline KAL2 & 13.58 & 0.01 & 2.75 & 0.00 & 10.42 & 0.01 & 2.49 & 0.00 & 6.55 & 0.01 & 1.99 & 0.00 \\
\hline KAS1 & 2.12 & 0.07 & 1.10 & 0.00 & 3.30 & 0.04 & 1.36 & 0.00 & 3.63 & 0.03 & 1.37 & 0.00 \\
\hline KAS2 & 0.54 & 0.66 & 0.60 & 0.01 & 0.57 & 0.65 & 0.60 & 0.01 & 0.53 & 0.62 & 0.57 & 0.02 \\
\hline KAS3 & 1.01 & 0.19 & 0.72 & 0.00 & 1.35 & 0.16 & 0.81 & 0.00 & 1.44 & 0.15 & 0.78 & 0.00 \\
\hline KAS4 & 0.69 & 0.45 & 0.63 & 0.01 & 0.81 & 0.42 & 0.65 & 0.00 & 0.82 & 0.41 & 0.63 & 0.01 \\
\hline KAS5 & 1.49 & 0.13 & 0.86 & 0.00 & 2.55 & 0.08 & 1.13 & 0.00 & 3.64 & 0.04 & 1.35 & 0.00 \\
\hline
\end{tabular}




$$
p=8, \rho=0.75
$$

\begin{tabular}{|c|c|c|c|c|c|c|c|c|c|c|c|c|}
\hline & \multicolumn{4}{|c|}{$\mathrm{n}=70$} & \multicolumn{4}{|c|}{$\mathrm{n}=100$} & \multicolumn{4}{|c|}{$\mathrm{n}=200$} \\
\hline & MSE & Bias & MAPE & Pr. & MSE & Bias & MAPE & Pr. & MSE & Bias & MAPE & Pr. \\
\hline ML & 1584.25 & 0.00 & 3.65 & 0.00 & 3.39 & 0.00 & 1.39 & 0.00 & 1.12 & 0.00 & 0.82 & 0.00 \\
\hline KH1 & 3.82 & 0.18 & 1.37 & 0.00 & 1.97 & 0.14 & 1.05 & 0.00 & 0.79 & 0.10 & 0.69 & 0.00 \\
\hline KH2 & 1.36 & 0.40 & 0.85 & 0.00 & 0.88 & 0.35 & 0.71 & 0.00 & 0.45 & 0.26 & 0.52 & 0.00 \\
\hline KL & 2.49 & 0.22 & 1.19 & 0.00 & 1.99 & 0.12 & 1.08 & 0.00 & 0.97 & 0.04 & 0.77 & 0.00 \\
\hline KHG & 4.56 & 0.12 & 1.54 & 0.00 & 2.44 & 0.08 & 1.18 & 0.00 & 0.93 & 0.05 & 0.75 & 0.00 \\
\hline $\mathrm{KBH}$ & 0.46 & 0.70 & 0.53 & 0.00 & 0.33 & 0.68 & 0.46 & 0.00 & 0.22 & 0.59 & 0.38 & 0.01 \\
\hline KNR & 0.41 & 0.95 & 0.55 & 0.00 & 0.32 & 1.00 & 0.50 & 0.00 & 0.27 & 1.03 & 0.48 & 0.01 \\
\hline KK1 & 0.54 & 0.80 & 0.59 & 0.00 & 0.41 & 0.78 & 0.53 & 0.01 & 0.27 & 0.62 & 0.43 & 0.02 \\
\hline KK2 & 0.63 & 1.67 & 0.74 & 0.02 & 0.59 & 1.66 & 0.71 & 0.06 & 0.50 & 1.52 & 0.65 & 0.21 \\
\hline KK3 & 0.72 & 0.69 & 0.64 & 0.00 & 0.50 & 0.65 & 0.56 & 0.00 & 0.32 & 0.53 & 0.45 & 0.02 \\
\hline KK4 & 0.59 & 0.53 & 0.60 & 0.00 & 0.55 & 0.43 & 0.58 & 0.00 & 0.42 & 0.27 & 0.51 & 0.00 \\
\hline KK5 & 1.49 & 0.26 & 0.98 & 0.00 & 1.52 & 0.13 & 0.99 & 0.00 & 0.91 & 0.04 & 0.75 & 0.00 \\
\hline KK6 & 0.70 & 0.48 & 0.66 & 0.00 & 0.64 & 0.38 & 0.63 & 0.00 & 0.46 & 0.24 & 0.53 & 0.00 \\
\hline KK7 & 0.60 & 0.52 & 0.63 & 0.00 & 0.70 & 0.31 & 0.68 & 0.00 & 0.65 & 0.11 & 0.64 & 0.00 \\
\hline KK8 & 1.29 & 0.30 & 0.91 & 0.00 & 1.36 & 0.16 & 0.93 & 0.00 & 0.88 & 0.05 & 0.74 & 0.00 \\
\hline KK9 & 0.50 & 1.35 & 0.65 & 0.01 & 0.44 & 1.25 & 0.60 & 0.03 & 0.33 & 0.97 & 0.50 & 0.07 \\
\hline KL1 & 0.69 & 1.82 & 0.78 & 0.02 & 0.64 & 1.68 & 0.74 & 0.06 & 0.51 & 1.29 & 0.63 & 0.17 \\
\hline KL2 & 0.44 & 1.21 & 0.60 & 0.00 & 0.33 & 0.95 & 0.50 & 0.00 & 0.21 & 0.63 & 0.38 & 0.00 \\
\hline KD1 & 3.04 & 0.19 & 1.30 & 0.00 & 2.10 & 0.11 & 1.10 & 0.00 & 0.97 & 0.04 & 0.77 & 0.00 \\
\hline KD2 & 1.71 & 0.35 & 0.96 & 0.00 & 1.37 & 0.25 & 0.88 & 0.00 & 0.80 & 0.10 & 0.69 & 0.00 \\
\hline KD3 & 1.27 & 0.42 & 0.83 & 0.00 & 1.12 & 0.30 & 0.80 & 0.00 & 0.74 & 0.13 & 0.66 & 0.00 \\
\hline KD4 & 0.70 & 1.20 & 0.72 & 0.01 & 0.68 & 1.08 & 0.69 & 0.03 & 0.51 & 0.72 & 0.59 & 0.08 \\
\hline KS & 15.44 & 0.05 & 1.88 & 0.00 & 2.96 & 0.03 & 1.31 & 0.00 & 1.07 & 0.01 & 0.81 & 0.00 \\
\hline KS1 & 2.39 & 0.17 & 1.23 & 0.00 & 2.00 & 0.09 & 1.11 & 0.00 & 0.96 & 0.04 & 0.76 & 0.00 \\
\hline KS2 & 0.39 & 0.76 & 0.51 & 0.00 & 0.35 & 0.55 & 0.48 & 0.00 & 0.35 & 0.28 & 0.47 & 0.00 \\
\hline KS3 & 0.40 & 0.71 & 0.51 & 0.00 & 0.37 & 0.52 & 0.49 & 0.00 & 0.37 & 0.27 & 0.48 & 0.00 \\
\hline KS4 & 2.50 & 0.16 & 1.25 & 0.00 & 2.03 & 0.09 & 1.12 & 0.00 & 0.96 & 0.03 & 0.77 & 0.00 \\
\hline KS5 & 0.39 & 0.72 & 0.51 & 0.00 & 0.37 & 0.53 & 0.49 & 0.00 & 0.36 & 0.27 & 0.48 & 0.00 \\
\hline KAL1 & 14.21 & 0.06 & 1.76 & 0.00 & 2.82 & 0.03 & 1.29 & 0.00 & 1.07 & 0.01 & 0.80 & 0.00 \\
\hline KAL2 & 14.47 & 0.06 & 1.79 & 0.00 & 2.86 & 0.03 & 1.29 & 0.00 & 1.07 & 0.01 & 0.80 & 0.00 \\
\hline KAS1 & 1.88 & 0.25 & 1.06 & 0.00 & 1.56 & 0.17 & 0.96 & 0.00 & 0.77 & 0.10 & 0.68 & 0.00 \\
\hline KAS2 & 0.78 & 2.23 & 0.87 & 0.03 & 0.76 & 2.21 & 0.85 & 0.09 & 0.71 & 2.12 & 0.81 & 0.36 \\
\hline KAS3 & 0.56 & 0.72 & 0.60 & 0.00 & 0.46 & 0.66 & 0.55 & 0.00 & 0.31 & 0.53 & 0.45 & 0.02 \\
\hline KAS4 & 0.62 & 1.68 & 0.74 & 0.02 & 0.58 & 1.67 & 0.71 & 0.06 & 0.50 & 1.53 & 0.65 & 0.21 \\
\hline KAS5 & 1.61 & 0.28 & 0.99 & 0.00 & 1.63 & 0.15 & 1.00 & 0.00 & 0.94 & 0.04 & 0.76 & 0.00 \\
\hline
\end{tabular}




$$
p=8, \rho=0.85
$$

\begin{tabular}{|c|c|c|c|c|c|c|c|c|c|c|c|c|}
\hline & \multicolumn{4}{|c|}{$\mathrm{n}=70$} & \multicolumn{4}{|c|}{$\mathrm{n}=100$} & \multicolumn{4}{|c|}{$\mathrm{n}=200$} \\
\hline & MSE & Bias & MAPE & Pr. & MSE & Bias & MAPE & Pr. & MSE & Bias & MAPE & Pr. \\
\hline ML & 37935.11 & 0.00 & 12.53 & 0.00 & 0.00 & 5.78 & 0.00 & 1.79 & 0.00 & 1.99 & 0.00 & 1.09 \\
\hline KH1 & 9.44 & 0.14 & 1.83 & 0.00 & 0.00 & 3.10 & 0.11 & 1.30 & 0.00 & 1.25 & 0.08 & 0.86 \\
\hline KH2 & 3.86 & 0.30 & 1.11 & 0.00 & 0.00 & 1.28 & 0.27 & 0.83 & 0.00 & 0.64 & 0.21 & 0.62 \\
\hline $\mathrm{KL}$ & 3.04 & 0.23 & 1.29 & 0.00 & 0.00 & 2.42 & 0.13 & 1.18 & 0.00 & 1.48 & 0.05 & 0.94 \\
\hline KHG & 9.93 & 0.10 & 2.02 & 0.00 & 0.00 & 3.71 & 0.07 & 1.44 & 0.00 & 1.50 & 0.05 & 0.95 \\
\hline $\mathrm{KBH}$ & 3.01 & 0.52 & 0.66 & 0.00 & 0.00 & 0.41 & 0.51 & 0.50 & 0.00 & 0.24 & 0.45 & 0.39 \\
\hline KNR & 1.80 & 0.69 & 0.60 & 0.00 & 0.00 & 0.32 & 0.73 & 0.47 & 0.00 & 0.21 & 0.75 & 0.40 \\
\hline KK1 & 2.04 & 0.63 & 0.70 & 0.00 & 0.00 & 0.49 & 0.63 & 0.55 & 0.00 & 0.31 & 0.52 & 0.44 \\
\hline KK2 & 1.06 & 1.49 & 0.75 & 0.00 & 0.01 & 0.56 & 1.53 & 0.69 & 0.02 & 0.47 & 1.39 & 0.62 \\
\hline KK3 & 2.51 & 0.54 & 0.79 & 0.00 & 0.00 & 0.67 & 0.53 & 0.61 & 0.00 & 0.39 & 0.43 & 0.49 \\
\hline KK4 & 0.72 & 0.46 & 0.66 & 0.00 & 0.00 & 0.64 & 0.36 & 0.62 & 0.00 & 0.53 & 0.23 & 0.57 \\
\hline KK5 & 1.47 & 0.30 & 0.97 & 0.00 & 0.00 & 1.77 & 0.14 & 1.07 & 0.00 & 1.36 & 0.05 & 0.93 \\
\hline KK6 & 0.87 & 0.41 & 0.72 & 0.00 & 0.00 & 0.77 & 0.32 & 0.68 & 0.00 & 0.61 & 0.21 & 0.61 \\
\hline KK7 & 0.54 & 0.57 & 0.60 & 0.00 & 0.00 & 0.67 & 0.32 & 0.66 & 0.00 & 0.82 & 0.12 & 0.73 \\
\hline KK8 & 1.24 & 0.34 & 0.88 & 0.00 & 0.00 & 1.54 & 0.16 & 1.00 & 0.00 & 1.27 & 0.06 & 0.90 \\
\hline KK9 & 0.49 & 1.24 & 0.63 & 0.00 & 0.00 & 0.41 & 1.14 & 0.57 & 0.01 & 0.32 & 0.88 & 0.49 \\
\hline KL1 & 0.70 & 1.72 & 0.78 & 0.00 & 0.01 & 0.62 & 1.62 & 0.73 & 0.02 & 0.51 & 1.21 & 0.63 \\
\hline KL2 & 0.46 & 1.31 & 0.63 & 0.00 & 0.00 & 0.32 & 0.98 & 0.51 & 0.00 & 0.20 & 0.64 & 0.38 \\
\hline KD1 & 4.65 & 0.18 & 1.57 & 0.00 & 0.00 & 3.06 & 0.10 & 1.32 & 0.00 & 1.60 & 0.04 & 0.98 \\
\hline KD2 & 2.55 & 0.32 & 1.13 & 0.00 & 0.00 & 1.88 & 0.22 & 1.01 & 0.00 & 1.26 & 0.09 & 0.86 \\
\hline KD3 & 1.86 & 0.37 & 0.97 & 0.00 & 0.00 & 1.48 & 0.26 & 0.89 & 0.00 & 1.12 & 0.11 & 0.81 \\
\hline KD4 & 0.91 & 1.13 & 0.77 & 0.00 & 0.00 & 0.75 & 1.00 & 0.70 & 0.01 & 0.64 & 0.66 & 0.64 \\
\hline KS & 39.22 & 0.04 & 2.63 & 0.00 & 0.00 & 4.80 & 0.02 & 1.66 & 0.00 & 1.86 & 0.01 & 1.06 \\
\hline KS1 & 3.16 & 0.16 & 1.42 & 0.00 & 0.00 & 2.77 & 0.08 & 1.31 & 0.00 & 1.54 & 0.03 & 0.97 \\
\hline KS2 & 0.37 & 0.80 & 0.51 & 0.00 & 0.00 & 0.32 & 0.55 & 0.45 & 0.00 & 0.36 & 0.28 & 0.48 \\
\hline KS3 & 0.37 & 0.74 & 0.51 & 0.00 & 0.00 & 0.34 & 0.51 & 0.47 & 0.00 & 0.38 & 0.27 & 0.49 \\
\hline KS4 & 3.36 & 0.16 & 1.46 & 0.00 & 0.00 & 2.84 & 0.08 & 1.33 & 0.00 & 1.55 & 0.03 & 0.97 \\
\hline KS5 & 0.37 & 0.75 & 0.51 & 0.00 & 0.00 & 0.34 & 0.52 & 0.46 & 0.00 & 0.38 & 0.27 & 0.49 \\
\hline KAL1 & 34.24 & 0.06 & 2.39 & 0.00 & 0.00 & 4.46 & 0.03 & 1.62 & 0.00 & 1.83 & 0.01 & 1.05 \\
\hline KAL2 & 35.39 & 0.05 & 2.46 & 0.00 & 0.00 & 4.56 & 0.03 & 1.63 & 0.00 & 1.84 & 0.01 & 1.05 \\
\hline KAS1 & 2.31 & 0.24 & 1.18 & 0.00 & 0.00 & 2.14 & 0.14 & 1.13 & 0.00 & 1.19 & 0.09 & 0.85 \\
\hline KAS2 & 0.74 & 2.07 & 0.83 & 0.01 & 0.01 & 0.73 & 2.13 & 0.83 & 0.03 & 0.67 & 2.03 & 0.78 \\
\hline KAS3 & 0.69 & 0.59 & 0.65 & 0.00 & 0.00 & 0.56 & 0.55 & 0.58 & 0.00 & 0.38 & 0.43 & 0.48 \\
\hline KAS4 & 0.61 & 1.51 & 0.72 & 0.00 & 0.01 & 0.55 & 1.53 & 0.69 & 0.02 & 0.47 & 1.40 & 0.62 \\
\hline KAS5 & 1.62 & 0.30 & 0.99 & 0.00 & 0.00 & 1.84 & 0.16 & 1.05 & 0.00 & 1.40 & 0.06 & 0.92 \\
\hline
\end{tabular}




$$
p=8, \rho=0.95
$$

\begin{tabular}{|c|c|c|c|c|c|c|c|c|c|c|c|c|}
\hline & \multicolumn{4}{|c|}{$\mathrm{n}=70$} & \multicolumn{4}{|c|}{$\mathrm{n}=100$} & \multicolumn{4}{|c|}{$\mathrm{n}=200$} \\
\hline & MSE & Bias & MAPE & Pr. & MSE & Bias & MAPE & Pr. & MSE & Bias & MAPE & Pr. \\
\hline ML & 242097.40 & 0.00 & 26.60 & 0 & 20.76 & 0.00 & 3.29 & 0 & 6.65 & 0.00 & 1.94 & 0.00 \\
\hline KH1 & 28.88 & 0.08 & 3.11 & 0 & 10.10 & 0.05 & 2.24 & 0 & 3.68 & 0.04 & 1.42 & 0.00 \\
\hline $\mathrm{KH} 2$ & 9.04 & 0.16 & 1.85 & 0 & 3.95 & 0.13 & 1.40 & 0 & 1.66 & 0.11 & 0.94 & 0.00 \\
\hline KL & 4.35 & 0.21 & 1.45 & 0 & 3.97 & 0.12 & 1.43 & 0 & 2.98 & 0.06 & 1.30 & 0.00 \\
\hline KHG & 22.81 & 0.08 & 2.99 & 0 & 9.56 & 0.05 & 2.22 & 0 & 3.60 & 0.04 & 1.43 & 0.00 \\
\hline KBH & 11.37 & 0.24 & 1.08 & 0 & 1.16 & 0.23 & 0.79 & 0 & 0.55 & 0.22 & 0.56 & 0.00 \\
\hline KNR & 2.52 & 0.32 & 0.91 & 0 & 0.89 & 0.31 & 0.67 & 0 & 0.35 & 0.34 & 0.44 & 0.00 \\
\hline KK1 & 2.33 & 0.34 & 0.98 & 0 & 1.21 & 0.32 & 0.76 & 0 & 0.58 & 0.30 & 0.55 & 0.00 \\
\hline KK2 & 0.90 & 1.11 & 0.75 & 0 & 0.65 & 1.13 & 0.67 & 0 & 0.45 & 1.08 & 0.58 & 0.01 \\
\hline KK3 & 3.43 & 0.29 & 1.19 & $\Omega$ & 1.79 & 0.27 & 0.91 & 0 & 0.80 & 0.25 & 0.64 & 0.00 \\
\hline KK4 & 0.97 & 0.31 & 0.76 & 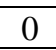 & 0.94 & 0.23 & 0.74 & 4 & 0.84 & 0.16 & 0.70 & 0.00 \\
\hline KK5 & 0.91 & 0.36 & 0.74 & 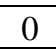 & 1.47 & 0.17 & 0.96 & . & 2.13 & 0.06 & 1.18 & 0.00 \\
\hline KK6 & 1.23 & 0.28 & 0.85 & 0 & 1.18 & 0.21 & 0.83 & 0 & 1.00 & 0.14 & 0.77 & 0.00 \\
\hline KK7 & 0.35 & 0.70 & 0.51 & 0 & 0.38 & 0.40 & 0.49 & 0 & 0.77 & 0.14 & 0.71 & 0.00 \\
\hline KK8 & 0.73 & 0.40 & 0.67 & 0 & 1.17 & 0.20 & 0.85 & 0 & 1.87 & 0.07 & 1.10 & 0.00 \\
\hline KK9 & 0.44 & 1.00 & 0.59 & 0 & 0.37 & 0.90 & 0.53 & 0 & 0.30 & 0.70 & 0.46 & 0.00 \\
\hline KL1 & 0.77 & 1.43 & 0.76 & 0 & 0.71 & 1.29 & 0.71 & 0 & 0.64 & 0.97 & 0.64 & 0.01 \\
\hline KL2 & 0.58 & 1.70 & 0.74 & 0 & 0.43 & 1.37 & 0.62 & 0 & 0.24 & 0.90 & 0.45 & 0.00 \\
\hline KD1 & 12.01 & 0.11 & 2.47 & 0 & 8.95 & 0.05 & 2.19 & 0 & 4.76 & 0.02 & 1.64 & 0.00 \\
\hline KD2 & 6.14 & 0.20 & 1.71 & 0 & 5.09 & 0.12 & 1.61 & 0 & 3.35 & 0.06 & 1.37 & 0.00 \\
\hline KD3 & 4.42 & 0.23 & 1.45 & 0 & 3.92 & 0.14 & 1.40 & 0 & 2.93 & 0.07 & 1.27 & 0.00 \\
\hline KD4 & 1.56 & 0.85 & 0.88 & 0 & 1.47 & 0.73 & 0.85 & 0 & 1.27 & 0.48 & 0.81 & 0.00 \\
\hline KS & 93.30 & 0.03 & 4.31 & 0 & 14.39 & 0.02 & 2.80 & 0 & 5.59 & 0.01 & 1.80 & 0.00 \\
\hline KS1 & 3.93 & 0.14 & 1.60 & 0 & 4.39 & 0.07 & 1.68 & 0 & 3.37 & 0.03 & 1.45 & 0.00 \\
\hline KS2 & 0.3 & 0.87 & 0.52 & 0 & 0.24 & 0.58 & 0.40 & 0 & 0.28 & 0.27 & 0.42 & 0.00 \\
\hline KS3 & 0.3 & 0.75 & 0.49 & 0 & 0.25 & 0.51 & 0.41 & 0 & 0.32 & 0.25 & 0.45 & 0.00 \\
\hline KS4 & 4.5 & 0.13 & 1.71 & 0 & 4.73 & 0.07 & 1.74 & 0 & 3.45 & 0.03 & 1.46 & 0.00 \\
\hline KS5 & 0.32 & 0.77 & 0.49 & 0 & 0.25 & 0.52 & 0.40 & 0 & 0.31 & 0.26 & 0.44 & 0.00 \\
\hline KAL1 & 71.70 & 0.04 & 3.46 & 0 & 10.83 & 0.02 & 2.53 & 0 & 5.23 & 0.01 & 1.76 & 0.00 \\
\hline KAL2 & 74.65 & 0.04 & 3.69 & 0 & 11.78 & 0.02 & 2.61 & 0 & 5.33 & 0.01 & 1.77 & 0.00 \\
\hline KAS1 & 3.11 & 0.19 & 1.37 & 0 & 3.96 & 0.09 & 1.54 & 0 & 3.09 & 0.05 & 1.33 & 0.00 \\
\hline KAS2 & 0.65 & 1.74 & 0.76 & 0 & 0.62 & 1.76 & 0.75 & 0 & 0.57 & 1.74 & 0.71 & 0.01 \\
\hline KAS3 & 1.06 & 0.36 & 0.77 & 0 & 1.08 & 0.30 & 0.76 & 0 & 0.74 & 0.26 & 0.63 & 0.00 \\
\hline KAS4 & 0.59 & 1.14 & 0.67 & 0 & 0.55 & 1.14 & 0.64 & 0 & 0.44 & 1.09 & 0.58 & 0.01 \\
\hline KAS5 & 1.57 & 0.28 & 0.94 & 0 & 2.27 & 0.15 & 1.13 & 0 & 2.61 & 0.06 & 1.23 & 0.00 \\
\hline
\end{tabular}




$$
p=8, \rho=0.99
$$

\begin{tabular}{|c|c|c|c|c|c|c|c|c|c|c|c|c|}
\hline & \multicolumn{4}{|c|}{$\mathrm{n}=70$} & \multicolumn{4}{|c|}{$\mathrm{n}=100$} & \multicolumn{4}{|c|}{$\mathrm{n}=200$} \\
\hline & MSE & Bias & MAPE & Pr. & MSE & Bias & MAPE & Pr. & MSE & Bias & MAPE & Pr. \\
\hline ML & 4058025.60 & 0.00 & 79.32 & 0 & 1935.48 & 0.00 & 8.59 & 0 & 36.15 & 0.00 & 4.43 & 0 \\
\hline KH1 & 344.56 & 0.03 & 7.30 & 0 & 53.40 & 0.02 & 5.03 & 0 & 18.44 & 0.01 & 3.07 & 0 \\
\hline KH2 & 56.80 & 0.05 & 4.21 & 0 & 20.14 & 0.04 & 3.11 & 0 & 7.62 & 0.03 & 1.96 & 0 \\
\hline KL & 13.08 & 0.13 & 2.16 & 0 & 11.07 & 0.08 & 2.13 & 0 & 8.21 & 0.04 & 1.97 & 0 \\
\hline KHG & 58.81 & 0.04 & 4.59 & 0 & 23.81 & 0.03 & 3.35 & 0 & 8.90 & 0.03 & 2.12 & 0 \\
\hline KBH & 20.22 & 0.06 & 2.51 & 0 & 6.57 & 0.06 & 1.86 & 0 & 2.74 & 0.05 & 1.21 & 0 \\
\hline KNR & 16.14 & 0.08 & 2.33 & 0 & 6.47 & 0.08 & 1.73 & 0 & 2.34 & 0.08 & 1.05 & 0 \\
\hline KK1 & 13.33 & 0.11 & 2.10 & 0 & 5.93 & 0.10 & 1.60 & 0 & 2.32 & 0.10 & 1.02 & 0 \\
\hline KK2 & 3.55 & 0.62 & 1.03 & 0 & 1.68 & 0.62 & 0.83 & 0 & 0.78 & 0.69 & 0.63 & 0 \\
\hline KK3 & 17.97 & 0.09 & 2.53 & 0 & 8.61 & 0.08 & 1.94 & 0 & 3.31 & 0.08 & 1.23 & 0 \\
\hline KK4 & 1.51 & 0.16 & 0.91 & 0 & 1.54 & 0.12 & 0.92 & 0 & 1.40 & 0.08 & 0.88 & 0 \\
\hline KK5 & 0.29 & 0.53 & 0.45 & 0 & 0.34 & 0.28 & 0.45 & 0 & 1.07 & 0.08 & 0.80 & 0 \\
\hline KK6 & 1.94 & 0.14 & 1.03 & 0 & 2.00 & 0.10 & 1.05 & 0 & 1.78 & 0.07 & 0.99 & 0 \\
\hline KK7 & 0.36 & 1.04 & 0.56 & 0 & 0.20 & 0.65 & 0.40 & 0 & 0.18 & 0.23 & 0.33 & 0 \\
\hline KK8 & 0.28 & 0.59 & 0.45 & 0 & 0.27 & 0.32 & 0.40 & 0 & 0.79 & 0.10 & 0.69 & 0 \\
\hline KK9 & 0.40 & 0.67 & 0.52 & 0 & 0.33 & 0.58 & 0.47 & 0 & 0.29 & 0.50 & 0.42 & 0 \\
\hline KL1 & 1.69 & 0.92 & 0.84 & 0 & 1.55 & 0.78 & 0.81 & 0 & 1.61 & 0.64 & 0.82 & 0 \\
\hline KL2 & 0.81 & 2.35 & 0.90 & 0 & 0.72 & 2.15 & 0.84 & 0 & 0.51 & 1.69 & 0.70 & 0 \\
\hline KD1 & 62.06 & 0.05 & 5.39 & 0 & 44.71 & 0.02 & 4.80 & 0 & 23.85 & 0.01 & 3.58 & 0 \\
\hline KD2 & 28.16 & 0.07 & 3.54 & 0 & 24.07 & 0.04 & 3.45 & 0 & 15.48 & 0.02 & 2.88 & 0 \\
\hline KD3 & 20.93 & 0.08 & 3.05 & 0 & 18.78 & 0.04 & 3.04 & 0 & 13.16 & 0.02 & 2.64 & 0 \\
\hline KD4 & 6.22 & 0.47 & 1.41 & 0 & 5.72 & 0.37 & 1.45 & 0 & 4.92 & 0.30 & 1.40 & 0 \\
\hline KS & 388.32 & 0.01 & 8.14 & 0 & 66.41 & 0.01 & 5.62 & 0 & 23.30 & 0.01 & 3.60 & 0 \\
\hline KS1 & 2.82 & 0.10 & 1.34 & 0 & 4.14 & 0.05 & 1.63 & 0 & 5.28 & 0.02 & 1.83 & 0 \\
\hline KS2 & 0.38 & 1.12 & 0.59 & 0 & 0.22 & 0.74 & 0.43 & 0 & 0.11 & 0.31 & 0.26 & 0 \\
\hline KS3 & 0.29 & 0.83 & 0.50 & 0 & 0.17 & 0.55 & 0.36 & 0 & 0.13 & 0.24 & 0.28 & 0 \\
\hline KS4 & 4.50 & 0.08 & 1.68 & 0 & 5.65 & 0.05 & 1.89 & 0 & 6.01 & 0.02 & 1.95 & 0 \\
\hline KS5 & 0.30 & 0.86 & 0.51 & 0 & 0.17 & 0.57 & 0.37 & 0 & 0.13 & 0.25 & 0.28 & 0 \\
\hline KAL1 & 53.52 & 0.03 & 3.76 & 0 & 25.19 & 0.02 & 3.57 & 0 & 14.26 & 0.01 & 2.98 & 0 \\
\hline KAL2 & 67.89 & 0.02 & 4.76 & 0 & 33.14 & 0.01 & 4.15 & 0 & 16.37 & 0.01 & 3.15 & 0 \\
\hline KAS1 & 3.10 & 0.14 & 1.33 & 0 & 6.30 & 0.06 & 1.95 & 0 & 9.56 & 0.02 & 2.37 & 0 \\
\hline KAS2 & 0.52 & 1.20 & 0.65 & 0 & 0.50 & 1.18 & 0.62 & 0 & 0.46 & 1.25 & 0.59 & 0 \\
\hline KAS3 & 1.43 & 0.19 & 0.88 & 0 & 2.39 & 0.12 & 1.13 & 0 & 2.50 & 0.08 & 1.11 & 0 \\
\hline KAS4 & 0.61 & 0.69 & 0.62 & 0 & 0.75 & 0.64 & 0.65 & 0 & 0.68 & 0.69 & 0.60 & 0 \\
\hline KAS5 & 1.48 & 0.21 & 0.86 & 0 & 2.99 & 0.12 & 1.23 & 0 & 5.38 & 0.04 & 1.67 & 0 \\
\hline
\end{tabular}


Table A3. Estimated MSEs, MAPEs, bias and Proportion of times in simulation when the ridge regression estimator produces a higher MSE than the ML estimator of the proposed estimators with intercept $=-1$ for the following cases:

$$
p=4, \rho=0.75
$$

\begin{tabular}{|c|c|c|c|c|c|c|c|c|c|c|c|c|}
\hline & \multicolumn{4}{|c|}{$\mathrm{n}=70$} & \multicolumn{4}{|c|}{$\mathrm{n}=100$} & \multicolumn{4}{|c|}{$\mathrm{n}=200$} \\
\hline & MSE & Bias & MAPE & Pr. & MSE & Bias & MAPE & Pr. & MSE & Bias & MAPE & Pr. \\
\hline ML & 1.63 & 0.00 & 0.98 & 0.00 & 0.94 & 0.00 & 0.75 & 0.00 & 0.40 & 0.00 & 0.50 & 0.00 \\
\hline KH1 & 0.95 & 0.14 & 0.73 & 0.02 & 0.61 & 0.11 & 0.60 & 0.03 & 0.30 & 0.07 & 0.43 & 0.05 \\
\hline KH2 & 0.57 & 0.28 & 0.57 & 0.04 & 0.40 & 0.23 & 0.48 & 0.05 & 0.23 & 0.14 & 0.38 & 0.07 \\
\hline KL & 0.98 & 0.11 & 0.76 & 0.02 & 0.73 & 0.06 & 0.66 & 0.02 & 0.37 & 0.02 & 0.48 & 0.03 \\
\hline KHG & 1.05 & 0.11 & 0.77 & 0.02 & 0.67 & 0.09 & 0.63 & 0.03 & 0.33 & 0.05 & 0.45 & 0.04 \\
\hline $\mathrm{KBH}$ & 0.28 & 0.56 & 0.44 & 0.09 & 0.22 & 0.50 & 0.40 & 0.12 & 0.15 & 0.39 & 0.32 & 0.18 \\
\hline KNR & 0.33 & 0.79 & 0.52 & 0.09 & 0.29 & 0.78 & 0.50 & 0.12 & 0.25 & 0.74 & 0.47 & 0.18 \\
\hline KK1 & 0.39 & 0.60 & 0.52 & 0.11 & 0.30 & 0.53 & 0.46 & 0.14 & 0.19 & 0.36 & 0.36 & 0.17 \\
\hline KK2 & 0.51 & 1.01 & 0.64 & 0.22 & 0.45 & 0.95 & 0.60 & 0.29 & 0.36 & 0.79 & 0.52 & 0.41 \\
\hline KK3 & 0.43 & 0.62 & 0.54 & 0.12 & 0.34 & 0.55 & 0.49 & 0.15 & 0.21 & 0.37 & 0.38 & 0.19 \\
\hline KK4 & 0.36 & 0.35 & 0.47 & 0.04 & 0.30 & 0.28 & 0.43 & 0.05 & 0.21 & 0.16 & 0.37 & 0.07 \\
\hline KK5 & 0.70 & 0.13 & 0.67 & 0.01 & 0.60 & 0.07 & 0.61 & 0.02 & 0.34 & 0.03 & 0.46 & 0.03 \\
\hline KK6 & 0.37 & 0.35 & 0.48 & 0.04 & 0.31 & 0.27 & 0.44 & 0.05 & 0.22 & 0.15 & 0.37 & 0.07 \\
\hline KK7 & 0.37 & 0.26 & 0.49 & 0.02 & 0.36 & 0.16 & 0.49 & 0.02 & 0.28 & 0.07 & 0.42 & 0.04 \\
\hline KK8 & 0.65 & 0.14 & 0.64 & 0.01 & 0.56 & 0.08 & 0.60 & 0.02 & 0.33 & 0.03 & 0.46 & 0.04 \\
\hline KK9 & 0.36 & 0.74 & 0.52 & 0.13 & 0.31 & 0.64 & 0.47 & 0.16 & 0.22 & 0.45 & 0.39 & 0.22 \\
\hline KL1 & 0.54 & 0.95 & 0.65 & 0.20 & 0.46 & 0.79 & 0.59 & 0.23 & 0.33 & 0.50 & 0.48 & 0.27 \\
\hline KL2 & 0.28 & 0.65 & 0.46 & 0.05 & 0.22 & 0.56 & 0.40 & 0.08 & 0.15 & 0.44 & 0.33 & 0.16 \\
\hline KD1 & 1.00 & 0.11 & 0.76 & 0.02 & 0.72 & 0.06 & 0.66 & 0.02 & 0.37 & 0.02 & 0.48 & 0.03 \\
\hline KD2 & 0.64 & 0.32 & 0.62 & 0.04 & 0.52 & 0.22 & 0.56 & 0.06 & 0.32 & 0.07 & 0.45 & 0.05 \\
\hline KD3 & 0.61 & 0.29 & 0.60 & 0.04 & 0.50 & 0.19 & 0.55 & 0.05 & 0.32 & 0.06 & 0.45 & 0.04 \\
\hline KD4 & 0.55 & 0.67 & 0.62 & 0.13 & 0.46 & 0.53 & 0.56 & 0.15 & 0.32 & 0.31 & 0.46 & 0.17 \\
\hline KS & 1.45 & 0.02 & 0.92 & 0.01 & 0.87 & 0.01 & 0.73 & 0.02 & 0.39 & 0.01 & 0.49 & 0.03 \\
\hline KS1 & 1.01 & 0.07 & 0.79 & 0.01 & 0.72 & 0.05 & 0.66 & 0.02 & 0.36 & 0.02 & 0.47 & 0.03 \\
\hline KS2 & 0.24 & 0.48 & 0.40 & 0.04 & 0.21 & 0.35 & 0.36 & 0.05 & 0.17 & 0.18 & 0.33 & 0.07 \\
\hline KS3 & 0.25 & 0.46 & 0.40 & 0.03 & 0.21 & 0.33 & 0.37 & 0.05 & 0.18 & 0.18 & 0.34 & 0.07 \\
\hline KS4 & 1.03 & 0.07 & 0.80 & 0.01 & 0.72 & 0.05 & 0.67 & 0.02 & 0.36 & 0.02 & 0.47 & 0.03 \\
\hline KS5 & 0.25 & 0.46 & 0.40 & 0.03 & 0.21 & 0.34 & 0.37 & 0.05 & 0.18 & 0.18 & 0.34 & 0.07 \\
\hline KAL1 & 1.40 & 0.02 & 0.91 & 0.01 & 0.86 & 0.02 & 0.72 & 0.02 & 0.39 & 0.01 & 0.49 & 0.03 \\
\hline KAL2 & 1.42 & 0.02 & 0.91 & 0.01 & 0.87 & 0.02 & 0.72 & 0.02 & 0.39 & 0.01 & 0.49 & 0.03 \\
\hline KAS1 & 0.72 & 0.18 & 0.65 & 0.02 & 0.55 & 0.13 & 0.57 & 0.03 & 0.30 & 0.07 & 0.43 & 0.05 \\
\hline KAS2 & 0.61 & 1.30 & 0.73 & 0.30 & 0.57 & 1.24 & 0.70 & 0.41 & 0.48 & 1.09 & 0.63 & 0.57 \\
\hline KAS3 & 0.39 & 0.63 & 0.52 & 0.12 & 0.33 & 0.56 & 0.48 & 0.15 & 0.21 & 0.38 & 0.38 & 0.19 \\
\hline KAS4 & 0.50 & 1.02 & 0.64 & 0.23 & 0.45 & 0.95 & 0.60 & 0.29 & 0.36 & 0.79 & 0.52 & 0.41 \\
\hline KAS5 & 0.77 & 0.15 & 0.68 & 0.02 & 0.66 & 0.08 & 0.63 & 0.02 & 0.37 & 0.02 & 0.48 & 0.03 \\
\hline
\end{tabular}




$$
p=4, \rho=0.85
$$

\begin{tabular}{|c|c|c|c|c|c|c|c|c|c|c|c|c|}
\hline & \multicolumn{4}{|c|}{$\mathrm{n}=70$} & \multicolumn{4}{|c|}{$\mathrm{n}=100$} & \multicolumn{4}{|c|}{$\mathrm{n}=200$} \\
\hline & MSE & Bias & MAPE & Pr. & MSE & Bias & MAPE & Pr. & MSE & Bias & MAPE & Pr. \\
\hline ML & 2.73 & 0.00 & 1.25 & 0.00 & 1.52 & 0.00 & 0.95 & 0.00 & 0.65 & 0.00 & 0.64 & 0.00 \\
\hline KH1 & 1.45 & 0.13 & 0.87 & 0.01 & 0.89 & 0.10 & 0.71 & 0.01 & 0.45 & 0.06 & 0.52 & 0.01 \\
\hline $\mathrm{KH} 2$ & 0.83 & 0.25 & 0.65 & 0.02 & 0.54 & 0.20 & 0.55 & 0.02 & 0.31 & 0.13 & 0.43 & 0.03 \\
\hline KL & 1.31 & 0.13 & 0.84 & 0.01 & 0.98 & 0.07 & 0.76 & 0.01 & 0.56 & 0.02 & 0.59 & 0.01 \\
\hline KHG & 1.55 & 0.11 & 0.91 & 0.01 & 0.95 & 0.09 & 0.74 & 0.01 & 0.47 & 0.05 & 0.54 & 0.02 \\
\hline KBH & 0.31 & 0.45 & 0.45 & 0.03 & 0.24 & 0.41 & 0.40 & 0.06 & 0.16 & 0.33 & 0.32 & 0.08 \\
\hline KNR & 0.31 & 0.64 & 0.49 & 0.03 & 0.25 & 0.62 & 0.45 & 0.06 & 0.20 & 0.58 & 0.40 & 0.08 \\
\hline KK1 & 0.49 & 0.53 & 0.55 & 0.05 & 0.35 & 0.47 & 0.48 & 0.08 & 0.22 & 0.35 & 0.38 & 0.10 \\
\hline KK2 & 0.57 & 0.94 & 0.65 & 0.12 & 0.47 & 0.90 & 0.61 & 0.21 & 0.36 & 0.77 & 0.52 & 0.29 \\
\hline KK3 & 0.55 & 0.55 & 0.58 & 0.06 & 0.40 & 0.49 & 0.51 & 0.10 & 0.25 & 0.37 & 0.40 & 0.11 \\
\hline KK4 & 0.42 & 0.32 & 0.50 & 0.02 & 0.36 & 0.25 & 0.47 & 0.02 & 0.26 & 0.15 & 0.40 & 0.03 \\
\hline KK5 & 0.82 & 0.13 & 0.73 & 0.00 & 0.75 & 0.08 & 0.70 & 0.00 & 0.50 & 0.03 & 0.56 & 0.01 \\
\hline KK6 & 0.45 & 0.32 & 0.52 & 0.02 & 0.39 & 0.25 & 0.48 & 0.02 & 0.27 & 0.15 & 0.41 & 0.03 \\
\hline KK7 & 0.38 & 0.26 & 0.50 & 0.00 & 0.41 & 0.16 & 0.51 & 0.01 & 0.36 & 0.07 & 0.48 & 0.01 \\
\hline KK8 & 0.73 & 0.15 & 0.69 & 0.00 & 0.70 & 0.09 & 0.67 & 0.00 & 0.49 & 0.03 & 0.55 & 0.01 \\
\hline KK9 & 0.37 & 0.69 & 0.53 & 0.07 & 0.31 & 0.60 & 0.48 & 0.09 & 0.23 & 0.44 & 0.40 & 0.14 \\
\hline KL1 & 0.62 & 0.91 & 0.68 & 0.11 & 0.51 & 0.77 & 0.61 & 0.16 & 0.37 & 0.51 & 0.51 & 0.18 \\
\hline KL2 & 0.28 & 0.66 & 0.47 & 0.02 & 0.22 & 0.55 & 0.41 & 0.03 & 0.15 & 0.44 & 0.33 & 0.08 \\
\hline KD1 & 1.48 & 0.11 & 0.90 & 0.00 & 1.06 & 0.06 & 0.79 & 0.01 & 0.58 & 0.02 & 0.60 & 0.01 \\
\hline KD2 & 0.93 & 0.29 & 0.70 & 0.02 & 0.73 & 0.20 & 0.64 & 0.03 & 0.46 & 0.08 & 0.53 & 0.03 \\
\hline KD3 & 0.87 & 0.27 & 0.68 & 0.02 & 0.70 & 0.17 & 0.63 & 0.02 & 0.46 & 0.06 & 0.53 & 0.02 \\
\hline KD4 & 0.71 & 0.64 & 0.67 & 0.07 & 0.57 & 0.51 & 0.60 & 0.09 & 0.40 & 0.31 & 0.51 & 0.12 \\
\hline KS & 2.31 & 0.02 & 1.15 & 0.00 & 1.37 & 0.01 & 0.91 & 0.00 & 0.62 & 0.01 & 0.62 & 0.01 \\
\hline KS1 & 1.38 & 0.07 & 0.93 & 0.00 & 1.03 & 0.05 & 0.80 & 0.00 & 0.55 & 0.02 & 0.59 & 0.01 \\
\hline KS2 & 0.23 & 0.47 & 0.39 & 0.02 & 0.21 & 0.34 & 0.36 & 0.02 & 0.19 & 0.18 & 0.35 & 0.03 \\
\hline KS3 & 0.23 & 0.45 & 0.39 & 0.02 & 0.21 & 0.33 & 0.37 & 0.02 & 0.20 & 0.18 & 0.35 & 0.03 \\
\hline KS4 & 1.43 & 0.07 & 0.94 & 0.00 & 1.04 & 0.04 & 0.80 & 0.00 & 0.55 & 0.02 & 0.59 & 0.01 \\
\hline KS5 & 0.23 & 0.46 & 0.39 & 0.02 & 0.21 & 0.33 & 0.37 & 0.02 & 0.20 & 0.18 & 0.35 & 0.03 \\
\hline KAL1 & 2.18 & 0.02 & 1.13 & 0.00 & 1.34 & 0.01 & 0.90 & 0.00 & 0.61 & 0.01 & 0.62 & 0.01 \\
\hline KAL2 & 2.23 & 0.02 & 1.14 & 0.00 & 1.35 & 0.01 & 0.90 & 0.00 & 0.62 & 0.01 & 0.62 & 0.01 \\
\hline KAS1 & 0.94 & 0.16 & 0.74 & 0.01 & 0.76 & 0.12 & 0.67 & 0.01 & 0.44 & 0.07 & 0.51 & 0.02 \\
\hline KAS2 & 0.60 & 1.23 & 0.72 & 0.18 & 0.56 & 1.20 & 0.70 & 0.29 & 0.47 & 1.06 & 0.62 & 0.42 \\
\hline KAS3 & 0.44 & 0.57 & 0.54 & 0.06 & 0.37 & 0.50 & 0.50 & 0.10 & 0.24 & 0.38 & 0.40 & 0.12 \\
\hline KAS4 & 0.52 & 0.95 & 0.64 & 0.12 & 0.46 & 0.91 & 0.60 & 0.21 & 0.36 & 0.77 & 0.52 & 0.29 \\
\hline KAS5 & 0.91 & 0.17 & 0.73 & 0.01 & 0.84 & 0.09 & 0.71 & 0.01 & 0.55 & 0.03 & 0.58 & 0.01 \\
\hline
\end{tabular}




$$
p=4, \rho=0.95
$$

\begin{tabular}{|c|c|c|c|c|c|c|c|c|c|c|c|c|}
\hline & \multicolumn{4}{|c|}{$\mathrm{n}=70$} & \multicolumn{4}{|c|}{$\mathrm{n}=100$} & \multicolumn{4}{|c|}{$\mathrm{n}=200$} \\
\hline & MSE & Bias & MAPE & Pr. & MSE & Bias & MAPE & Pr. & MSE & Bias & MAPE & Pr. \\
\hline ML & 8.86 & 0.00 & 2.20 & 0.00 & 5.10 & 0.00 & 1.74 & 0.00 & 2.07 & 0.00 & 1.14 & 0.00 \\
\hline KH1 & 3.85 & 0.08 & 1.36 & 0.00 & 2.48 & 0.07 & 1.13 & 0.00 & 1.13 & 0.05 & 0.80 & 0.00 \\
\hline KH2 & 1.98 & 0.16 & 0.95 & 0.00 & 1.36 & 0.14 & 0.81 & 0.00 & 0.65 & 0.10 & 0.59 & 0.00 \\
\hline KL & 2.31 & 0.14 & 1.04 & 0.00 & 2.10 & 0.09 & 1.03 & 0.00 & 1.30 & 0.04 & 0.87 & 0.00 \\
\hline KHG & 3.11 & 0.10 & 1.22 & 0.00 & 2.09 & 0.09 & 1.02 & 0.00 & 0.95 & 0.07 & 0.73 & 0.00 \\
\hline KBH & 0.59 & 0.25 & 0.55 & 0.00 & 0.43 & 0.24 & 0.48 & 0.00 & 0.23 & 0.20 & 0.37 & 0.01 \\
\hline KNR & 0.49 & 0.38 & 0.52 & 0.00 & 0.34 & 0.37 & 0.45 & 0.00 & 0.18 & 0.34 & 0.35 & 0.01 \\
\hline KK1 & 0.94 & 0.37 & 0.66 & 0.01 & 0.67 & 0.34 & 0.58 & 0.01 & 0.36 & 0.28 & 0.45 & 0.02 \\
\hline KK2 & 0.74 & 0.77 & 0.68 & 0.03 & 0.59 & 0.73 & 0.63 & 0.04 & 0.42 & 0.67 & 0.54 & 0.09 \\
\hline KK3 & 1.07 & 0.40 & 0.71 & 0.02 & 0.76 & 0.36 & 0.62 & 0.02 & 0.40 & 0.32 & 0.48 & 0.03 \\
\hline KK4 & 0.55 & 0.24 & 0.55 & 0.00 & 0.53 & 0.19 & 0.54 & 0.00 & 0.41 & 0.13 & 0.49 & 0.00 \\
\hline KK5 & 0.73 & 0.15 & 0.67 & 0.00 & 0.90 & 0.09 & 0.76 & 0.00 & 0.94 & 0.04 & 0.79 & 0.00 \\
\hline KK6 & 0.61 & 0.24 & 0.58 & 0.00 & 0.58 & 0.19 & 0.57 & 0.00 & 0.43 & 0.13 & 0.50 & 0.00 \\
\hline KK7 & 0.26 & 0.30 & 0.40 & 0.00 & 0.32 & 0.19 & 0.45 & 0.00 & 0.46 & 0.08 & 0.55 & 0.00 \\
\hline KK8 & 0.59 & 0.18 & 0.61 & 0.00 & 0.75 & 0.10 & 0.70 & 0.00 & 0.87 & 0.04 & 0.76 & 0.00 \\
\hline KK9 & 0.37 & 0.59 & 0.51 & 0.01 & 0.34 & 0.51 & 0.48 & 0.02 & 0.27 & 0.38 & 0.42 & 0.03 \\
\hline KL1 & 0.91 & 0.77 & 0.73 & 0.03 & 0.86 & 0.64 & 0.70 & 0.04 & 0.68 & 0.44 & 0.63 & 0.06 \\
\hline KL2 & 0.35 & 0.85 & 0.55 & 0.00 & 0.29 & 0.73 & 0.49 & 0.00 & 0.18 & 0.54 & 0.38 & 0.01 \\
\hline KD1 & 3.76 & 0.07 & 1.39 & 0.00 & 3.11 & 0.04 & 1.31 & 0.00 & 1.68 & 0.02 & 1.01 & 0.00 \\
\hline KD2 & 2.23 & 0.22 & 1.01 & 0.01 & 2.00 & 0.15 & 0.99 & 0.00 & 1.20 & 0.07 & 0.82 & 0.00 \\
\hline KD3 & 2.07 & 0.20 & 0.97 & 0.00 & 1.91 & 0.13 & 0.97 & 0.00 & 1.21 & 0.05 & 0.83 & 0.00 \\
\hline KD4 & 1.36 & 0.53 & 0.82 & 0.01 & 1.26 & 0.42 & 0.80 & 0.02 & 0.89 & 0.27 & 0.70 & 0.03 \\
\hline KS & 6.06 & 0.02 & 1.85 & 0.00 & 4.00 & 0.01 & 1.54 & 0.00 & 1.82 & 0.01 & 1.07 & 0.00 \\
\hline KS1 & 2.06 & 0.06 & 1.15 & 0.00 & 1.94 & 0.04 & 1.11 & 0.00 & 1.29 & 0.02 & 0.91 & 0.00 \\
\hline KS2 & 0.19 & 0.48 & 0.37 & 0.00 & 0.16 & 0.34 & 0.31 & 0.00 & 0.18 & 0.17 & 0.33 & 0.00 \\
\hline KS3 & 0.19 & 0.44 & 0.36 & 0.00 & 0.16 & 0.32 & 0.32 & 0.00 & 0.19 & 0.16 & 0.35 & 0.00 \\
\hline KS4 & 2.23 & 0.06 & 1.19 & 0.00 & 2.04 & 0.04 & 1.13 & 0.00 & 1.31 & 0.02 & 0.91 & 0.00 \\
\hline KS5 & 0.19 & 0.45 & 0.36 & 0.00 & 0.16 & 0.32 & 0.32 & 0.00 & 0.19 & 0.17 & 0.35 & 0.00 \\
\hline KAL1 & 4.88 & 0.02 & 1.71 & 0.00 & 3.59 & 0.02 & 1.48 & 0.00 & 1.76 & 0.01 & 1.05 & 0.00 \\
\hline KAL2 & 5.28 & 0.02 & 1.77 & 0.00 & 3.74 & 0.01 & 1.50 & 0.00 & 1.78 & 0.01 & 1.06 & 0.00 \\
\hline KAS1 & 1.54 & 0.12 & 0.94 & 0.00 & 1.65 & 0.09 & 0.96 & 0.00 & 1.04 & 0.05 & 0.78 & 0.00 \\
\hline KAS2 & 0.57 & 1.06 & 0.68 & 0.04 & 0.53 & 1.01 & 0.65 & 0.06 & 0.46 & 0.94 & 0.60 & 0.14 \\
\hline KAS3 & 0.61 & 0.42 & 0.60 & 0.02 & 0.60 & 0.37 & 0.58 & 0.02 & 0.39 & 0.32 & 0.47 & 0.03 \\
\hline KAS4 & 0.56 & 0.78 & 0.63 & 0.03 & 0.52 & 0.74 & 0.60 & 0.04 & 0.41 & 0.67 & 0.54 & 0.09 \\
\hline KAS5 & 1.18 & 0.18 & 0.79 & 0.00 & 1.47 & 0.11 & 0.89 & 0.00 & 1.20 & 0.04 & 0.84 & 0.00 \\
\hline
\end{tabular}




$$
p=4, \rho=0.99
$$

\begin{tabular}{|c|c|c|c|c|c|c|c|c|c|c|c|c|}
\hline & \multicolumn{4}{|c|}{$\mathrm{n}=70$} & \multicolumn{4}{|c|}{$\mathrm{n}=100$} & \multicolumn{4}{|c|}{$\mathrm{n}=200$} \\
\hline & MSE & Bias & MAPE & Pr. & MSE & Bias & MAPE & Pr. & MSE & Bias & MAPE & Pr. \\
\hline ML & 46.54 & 0.00 & 5.09 & 0 & 27.43 & 0.00 & 4.04 & 0.00 & 11.39 & 0.00 & 2.61 & 0.00 \\
\hline KH1 & 19.18 & 0.03 & 2.91 & 0 & 11.64 & 0.03 & 2.37 & 0.00 & 5.05 & 0.02 & 1.57 & 0.00 \\
\hline KH2 & 10.19 & 0.06 & 2.02 & 0 & 6.27 & 0.05 & 1.66 & 0.00 & 2.82 & 0.05 & 1.12 & 0.00 \\
\hline KL & 8.43 & 0.10 & 1.78 & 0 & 7.29 & 0.07 & 1.74 & 0.00 & 4.81 & 0.03 & 1.51 & 0.00 \\
\hline KHG & 9.06 & 0.08 & 1.85 & 0 & 5.84 & 0.07 & 1.54 & 0.00 & 2.50 & 0.06 & 1.03 & 0.00 \\
\hline $\mathrm{KBH}$ & 3.10 & 0.08 & 1.18 & 0 & 1.97 & 0.07 & 0.97 & 0.00 & 0.92 & 0.07 & 0.66 & 0.00 \\
\hline KNR & 3.00 & 0.14 & 1.06 & 0 & 1.75 & 0.14 & 0.85 & 0.00 & 0.73 & 0.13 & 0.56 & 0.00 \\
\hline KK1 & 4.63 & 0.15 & 1.28 & 0 & 2.86 & 0.14 & 1.03 & 0.00 & 1.38 & 0.13 & 0.73 & 0.00 \\
\hline KK2 & 2.64 & 0.44 & 0.97 & 0 & 1.71 & 0.44 & 0.81 & 0.00 & 0.91 & 0.43 & 0.63 & 0.01 \\
\hline KK3 & 5.19 & 0.17 & 1.34 & 0 & 3.18 & 0.16 & 1.09 & 0.00 & 1.54 & 0.15 & 0.77 & 0.00 \\
\hline KK4 & 0.88 & 0.13 & 0.67 & 0 & 0.85 & 0.11 & 0.65 & 0.00 & 0.74 & 0.07 & 0.61 & 0.00 \\
\hline KK5 & 0.23 & 0.25 & 0.37 & 0 & 0.32 & 0.15 & 0.42 & 0.00 & 0.63 & 0.05 & 0.62 & 0.00 \\
\hline KK6 & 0.99 & 0.13 & 0.71 & 0 & 0.96 & 0.11 & 0.69 & 0.00 & 0.83 & 0.07 & 0.64 & 0.00 \\
\hline KK7 & 0.17 & 0.46 & 0.36 & 0 & 0.11 & 0.29 & 0.27 & 0.00 & 0.17 & 0.11 & 0.32 & 0.00 \\
\hline KK8 & 0.19 & 0.29 & 0.34 & 0 & 0.23 & 0.17 & 0.36 & 0.00 & 0.47 & 0.06 & 0.54 & 0.00 \\
\hline KK9 & 0.40 & 0.38 & 0.49 & 0 & 0.37 & 0.34 & 0.46 & 0.00 & 0.32 & 0.26 & 0.41 & 0.00 \\
\hline KL1 & 3.10 & 0.46 & 1.06 & 0 & 2.97 & 0.39 & 1.04 & 0.00 & 2.55 & 0.28 & 1.00 & 0.01 \\
\hline KL2 & 0.60 & 1.32 & 0.75 & 0 & 0.52 & 1.20 & 0.69 & 0.00 & 0.36 & 0.93 & 0.56 & 0.00 \\
\hline KD1 & 19.35 & 0.03 & 3.02 & 0 & 15.16 & 0.02 & 2.80 & 0.00 & 8.49 & 0.01 & 2.16 & 0.00 \\
\hline KD2 & 11.31 & 0.09 & 2.14 & 0 & 9.40 & 0.06 & 2.05 & 0.00 & 6.11 & 0.03 & 1.74 & 0.00 \\
\hline KD3 & 10.75 & 0.08 & 2.10 & 0 & 9.08 & 0.05 & 2.02 & 0.00 & 6.11 & 0.02 & 1.74 & 0.00 \\
\hline KD4 & 6.18 & 0.29 & 1.49 & 0 & 5.51 & 0.24 & 1.44 & 0.00 & 4.02 & 0.16 & 1.30 & 0.00 \\
\hline KS & 23.84 & 0.01 & 3.50 & 0 & 15.39 & 0.01 & 2.95 & 0.00 & 7.52 & 0.01 & 2.10 & 0.00 \\
\hline KS1 & 1.81 & 0.05 & 1.07 & 0 & 2.14 & 0.04 & 1.17 & 0.00 & 2.26 & 0.02 & 1.20 & 0.00 \\
\hline KS2 & 0.20 & 0.57 & 0.41 & 0 & 0.11 & 0.39 & 0.29 & 0.00 & 0.07 & 0.18 & 0.21 & 0.00 \\
\hline KS3 & 0.17 & 0.48 & 0.37 & 0 & 0.10 & 0.33 & 0.26 & 0.00 & 0.08 & 0.16 & 0.22 & 0.00 \\
\hline KS4 & 2.49 & 0.05 & 1.24 & 0 & 2.70 & 0.03 & 1.30 & 0.00 & 2.55 & 0.02 & 1.26 & 0.00 \\
\hline KS5 & 0.17 & 0.49 & 0.37 & 0 & 0.10 & 0.34 & 0.27 & 0.00 & 0.08 & 0.16 & 0.22 & 0.00 \\
\hline KAL1 & 9.74 & 0.02 & 2.38 & 0 & 8.33 & 0.01 & 2.26 & 0.00 & 5.67 & 0.01 & 1.87 & 0.00 \\
\hline KAL2 & 13.72 & 0.01 & 2.78 & 0 & 10.64 & 0.01 & 2.52 & 0.00 & 6.37 & 0.01 & 1.96 & 0.00 \\
\hline KAS1 & 2.13 & 0.07 & 1.10 & 0 & 3.30 & 0.04 & 1.37 & 0.00 & 3.51 & 0.03 & 1.36 & 0.00 \\
\hline KAS2 & 0.53 & 0.67 & 0.60 & 0 & 0.57 & 0.67 & 0.60 & 0.01 & 0.52 & 0.65 & 0.56 & 0.02 \\
\hline KAS3 & 0.97 & 0.20 & 0.71 & 0 & 1.26 & 0.18 & 0.78 & 0.00 & 1.20 & 0.15 & 0.71 & 0.00 \\
\hline KAS4 & 0.68 & 0.46 & 0.63 & 0 & 0.81 & 0.45 & 0.66 & 0.00 & 0.75 & 0.43 & 0.60 & 0.01 \\
\hline KAS5 & 1.50 & 0.14 & 0.86 & 0 & 2.49 & 0.08 & 1.11 & 0.00 & 3.39 & 0.04 & 1.31 & 0.00 \\
\hline
\end{tabular}




$$
p=8, \rho=0.75
$$

\begin{tabular}{|c|c|c|c|c|c|c|c|c|c|c|c|c|}
\hline & \multicolumn{4}{|c|}{$\mathrm{n}=70$} & \multicolumn{4}{|c|}{$\mathrm{n}=100$} & \multicolumn{4}{|c|}{$\mathrm{n}=200$} \\
\hline & MSE & Bias & MAPE & Pr. & MSE & Bias & MAPE & Pr. & MSE & Bias & MAPE & Pr. \\
\hline ML & 13821.74 & 0.00 & 6.64 & 0.00 & 3.39 & 0.00 & 1.38 & 0.00 & 1.12 & 0.00 & 0.82 & 0.00 \\
\hline KH1 & 4.22 & 0.18 & 1.41 & 0.00 & 2.03 & 0.14 & 1.06 & 0.00 & 0.80 & 0.09 & 0.69 & 0.00 \\
\hline KH2 & 1.46 & 0.40 & 0.86 & 0.00 & 0.90 & 0.34 & 0.71 & 0.00 & 0.46 & 0.25 & 0.53 & 0.00 \\
\hline $\mathrm{KL}$ & 2.56 & 0.23 & 1.19 & 0.00 & 1.96 & 0.12 & 1.07 & 0.00 & 0.96 & 0.04 & 0.76 & 0.00 \\
\hline KHG & 5.20 & 0.12 & 1.58 & 0.00 & 2.42 & 0.08 & 1.17 & 0.00 & 0.93 & 0.05 & 0.75 & 0.00 \\
\hline KBH & 0.46 & 0.71 & 0.53 & 0.00 & 0.33 & 0.67 & 0.47 & 0.00 & 0.22 & 0.57 & 0.38 & 0.01 \\
\hline KNR & 0.41 & 0.95 & 0.54 & 0.00 & 0.33 & 0.98 & 0.50 & 0.00 & 0.26 & 0.99 & 0.47 & 0.01 \\
\hline KK1 & 0.58 & 0.83 & 0.60 & 0.00 & 0.41 & 0.77 & 0.53 & 0.01 & 0.27 & 0.61 & 0.42 & 0.02 \\
\hline KK2 & 0.65 & 1.68 & 0.74 & 0.02 & 0.58 & 1.65 & 0.71 & 0.06 & 0.50 & 1.53 & 0.65 & 0.21 \\
\hline KK3 & 0.75 & 0.71 & 0.65 & 0.00 & 0.50 & 0.66 & 0.56 & 0.01 & 0.31 & 0.52 & 0.44 & 0.02 \\
\hline KK4 & 0.58 & 0.55 & 0.60 & 0.00 & 0.55 & 0.42 & 0.58 & 0.00 & 0.41 & 0.26 & 0.51 & 0.00 \\
\hline KK5 & 1.44 & 0.28 & 0.96 & 0.00 & 1.53 & 0.13 & 0.98 & 0.00 & 0.91 & 0.04 & 0.75 & 0.00 \\
\hline KK6 & 0.68 & 0.50 & 0.65 & 0.00 & 0.64 & 0.38 & $\begin{array}{l}0.63 \\
\end{array}$ & 0.00 & 0.46 & 0.24 & 0.53 & 0.00 \\
\hline KK7 & 0.58 & 0.55 & 0.62 & 0.00 & 0.70 & 0.31 & 0.67 & 0.00 & 0.64 & 0.12 & 0.64 & 0.00 \\
\hline KK8 & 1.25 & 0.32 & 0.90 & 0.00 & 1.38 & 0.15 & 0.94 & 0.00 & 0.88 & 0.05 & 0.74 & 0.00 \\
\hline KK9 & 0.50 & 1.38 & 0.65 & 0.01 & 0.43 & 1.23 & 0.59 & 0.03 & 0.32 & 0.96 & 0.50 & 0.07 \\
\hline KL1 & 0.70 & 1.83 & 0.78 & 0.03 & 0.62 & 1.67 & 0.73 & 0.06 & 0.50 & 1.29 & 0.63 & 0.16 \\
\hline KL2 & 0.44 & 1.25 & 0.60 & 0.00 & 0.33 & 0.96 & 0.50 & 0.00 & 0.21 & 0.65 & 0.38 & 0.00 \\
\hline KD1 & 3.16 & 0.19 & 1.31 & 0.00 & 2.14 & 0.11 & 1.11 & 0.00 & 0.97 & 0.04 & 0.77 & 0.00 \\
\hline KD2 & 1.74 & 0.38 & 0.95 & 0.00 & 1.37 & 0.25 & 0.88 & 0.00 & 0.80 & 0.10 & 0.69 & 0.00 \\
\hline KD3 & 1.32 & 0.44 & 0.84 & 0.00 & 1.13 & 0.29 & 0.80 & 0.00 & 0.73 & 0.12 & 0.66 & 0.00 \\
\hline KD4 & 0.75 & 1.23 & 0.73 & 0.01 & 0.67 & 1.04 & 0.68 & 0.03 & 0.50 & 0.71 & 0.58 & 0.07 \\
\hline KS & 10.89 & 0.05 & 1.87 & 0.00 & 2.97 & 0.02 & 1.30 & 0.00 & 1.07 & 0.01 & 0.80 & 0.00 \\
\hline KS1 & 2.36 & 0.18 & 1.22 & 0.00 & 2.00 & 0.09 & 1.11 & 0.00 & 0.95 & 0.04 & 0.76 & 0.00 \\
\hline KS2 & 0.38 & 0.79 & 0.51 & 0.00 & 0.36 & 0.54 & 0.48 & 0.00 & 0.35 & 0.28 & 0.47 & 0.00 \\
\hline KS3 & 0.39 & 0.73 & 0.51 & 0.00 & 0.38 & 0.51 & 0.49 & 0.00 & 0.36 & 0.27 & 0.48 & 0.00 \\
\hline KS4 & 2.47 & 0.17 & 1.25 & 0.00 & 2.03 & 0.09 & 1.11 & 0.00 & 0.96 & 0.03 & 0.76 & 0.00 \\
\hline KS5 & 0.39 & 0.74 & 0.51 & 0.00 & 0.38 & 0.52 & 0.49 & 0.00 & 0.36 & 0.28 & 0.48 & 0.00 \\
\hline KAL1 & 9.27 & 0.07 & 1.73 & 0.00 & 2.82 & 0.03 & 1.28 & 0.00 & 1.06 & 0.01 & 0.80 & 0.00 \\
\hline KAL2 & 9.59 & 0.06 & 1.77 & 0.00 & 2.86 & 0.03 & 1.29 & 0.00 & 1.06 & 0.01 & 0.80 & 0.00 \\
\hline KAS1 & 1.85 & 0.26 & 1.06 & 0.00 & 1.61 & 0.17 & 0.97 & 0.00 & 0.78 & 0.10 & 0.68 & 0.00 \\
\hline KAS2 & 0.78 & 2.23 & 0.86 & 0.04 & 0.76 & 2.22 & 0.85 & 0.09 & 0.71 & 2.13 & 0.81 & 0.37 \\
\hline KAS3 & 0.55 & 0.75 & 0.59 & 0.00 & 0.46 & 0.67 & 0.55 & 0.01 & 0.30 & 0.52 & 0.44 & 0.02 \\
\hline KAS4 & 0.62 & 1.69 & 0.74 & 0.02 & 0.58 & 1.66 & 0.71 & 0.06 & 0.50 & 1.53 & 0.65 & 0.21 \\
\hline KAS5 & 1.59 & 0.29 & 0.98 & 0.00 & 1.62 & 0.15 & 0.99 & 0.00 & 0.94 & 0.05 & 0.75 & 0.00 \\
\hline
\end{tabular}




$$
p=8, \rho=0.85
$$

\begin{tabular}{|c|c|c|c|c|c|c|c|c|c|c|c|c|}
\hline & \multicolumn{4}{|c|}{$\mathrm{n}=70$} & \multicolumn{4}{|c|}{$\mathrm{n}=100$} & \multicolumn{4}{|c|}{$\mathrm{n}=200$} \\
\hline & MSE & Bias & MAPE & Pr. & MSE & Bias & MAPE & Pr. & MSE & Bias & MAPE & Pr. \\
\hline $\mathrm{ML}$ & 11779.38 & 0.00 & 9.64 & 0.00 & 186.81 & 0.00 & 2.04 & 0.00 & 1.97 & 0.00 & 1.09 & 0.00 \\
\hline KH1 & 6.76 & 0.15 & 1.76 & 0.00 & 3.25 & 0.11 & 1.33 & 0.00 & 1.30 & 0.08 & 0.88 & 0.00 \\
\hline KH2 & 2.27 & 0.32 & 1.05 & 0.00 & 1.35 & 0.27 & 0.86 & 0.00 & 0.65 & 0.21 & 0.62 & 0.00 \\
\hline KL & 2.88 & 0.25 & 1.25 & 0.00 & 2.49 & 0.14 & 1.20 & 0.00 & 1.46 & 0.05 & 0.94 & 0.00 \\
\hline KHG & 7.69 & 0.12 & 1.93 & 0.00 & 3.85 & 0.07 & 1.47 & 0.00 & 1.48 & 0.05 & 0.94 & 0.00 \\
\hline KBH & 0.89 & 0.53 & 0.62 & 0.00 & 0.43 & 0.50 & 0.51 & 0.00 & 0.25 & 0.44 & 0.40 & 0.00 \\
\hline KNR & 0.54 & 0.71 & 0.56 & 0.00 & 0.33 & 0.72 & 0.48 & 0.00 & 0.21 & 0.74 & 0.40 & 0.00 \\
\hline KK1 & 0.78 & 0.66 & 0.65 & 0.00 & 0.50 & 0.63 & 0.55 & 0.00 & 0.29 & 0.52 & 0.44 & 0.00 \\
\hline KK2 & 0.67 & 1.49 & 0.72 & 0.00 & 0.58 & 1.54 & 0.69 & 0.02 & 0.46 & 1.41 & 0.62 & 0.07 \\
\hline KK3 & 1.10 & 0.57 & 0.74 & 0.00 & 0.69 & 0.52 & 0.62 & 0.00 & 0.37 & 0.44 & 0.48 & 0.00 \\
\hline KK4 & 0.67 & 0.47 & 0.64 & 0.00 & 0.65 & 0.37 & 0.62 & 0.00 & 0.52 & 0.23 & 0.57 & 0.00 \\
\hline KK5 & 1.46 & 0.31 & 0.97 & 0.00 & 1.80 & 0.14 & 1.08 & 0.00 & 1.38 & 0.04 & 0.93 & 0.00 \\
\hline KK6 & 0.81 & 0.43 & 0.70 & 0.00 & 0.78 & 0.33 & 0.69 & 0.00 & 0.59 & 0.21 & 0.60 & 0.00 \\
\hline KK7 & 0.52 & 0.58 & 0.59 & 0.00 & 0.66 & 0.33 & 0.65 & 0.00 & 0.80 & 0.12 & 0.72 & 0.00 \\
\hline KK8 & 1.24 & 0.34 & 0.89 & 0.00 & 1.56 & 0.17 & 1.00 & 0.00 & 1.31 & 0.05 & 0.91 & 0.00 \\
\hline KK9 & 0.47 & 1.24 & 0.63 & 0.00 & 0.42 & 1.15 & 0.58 & 0.00 & 0.31 & 0.88 & 0.48 & 0.02 \\
\hline KL1 & 0.68 & 1.74 & 0.77 & 0.00 & 0.63 & 1.63 & 0.73 & 0.02 & 0.49 & 1.21 & 0.62 & 0.06 \\
\hline KL2 & 0.45 & 1.31 & 0.63 & 0.00 & 0.33 & 1.00 & 0.52 & 0.00 & 0.21 & 0.67 & 0.38 & 0.00 \\
\hline KD1 & 4.30 & 0.19 & 1.51 & 0.00 & 3.16 & 0.10 & 1.34 & 0.00 & 1.60 & 0.04 & 0.98 & 0.00 \\
\hline KD2 & 2.27 & 0.34 & 1.07 & 0.00 & 1.92 & 0.22 & 1.02 & 0.00 & 1.20 & 0.09 & 0.84 & 0.00 \\
\hline KD3 & 1.65 & 0.39 & 0.93 & 0.00 & 1.50 & 0.27 & 0.90 & 0.00 & 1.08 & 0.11 & 0.80 & 0.00 \\
\hline KD4 & 0.81 & 1.12 & 0.74 & 0.00 & 0.76 & 1.01 & 0.70 & 0.01 & 0.60 & 0.65 & 0.62 & 0.03 \\
\hline KS & 41.24 & 0.04 & 2.66 & 0.00 & 7.65 & 0.02 & 1.72 & 0.00 & 1.85 & 0.01 & 1.05 & 0.00 \\
\hline KS1 & 3.02 & 0.17 & 1.39 & 0.00 & 2.86 & 0.08 & 1.33 & 0.00 & 1.53 & 0.03 & 0.97 & 0.00 \\
\hline KS2 & 0.36 & 0.81 & 0.51 & 0.00 & 0.32 & 0.55 & 0.45 & 0.00 & 0.37 & 0.28 & 0.48 & 0.00 \\
\hline KS3 & 0.37 & 0.75 & 0.50 & 0.00 & 0.34 & 0.52 & 0.47 & 0.00 & 0.39 & 0.27 & 0.50 & 0.00 \\
\hline KS4 & 3.20 & 0.17 & 1.43 & 0.00 & 2.93 & 0.08 & 1.35 & 0.00 & 1.54 & 0.03 & 0.97 & 0.00 \\
\hline KS5 & 0.36 & 0.76 & 0.50 & 0.00 & 0.34 & 0.52 & 0.46 & 0.00 & 0.38 & 0.27 & 0.50 & 0.00 \\
\hline KAL1 & 38.29 & 0.06 & 2.44 & 0.00 & 7.30 & 0.03 & 1.68 & 0.00 & 1.82 & 0.01 & 1.05 & 0.00 \\
\hline KAL2 & 38.93 & 0.05 & 2.50 & 0.00 & 7.40 & 0.03 & 1.69 & 0.00 & 1.83 & 0.01 & 1.05 & 0.00 \\
\hline KAS1 & 2.21 & 0.25 & 1.16 & 0.00 & 2.21 & 0.14 & 1.15 & 0.00 & 1.23 & 0.08 & 0.86 & 0.00 \\
\hline KAS2 & 0.74 & 2.10 & 0.84 & 0.01 & 0.73 & 2.14 & 0.83 & 0.03 & 0.67 & 2.04 & 0.79 & 0.14 \\
\hline KAS3 & 0.63 & 0.62 & 0.63 & 0.00 & 0.57 & 0.54 & 0.58 & 0.00 & 0.36 & 0.45 & 0.47 & 0.00 \\
\hline KAS4 & 0.59 & 1.51 & 0.71 & 0.00 & 0.56 & 1.54 & 0.69 & 0.02 & 0.46 & 1.41 & 0.62 & 0.07 \\
\hline KAS5 & 1.54 & 0.31 & 0.96 & 0.00 & 1.88 & 0.17 & 1.06 & 0.00 & 1.39 & 0.06 & 0.92 & 0.00 \\
\hline
\end{tabular}




$$
p=8, \rho=0.95
$$

\begin{tabular}{|c|c|c|c|c|c|c|c|c|c|c|c|c|}
\hline & \multicolumn{4}{|c|}{$\mathrm{n}=70$} & \multicolumn{4}{|c|}{$\mathrm{n}=100$} & \multicolumn{4}{|c|}{$\mathrm{n}=200$} \\
\hline & MSE & Bias & MAPE & Pr. & MSE & Bias & MAPE & Pr. & MSE & Bias & MAPE & Pr. \\
\hline ML & 807972.67 & 0.00 & 42.27 & 0 & 546.22 & 0.00 & 3.75 & 0 & 6.63 & 0.00 & 1.95 & 0.00 \\
\hline KH1 & 25.39 & 0.08 & 3.25 & 0 & 10.82 & 0.05 & 2.29 & 0 & 3.68 & 0.04 & 1.43 & 0.00 \\
\hline KH2 & 8.80 & 0.16 & 1.92 & 0 & 4.26 & 0.13 & 1.43 & 0 & 1.65 & 0.11 & 0.95 & 0.00 \\
\hline KL & 4.53 & 0.22 & 1.47 & 0 & 4.32 & 0.12 & 1.47 & 0 & 3.05 & 0.05 & 1.31 & 0.00 \\
\hline KHG & 22.20 & 0.09 & 3.10 & 0 & 9.93 & 0.05 & 2.23 & 0 & 3.55 & 0.04 & 1.42 & 0.00 \\
\hline $\mathrm{KBH}$ & 3.42 & 0.24 & 1.09 & 0 & 1.23 & 0.23 & 0.81 & 0 & 0.55 & 0.22 & 0.56 & 0.00 \\
\hline KNR & 2.39 & 0.32 & 0.94 & 0 & 0.96 & 0.31 & 0.69 & 0 & 0.35 & 0.33 & 0.44 & 0.00 \\
\hline KK1 & 2.90 & 0.35 & 1.02 & 0 & 1.28 & 0.33 & 0.76 & 0 & 0.59 & 0.31 & 0.55 & 0.00 \\
\hline KK2 & 1.25 & 1.13 & 0.78 & 0 & 0.64 & 1.13 & 0.66 & 0 & 0.46 & 1.11 & 0.58 & 0.00 \\
\hline KK3 & 4.15 & 0.30 & 1.23 & 0 & 1.89 & 0.27 & 0.92 & 0 & 0.82 & 0.25 & 0.64 & 0.00 \\
\hline KK4 & 0.98 & 0.32 & 0.76 & 0 & 0.96 & 0.23 & 0.74 & 0 & 0.84 & 0.16 & 0.70 & 0.00 \\
\hline KK5 & 0.92 & 0.38 & 0.75 & 0 & 1.49 & 0.17 & 0.96 & 0 & 2.14 & 0.06 & 1.18 & 0.00 \\
\hline KK6 & 1.23 & 0.29 & 0.85 & 0 & 1.21 & 0.21 & 0.84 & 0 & 1.00 & 0.14 & 0.76 & 0.00 \\
\hline KK7 & 0.36 & 0.73 & 0.51 & 0 & 0.38 & 0.40 & 0.49 & 0 & 0.75 & 0.14 & 0.70 & 0.00 \\
\hline KK8 & 0.73 & 0.43 & 0.67 & 0 & 1.19 & 0.20 & 0.85 & 0 & 1.87 & 0.07 & 1.10 & 0.00 \\
\hline KK9 & 0.45 & 1.03 & 0.60 & 0 & 0.37 & 0.91 & 0.53 & 0 & 0.31 & 0.72 & 0.46 & 0.00 \\
\hline KL1 & 0.79 & 1.46 & 0.77 & 0 & 0.69 & 1.30 & 0.70 & 0 & 0.65 & 1.00 & 0.65 & 0.00 \\
\hline KL2 & 0.59 & 1.73 & 0.74 & 0 & 0.44 & 1.39 & 0.63 & 0 & 0.24 & 0.93 & 0.46 & 0.00 \\
\hline KD1 & 12.65 & 0.12 & 2.52 & 0 & 9.57 & 0.05 & 2.22 & 0 & 4.76 & 0.02 & 1.65 & 0.00 \\
\hline KD2 & 6.29 & 0.21 & 1.72 & 0 & 5.43 & 0.12 & 1.63 & 0 & 3.39 & 0.06 & 1.37 & 0.00 \\
\hline KD3 & 4.53 & 0.24 & 1.45 & 0 & 4.18 & 0.14 & 1.42 & 0 & 2.94 & 0.07 & 1.27 & 0.00 \\
\hline KD4 & 1.60 & 0.89 & 0.89 & 0 & 1.43 & 0.72 & 0.83 & 0 & 1.28 & 0.50 & 0.81 & 0.00 \\
\hline $\mathrm{KS}$ & 120.11 & 0.03 & 4.64 & 0 & 23.01 & 0.02 & 2.88 & 0 & 5.56 & 0.01 & 1.80 & 0.00 \\
\hline KS1 & 3.91 & 0.15 & 1.60 & 0 & 4.47 & 0.07 & 1.69 & 0 & 3.36 & 0.03 & 1.45 & 0.00 \\
\hline KS2 & 0.34 & 0.91 & 0.53 & 0 & 0.24 & 0.58 & 0.41 & 0 & 0.28 & 0.27 & 0.42 & 0.00 \\
\hline KS3 & 0.32 & 0.78 & 0.50 & 0 & 0.25 & 0.51 & 0.41 & 0 & 0.32 & 0.25 & 0.44 & 0.00 \\
\hline KS4 & 4.50 & 0.14 & 1.71 & 0 & 4.83 & 0.07 & 1.75 & 0 & 3.44 & 0.03 & 1.46 & 0.00 \\
\hline KS5 & 0.33 & 0.80 & 0.50 & 0 & 0.25 & 0.52 & 0.41 & 0 & 0.31 & 0.25 & 0.44 & 0.00 \\
\hline KAL1 & 102.63 & 0.04 & 3.71 & 0 & 19.02 & 0.02 & 2.59 & 0 & 5.21 & 0.01 & 1.76 & 0.00 \\
\hline KAL2 & 106.05 & 0.04 & 3.96 & 0 & 20.07 & 0.02 & 2.67 & 0 & 5.31 & 0.01 & 1.77 & 0.00 \\
\hline KAS1 & 3.08 & 0.20 & 1.36 & 0 & 4.13 & 0.09 & 1.57 & 0 & 3.14 & 0.05 & 1.34 & 0.00 \\
\hline KAS2 & 0.65 & 1.76 & 0.77 & 0 & 0.63 & 1.79 & 0.75 & 0 & 0.58 & 1.76 & 0.72 & 0.01 \\
\hline KAS3 & 1.02 & 0.38 & 0.76 & 0 & 1.11 & 0.30 & 0.77 & 0 & 0.76 & 0.26 & 0.63 & 0.00 \\
\hline KAS4 & 0.59 & 1.18 & 0.68 & 0 & 0.53 & 1.14 & 0.63 & 0 & 0.46 & 1.11 & 0.58 & 0.00 \\
\hline KAS5 & 1.55 & 0.29 & 0.93 & 0 & 2.39 & 0.16 & 1.15 & 0 & 2.67 & 0.06 & 1.24 & 0.00 \\
\hline
\end{tabular}




$$
p=8, \rho=0.99
$$

\begin{tabular}{|c|c|c|c|c|c|c|c|c|c|c|c|c|}
\hline & \multicolumn{4}{|c|}{$\mathrm{n}=70$} & \multicolumn{4}{|c|}{$\mathrm{n}=100$} & \multicolumn{4}{|c|}{$\mathrm{n}=200$} \\
\hline & MSE & Bias & MAPE & Pr. & MSE & Bias & MAPE & Pr. & MSE & Bias & MAPE & Pr. \\
\hline $\mathrm{ML}$ & 680031.36 & 0.00 & 53.95 & 0 & 116.09 & 0.00 & 7.65 & 0 & 36.81 & 0.00 & 4.48 & 0 \\
\hline KH1 & 146.38 & 0.03 & 7.31 & 0 & 56.76 & 0.01 & 5.18 & 0 & 19.19 & 0.01 & 3.13 & 0 \\
\hline KH2 & 44.14 & 0.05 & 4.29 & 0 & 21.31 & 0.03 & 3.20 & 0 & 7.87 & 0.03 & 1.99 & 0 \\
\hline KL & 13.13 & 0.13 & 2.21 & 0 & 11.36 & 0.07 & 2.19 & 0 & 8.55 & 0.04 & 2.03 & 0 \\
\hline KHG & 61.42 & 0.05 & 4.71 & 0 & 24.86 & 0.03 & 3.42 & 0 & 8.76 & 0.03 & 2.11 & 0 \\
\hline $\mathrm{KBH}$ & 19.98 & 0.06 & 2.53 & 0 & 6.86 & 0.05 & 1.90 & 0 & 2.82 & 0.05 & 1.23 & 0 \\
\hline KNR & 13.20 & 0.09 & 2.38 & 0 & 6.91 & 0.07 & 1.77 & 0 & 2.44 & 0.08 & 1.07 & 0 \\
\hline KK1 & 11.95 & 0.11 & 2.14 & 0 & 6.10 & 0.09 & 1.62 & 0 & 2.41 & 0.10 & 1.03 & 0 \\
\hline KK2 & 3.43 & 0.61 & 1.05 & 0 & 1.72 & 0.64 & 0.83 & 0 & 0.81 & 0.66 & 0.63 & 0 \\
\hline KK3 & 17.19 & 0.10 & 2.61 & 0 & 8.77 & 0.07 & 1.97 & 0 & 3.34 & 0.08 & 1.23 & 0 \\
\hline KK4 & 1.53 & 0.16 & 0.93 & 0 & 1.57 & 0.11 & 0.93 & 0 & 1.44 & 0.08 & 0.89 & 0 \\
\hline KK5 & 0.29 & 0.55 & 0.46 & 0 & 0.34 & 0.27 & 0.45 & 0 & 1.06 & 0.08 & 0.80 & 0 \\
\hline KK6 & 2.00 & 0.15 & 1.06 & 0 & 2.03 & 0.10 & 1.07 & 0 & 1.78 & 0.07 & 0.99 & 0 \\
\hline KK7 & 0.37 & 1.07 & 0.57 & 0 & 0.20 & 0.65 & 0.40 & 0 & 0.17 & 0.24 & 0.32 & 0 \\
\hline KK8 & 0.28 & 0.62 & 0.46 & 0 & 0.27 & 0.32 & 0.40 & 0 & 0.80 & 0.10 & 0.69 & 0 \\
\hline KK9 & 0.40 & 0.67 & 0.53 & 0 & 0.34 & 0.60 & 0.47 & 0 & 0.29 & 0.47 & 0.42 & 0 \\
\hline KL1 & 1.70 & 0.91 & 0.84 & 0 & 1.65 & 0.81 & 0.82 & 0 & 1.71 & 0.61 & 0.83 & 0 \\
\hline KL2 & 0.82 & 2.38 & 0.90 & 0 & 0.73 & 2.17 & 0.84 & 0 & 0.52 & 1.71 & 0.70 & 0 \\
\hline KD1 & 62.48 & 0.05 & 5.51 & 0 & 46.71 & 0.01 & 4.92 & 0 & 24.31 & 0.01 & 3.62 & 0 \\
\hline KD2 & 28.17 & 0.08 & 3.63 & 0 & 24.40 & 0.03 & 3.51 & 0 & 15.41 & 0.02 & 2.87 & 0 \\
\hline KD3 & 20.82 & 0.09 & 3.10 & 0 & 19.32 & 0.04 & 3.09 & 0 & 13.40 & 0.02 & 2.66 & 0 \\
\hline KD4 & 6.09 & 0.47 & 1.43 & 0 & 6.02 & 0.39 & 1.46 & 0 & 5.09 & 0.27 & 1.43 & 0 \\
\hline KS & 249.79 & 0.01 & 8.39 & 0 & 64.33 & 0.01 & 5.70 & 0 & 24.01 & 0.01 & 3.65 & 0 \\
\hline KS1 & 2.82 & 0.11 & 1.34 & 0 & 4.17 & 0.05 & 1.64 & 0 & 5.37 & 0.02 & 1.85 & 0 \\
\hline KS2 & 0.39 & 1.15 & 0.60 & 0 & 0.22 & 0.74 & 0.43 & 0 & 0.10 & 0.32 & 0.26 & 0 \\
\hline KS3 & 0.30 & 0.85 & 0.51 & 0 & 0.17 & 0.54 & 0.36 & 0 & 0.13 & 0.25 & 0.28 & 0 \\
\hline KS4 & 4.52 & 0.09 & 1.70 & 0 & 5.70 & 0.04 & 1.91 & 0 & 6.12 & 0.02 & 1.96 & 0 \\
\hline KS5 & 0.31 & 0.88 & 0.52 & 0 & 0.17 & 0.56 & 0.37 & 0 & 0.12 & 0.25 & 0.27 & 0 \\
\hline KAL1 & 113.18 & 0.03 & 4.05 & 0 & 20.18 & 0.02 & 3.54 & 0 & 14.59 & 0.01 & 3.01 & 0 \\
\hline KAL2 & 127.68 & 0.02 & 5.07 & 0 & 28.40 & 0.01 & 4.13 & 0 & 16.71 & 0.01 & 3.19 & 0 \\
\hline KAS1 & 3.14 & 0.15 & 1.33 & 0 & 6.52 & 0.05 & 1.99 & 0 & 9.76 & 0.02 & 2.40 & 0 \\
\hline KAS2 & 0.52 & 1.18 & 0.65 & 0 & 0.51 & 1.20 & 0.62 & 0 & 0.46 & 1.22 & 0.59 & 0 \\
\hline KAS3 & 1.48 & 0.20 & 0.90 & 0 & 2.47 & 0.11 & 1.15 & 0 & 2.51 & 0.09 & 1.10 & 0 \\
\hline KAS4 & 0.63 & 0.68 & 0.63 & 0 & 0.76 & 0.66 & 0.66 & 0 & 0.70 & 0.66 & 0.60 & 0 \\
\hline KAS5 & 1.52 & 0.22 & 0.88 & 0 & 3.12 & 0.10 & 1.26 & 0 & 5.57 & 0.04 & 1.71 & 0 \\
\hline
\end{tabular}


Table A4. Estimated MSEs, MAPEs, bias and proportion of times in simulation when the ridge regression estimator produces a higher MSE than the ML estimator of the proposed and new estimators for the following cases:

$$
p=4, \rho=0.95, \text { intercept }=0
$$

\begin{tabular}{|c|c|c|c|c|c|c|c|c|c|c|c|c|}
\hline & \multicolumn{4}{|c|}{$\mathrm{n}=70$} & \multicolumn{4}{|c|}{$\mathrm{n}=100$} & \multicolumn{4}{|c|}{$\mathrm{n}=200$} \\
\hline & MSE & Bias & MAPE & Pr. & MSE & Bias & MAPE & Pr. & MSE & Bias & MAPE & Pr. \\
\hline ML & 8.34 & 0.00 & 2.19 & 0.00 & 4.70 & 0.00 & 1.67 & 0.00 & 1.88 & 0.00 & 1.07 & 0.00 \\
\hline KH1 & 3.72 & 0.09 & 1.33 & 0.00 & 2.15 & 0.08 & 1.04 & 0.00 & 0.92 & 0.07 & 0.70 & 0.00 \\
\hline KH2 & 2.06 & 0.17 & 0.95 & 0.00 & 1.23 & 0.16 & 0.76 & 0.01 & 0.54 & 0.13 & 0.53 & 0.00 \\
\hline KL & 2.94 & 0.12 & 1.17 & 0.00 & 2.29 & 0.08 & 1.08 & 0.00 & 1.30 & 0.03 & 0.86 & 0.00 \\
\hline KHG & 2.96 & 0.12 & 1.17 & 0.00 & 1.71 & 0.11 & 0.92 & 0.00 & 0.76 & 0.09 & 0.63 & 0.00 \\
\hline $\mathrm{KBH}$ & 0.63 & 0.28 & 0.56 & 0.00 & 0.41 & 0.27 & 0.46 & 0.01 & 0.20 & 0.24 & 0.33 & 0.01 \\
\hline KNR & 0.49 & 0.43 & 0.50 & 0.00 & 0.31 & 0.44 & 0.42 & 0.01 & 0.15 & 0.43 & 0.31 & 0.01 \\
\hline KK1 & 1.02 & 0.37 & 0.67 & 0.01 & 0.66 & 0.35 & 0.57 & 0.02 & 0.31 & 0.31 & 0.41 & 0.02 \\
\hline KK2 & 0.75 & 0.77 & 0.66 & 0.03 & 0.55 & 0.73 & 0.58 & 0.05 & 0.36 & 0.70 & 0.49 & 0.10 \\
\hline KK3 & 1.15 & 0.37 & 0.71 & 0.01 & 0.75 & 0.37 & 0.61 & 0.02 & 0.35 & 0.32 & 0.43 & 0.02 \\
\hline KK4 & 0.62 & 0.24 & 0.58 & 0.00 & 0.57 & 0.19 & 0.56 & 0.00 & 0.40 & 0.13 & 0.47 & 0.00 \\
\hline KK5 & 0.79 & 0.15 & 0.72 & 0.00 & 0.93 & 0.09 & 0.78 & 0.00 & 0.92 & 0.03 & 0.78 & 0.00 \\
\hline KK6 & 0.69 & 0.23 & 0.61 & 0.00 & 0.62 & 0.19 & 0.58 & 0.00 & 0.43 & 0.13 & 0.49 & 0.00 \\
\hline KK7 & 0.29 & 0.28 & 0.43 & 0.00 & 0.39 & 0.17 & 0.51 & 0.00 & 0.53 & 0.06 & 0.59 & 0.00 \\
\hline KK8 & 0.61 & 0.18 & 0.63 & 0.00 & 0.76 & 0.10 & 0.71 & 0.00 & 0.82 & 0.04 & 0.73 & 0.00 \\
\hline KK9 & 0.34 & 0.59 & 0.48 & 0.01 & 0.31 & 0.50 & 0.44 & 0.02 & 0.24 & 0.39 & 0.38 & 0.02 \\
\hline KL1 & 1.09 & 0.68 & 0.75 & 0.02 & 0.98 & 0.54 & 0.71 & 0.04 & 0.69 & 0.39 & 0.61 & 0.04 \\
\hline KL2 & 0.31 & 0.93 & 0.50 & 0.00 & 0.23 & 0.77 & 0.43 & 0.00 & 0.13 & 0.55 & 0.30 & 0.01 \\
\hline KD1 & 4.71 & 0.06 & 1.56 & 0.00 & 3.25 & 0.04 & 1.34 & 0.00 & 1.59 & 0.01 & 0.97 & 0.00 \\
\hline KD2 & 3.09 & 0.15 & 1.20 & 0.00 & 2.39 & 0.11 & 1.09 & 0.00 & 1.30 & 0.05 & 0.85 & 0.00 \\
\hline KD3 & 2.92 & 0.14 & 1.16 & 0.00 & 2.31 & 0.09 & 1.08 & 0.00 & 1.29 & 0.04 & 0.85 & 0.00 \\
\hline KD4 & 1.81 & 0.45 & 0.91 & 0.01 & 1.52 & 0.33 & 0.85 & 0.02 & 0.93 & 0.23 & 0.71 & 0.02 \\
\hline KS & 5.63 & 0.02 & 1.79 & 0.00 & 3.50 & 0.02 & 1.44 & 0.00 & 1.60 & 0.01 & 0.99 & 0.00 \\
\hline KS1 & 1.91 & 0.07 & 1.11 & 0.00 & 1.73 & 0.05 & 1.04 & 0.00 & 1.14 & 0.02 & 0.84 & 0.00 \\
\hline KS2 & 0.15 & 0.44 & 0.30 & 0.00 & 0.16 & 0.30 & 0.32 & 0.00 & 0.22 & 0.14 & 0.38 & 0.00 \\
\hline KS3 & 0.16 & 0.40 & 0.31 & 0.00 & 0.18 & 0.28 & 0.34 & 0.00 & 0.24 & 0.14 & 0.39 & 0.00 \\
\hline KS4 & 2.13 & 0.07 & 1.16 & 0.00 & 1.84 & 0.05 & 1.07 & 0.00 & 1.16 & 0.02 & 0.85 & 0.00 \\
\hline KS5 & 0.16 & 0.41 & 0.31 & 0.00 & 0.18 & 0.28 & 0.33 & 0.00 & 0.24 & 0.14 & 0.39 & 0.00 \\
\hline KAL1 & 4.26 & 0.03 & 1.61 & 0.00 & 3.05 & 0.02 & 1.36 & 0.00 & 1.53 & 0.01 & 0.97 & 0.00 \\
\hline KAL2 & 4.79 & 0.03 & 1.68 & 0.00 & 3.23 & 0.02 & 1.40 & 0.00 & 1.56 & 0.01 & 0.98 & 0.00 \\
\hline KAS1 & 1.92 & 0.12 & 1.03 & 0.00 & 1.69 & 0.09 & 0.95 & 0.00 & 0.89 & 0.07 & 0.69 & 0.00 \\
\hline KAS2 & 0.54 & 1.07 & 0.64 & 0.04 & 0.49 & 1.03 & 0.61 & 0.08 & 0.41 & 0.99 & 0.56 & 0.16 \\
\hline KAS3 & 0.71 & 0.39 & 0.62 & 0.01 & 0.64 & 0.37 & 0.58 & 0.02 & 0.34 & 0.32 & 0.43 & 0.02 \\
\hline KAS4 & 0.57 & 0.78 & 0.61 & 0.03 & 0.50 & 0.73 & 0.57 & 0.05 & 0.36 & 0.70 & 0.49 & 0.10 \\
\hline KAS5 & 1.66 & 0.15 & 0.95 & 0.00 & 1.79 & 0.09 & 0.98 & 0.00 & 1.24 & 0.03 & 0.84 & 0.00 \\
\hline KN1 & 0.25 & 0.73 & 0.42 & 0.02 & 0.22 & 0.63 & 0.39 & 0.03 & 0.17 & 0.52 & 0.35 & 0.05 \\
\hline KN2 & 0.3 & 0.4 & 0.44 & 0.01 & 0.32 & 0.33 & 0.45 & 0.01 & 0.27 & 0.21 & 0.4 & 0.01 \\
\hline KN3 & 0.51 & 0.25 & 0.53 & 0.00 & 0.45 & 0.2 & 0.5 & 0.00 & 0.35 & 0.12 & 0.46 & 0.00 \\
\hline KN4 & 1.29 & 0.16 & 0.8 & 0.00 & 1.23 & 0.11 & 0.81 & 0.00 & 0.9 & 0.05 & 0.72 & 0.00 \\
\hline
\end{tabular}




$$
p=4, \rho=0.95, \text { intercept }=1
$$

\begin{tabular}{|c|c|c|c|c|c|c|c|c|c|c|c|c|}
\hline & \multicolumn{4}{|c|}{$\mathrm{n}=70$} & \multicolumn{4}{|c|}{$\mathrm{n}=100$} & \multicolumn{4}{|c|}{$\mathrm{n}=200$} \\
\hline & MSE & Bias & MAPE & Pr. & MSE & Bias & MAPE & Pr. & MSE & Bias & MAPE & Pr. \\
\hline ML & 8.64 & 0.00 & 2.20 & 0.00 & 4.92 & 0.00 & 1.72 & 0.00 & 2.11 & 0.00 & 1.14 & 0.00 \\
\hline KH1 & 3.85 & 0.09 & 1.34 & 0.00 & 2.31 & 0.07 & 1.09 & 0.00 & 1.11 & 0.05 & 0.79 & 0.00 \\
\hline KH2 & 2.07 & 0.16 & 0.96 & 0.00 & 1.29 & 0.14 & 0.79 & 0.00 & 0.67 & 0.10 & 0.60 & 0.00 \\
\hline KL & 2.60 & 0.14 & 1.08 & 0.00 & 2.07 & 0.09 & 1.04 & 0.00 & 1.40 & 0.03 & 0.90 & 0.00 \\
\hline KHG & 3.36 & 0.10 & 1.24 & 0.00 & 2.05 & 0.09 & 1.02 & 0.00 & 1.01 & 0.06 & 0.75 & 0.00 \\
\hline $\mathrm{KBH}$ & 0.61 & 0.26 & 0.56 & 0.00 & 0.41 & 0.25 & 0.47 & 0.01 & 0.23 & 0.21 & 0.37 & 0.00 \\
\hline KNR & 0.49 & 0.39 & 0.52 & 0.00 & 0.32 & 0.38 & 0.44 & 0.01 & 0.17 & 0.36 & 0.35 & 0.00 \\
\hline KK1 & 1.05 & 0.35 & 0.69 & 0.01 & 0.68 & 0.33 & 0.59 & 0.02 & 0.40 & 0.27 & 0.47 & 0.02 \\
\hline KK2 & 0.83 & 0.71 & 0.68 & 0.03 & 0.60 & 0.69 & 0.62 & 0.05 & 0.43 & 0.62 & 0.54 & 0.09 \\
\hline KK3 & 1.16 & 0.37 & 0.73 & 0.01 & 0.79 & 0.35 & 0.63 & 0.02 & 0.46 & 0.31 & 0.51 & 0.04 \\
\hline KK4 & 0.57 & 0.24 & 0.56 & 0.00 & 0.54 & 0.19 & 0.55 & 0.00 & 0.44 & 0.12 & 0.50 & 0.00 \\
\hline KK5 & 0.69 & 0.16 & 0.66 & 0.00 & 0.88 & 0.09 & 0.75 & 0.00 & 0.89 & 0.04 & 0.77 & 0.00 \\
\hline KK6 & 0.63 & 0.23 & 0.59 & 0.00 & 0.59 & 0.19 & 0.57 & 0.00 & 0.47 & 0.13 & 0.52 & 0.00 \\
\hline KK7 & 0.26 & 0.30 & 0.41 & 0.00 & 0.33 & 0.18 & 0.46 & 0.00 & 0.47 & 0.08 & 0.56 & 0.00 \\
\hline KK8 & 0.56 & 0.18 & 0.59 & 0.00 & 0.74 & 0.11 & 0.69 & 0.00 & 0.82 & 0.04 & 0.74 & 0.00 \\
\hline KK9 & 0.37 & 0.55 & 0.50 & 0.02 & 0.34 & 0.48 & 0.48 & 0.02 & 0.28 & 0.35 & 0.42 & 0.03 \\
\hline KL1 & 0.98 & 0.71 & 0.73 & 0.03 & 0.86 & 0.59 & 0.71 & 0.04 & 0.76 & 0.40 & 0.66 & 0.06 \\
\hline KL2 & 0.35 & 0.82 & 0.54 & 0.00 & 0.27 & 0.70 & 0.48 & 0.00 & 0.18 & 0.53 & 0.38 & 0.01 \\
\hline KD1 & 3.91 & 0.08 & 1.39 & 0.00 & 2.94 & 0.05 & 1.27 & 0.00 & 1.70 & 0.02 & 1.01 & 0.00 \\
\hline KD2 & 2.41 & 0.20 & 1.04 & 0.00 & 1.98 & 0.14 & 1.00 & 0.01 & 1.35 & 0.07 & 0.86 & 0.01 \\
\hline KD3 & 2.29 & 0.19 & 1.01 & 0.00 & 1.89 & 0.12 & 0.97 & 0.00 & 1.33 & 0.05 & 0.86 & 0.00 \\
\hline KD4 & 1.52 & 0.48 & 0.85 & 0.02 & 1.29 & 0.39 & 0.82 & 0.02 & 1.01 & 0.24 & 0.74 & 0.03 \\
\hline KS & 6.08 & 0.02 & 1.85 & 0.00 & 3.86 & 0.01 & 1.52 & 0.00 & 1.85 & 0.01 & 1.07 & 0.00 \\
\hline KS1 & 2.06 & 0.06 & 1.15 & 0.00 & 1.91 & 0.04 & 1.10 & 0.00 & 1.32 & 0.02 & 0.91 & 0.00 \\
\hline KS2 & 0.19 & 0.48 & 0.37 & 0.00 & 0.16 & 0.34 & 0.31 & 0.00 & 0.17 & 0.18 & 0.33 & 0.00 \\
\hline KS3 & 0.19 & 0.45 & 0.36 & 0.00 & 0.17 & 0.32 & 0.32 & 0.00 & 0.19 & 0.17 & 0.34 & 0.00 \\
\hline KS4 & 2.24 & 0.06 & 1.19 & 0.00 & 2.00 & 0.04 & 1.12 & 0.00 & 1.34 & 0.02 & 0.92 & 0.00 \\
\hline KS5 & 0.19 & 0.45 & 0.36 & 0.00 & 0.16 & 0.32 & 0.32 & 0.00 & 0.19 & 0.17 & 0.34 & 0.00 \\
\hline KAL1 & 4.95 & 0.02 & 1.71 & 0.00 & 3.50 & 0.01 & 1.46 & 0.00 & 1.80 & 0.01 & 1.06 & 0.00 \\
\hline KAL2 & 5.37 & 0.02 & 1.77 & 0.00 & 3.64 & 0.01 & 1.49 & 0.00 & 1.82 & 0.01 & 1.06 & 0.00 \\
\hline KAS1 & 1.52 & 0.13 & 0.92 & 0.00 & 1.55 & 0.09 & 0.93 & 0.00 & 1.03 & 0.05 & 0.77 & 0.00 \\
\hline KAS2 & 0.54 & 0.99 & 0.66 & 0.04 & 0.51 & 0.96 & 0.64 & 0.07 & 0.45 & 0.88 & 0.59 & 0.14 \\
\hline KAS3 & 0.62 & 0.39 & 0.60 & 0.01 & 0.61 & 0.36 & 0.59 & 0.02 & 0.44 & 0.31 & 0.50 & 0.04 \\
\hline KAS4 & 0.54 & 0.73 & 0.62 & 0.03 & 0.51 & 0.69 & 0.60 & 0.05 & 0.42 & 0.62 & 0.54 & 0.09 \\
\hline KAS5 & 1.22 & 0.17 & 0.81 & 0.00 & 1.46 & 0.10 & 0.90 & 0.00 & 1.28 & 0.04 & 0.87 & 0.00 \\
\hline KN1 & 0.32 & 0.75 & 0.49 & 0.02 & 0.27 & 0.64 & 0.44 & 0.04 & 0.2 & 0.5 & 0.38 & 0.06 \\
\hline KN2 & 0.29 & 0.42 & 0.44 & 0.01 & 0.3 & 0.34 & 0.44 & 0.01 & 0.27 & 0.23 & 0.41 & 0.02 \\
\hline KN3 & 0.54 & 0.25 & 0.54 & 0 & 0.44 & 0.2 & 0.49 & 0 & 0.35 & 0.13 & 0.45 & 0.00 \\
\hline KN4 & 1.25 & 0.17 & 0.78 & 0 & 1.06 & 0.13 & 0.74 & 0 & 0.84 & 0.06 & 0.7 & 0.00 \\
\hline
\end{tabular}




$$
p=4, \rho=0.95, \text { intercept }=-1
$$

\begin{tabular}{|c|c|c|c|c|c|c|c|c|c|c|c|c|}
\hline & \multicolumn{4}{|c|}{$\mathrm{n}=70$} & \multicolumn{4}{|c|}{$\mathrm{n}=100$} & \multicolumn{4}{|c|}{$\mathrm{n}=200$} \\
\hline & MSE & Bias & MAPE & Pr. & MSE & Bias & MAPE & Pr. & MSE & Bias & MAPE & Pr. \\
\hline ML & 8.91 & 0.00 & 2.22 & 0.00 & 4.91 & 0.00 & 1.71 & 0.00 & 2.05 & 0.00 & 1.12 & 0.00 \\
\hline KH1 & 4.03 & 0.08 & 1.38 & 0.00 & 2.37 & 0.07 & 1.10 & 0.00 & 1.11 & 0.05 & 0.79 & 0.00 \\
\hline KH2 & 2.10 & 0.16 & 0.97 & 0.00 & 1.30 & 0.14 & 0.79 & 0.00 & 0.64 & 0.10 & 0.58 & 0.00 \\
\hline KL & 2.39 & 0.14 & 1.06 & 0.00 & 2.01 & 0.09 & 1.01 & 0.00 & 1.30 & 0.04 & 0.87 & 0.00 \\
\hline KHG & 3.23 & 0.10 & 1.23 & 0.00 & 1.97 & 0.09 & 0.99 & 0.00 & 0.95 & 0.07 & 0.72 & 0.00 \\
\hline $\mathrm{KBH}$ & 0.62 & 0.25 & 0.57 & 0.00 & 0.42 & 0.24 & 0.47 & 0.00 & 0.23 & 0.21 & 0.36 & 0.01 \\
\hline KNR & 0.52 & 0.38 & 0.53 & 0.00 & 0.34 & 0.37 & 0.44 & 0.00 & 0.18 & 0.35 & 0.35 & 0.01 \\
\hline KK1 & 1.04 & 0.37 & 0.68 & 0.01 & 0.67 & 0.34 & 0.58 & 0.01 & 0.35 & 0.29 & 0.45 & 0.03 \\
\hline KK2 & 0.83 & 0.76 & 0.69 & 0.03 & 0.59 & 0.71 & 0.61 & 0.04 & 0.42 & 0.70 & 0.55 & 0.11 \\
\hline KK3 & 1.15 & 0.38 & 0.72 & 0.01 & 0.75 & 0.36 & 0.61 & 0.01 & 0.40 & 0.33 & 0.48 & 0.04 \\
\hline KK4 & 0.57 & 0.24 & 0.56 & 0.00 & 0.53 & 0.19 & 0.54 & 0.00 & 0.40 & 0.13 & 0.48 & 0.00 \\
\hline KK5 & 0.70 & 0.16 & 0.67 & 0.00 & 0.89 & 0.09 & 0.76 & 0.00 & 0.93 & 0.04 & 0.78 & 0.00 \\
\hline KK6 & 0.62 & 0.24 & 0.59 & 0.00 & 0.57 & 0.19 & 0.56 & 0.00 & 0.42 & 0.13 & 0.49 & 0.00 \\
\hline KK7 & 0.26 & 0.30 & 0.40 & 0.00 & 0.33 & 0.19 & 0.45 & 0.00 & 0.45 & 0.08 & 0.55 & 0.00 \\
\hline KK8 & 0.57 & 0.18 & 0.60 & 0.00 & 0.77 & 0.10 & 0.71 & 0.00 & 0.86 & 0.04 & 0.75 & 0.00 \\
\hline KK9 & 0.38 & 0.58 & 0.51 & 0.02 & 0.33 & 0.49 & 0.47 & 0.01 & 0.27 & 0.39 & 0.42 & 0.04 \\
\hline KL1 & 0.98 & 0.75 & 0.75 & 0.03 & 0.84 & 0.62 & 0.69 & 0.03 & 0.67 & 0.46 & 0.63 & 0.06 \\
\hline KL2 & 0.35 & 0.85 & 0.55 & 0.00 & 0.28 & 0.71 & 0.48 & 0.00 & 0.18 & 0.54 & 0.38 & 0.02 \\
\hline KD1 & 3.96 & 0.07 & 1.41 & 0.00 & 2.96 & 0.05 & 1.27 & 0.00 & 1.65 & 0.02 & 0.99 & 0.00 \\
\hline KD2 & 2.37 & 0.21 & 1.04 & 0.00 & 1.92 & 0.15 & 0.97 & 0.00 & 1.19 & 0.07 & 0.81 & 0.01 \\
\hline KD3 & 2.23 & 0.19 & 1.00 & 0.00 & 1.86 & 0.13 & 0.95 & 0.00 & 1.19 & 0.06 & 0.81 & 0.00 \\
\hline KD4 & 1.49 & 0.52 & 0.85 & 0.02 & 1.24 & 0.40 & 0.79 & 0.02 & 0.87 & 0.28 & 0.69 & 0.03 \\
\hline KS & 6.25 & 0.02 & 1.87 & 0.00 & 3.86 & 0.01 & 1.52 & 0.00 & 1.80 & 0.01 & 1.05 & 0.00 \\
\hline KS1 & 2.06 & 0.06 & 1.15 & 0.00 & 1.90 & 0.04 & 1.10 & 0.00 & 1.28 & 0.02 & 0.90 & 0.00 \\
\hline KS2 & 0.19 & 0.48 & 0.37 & 0.00 & 0.15 & 0.34 & 0.31 & 0.00 & 0.17 & 0.17 & 0.33 & 0.00 \\
\hline KS3 & 0.19 & 0.44 & 0.36 & 0.00 & 0.16 & 0.32 & 0.32 & 0.00 & 0.19 & 0.16 & 0.34 & 0.00 \\
\hline KS4 & 2.24 & 0.06 & 1.19 & 0.00 & 1.99 & 0.04 & 1.12 & 0.00 & 1.30 & 0.02 & 0.90 & 0.00 \\
\hline KS5 & 0.19 & 0.45 & 0.36 & 0.00 & 0.16 & 0.32 & 0.31 & 0.00 & 0.18 & 0.17 & 0.34 & 0.00 \\
\hline KAL1 & 5.03 & 0.02 & 1.72 & 0.00 & 3.47 & 0.01 & 1.45 & 0.00 & 1.75 & 0.01 & 1.04 & 0.00 \\
\hline KAL2 & 5.47 & 0.02 & 1.78 & 0.00 & 3.62 & 0.01 & 1.48 & 0.00 & 1.77 & 0.01 & 1.04 & 0.00 \\
\hline KAS1 & 1.56 & 0.12 & 0.94 & 0.00 & 1.58 & 0.09 & 0.94 & 0.00 & 1.03 & 0.05 & 0.76 & 0.00 \\
\hline KAS2 & 0.56 & 1.03 & 0.67 & 0.05 & 0.53 & 1.00 & 0.64 & 0.06 & 0.47 & 0.97 & 0.61 & 0.15 \\
\hline KAS3 & 0.62 & 0.41 & 0.60 & 0.01 & 0.59 & 0.37 & 0.57 & 0.01 & 0.39 & 0.33 & 0.47 & 0.04 \\
\hline KAS4 & 0.56 & 0.77 & 0.63 & 0.03 & 0.51 & 0.72 & 0.59 & 0.04 & 0.42 & 0.70 & 0.54 & 0.11 \\
\hline KAS5 & 1.20 & 0.17 & 0.80 & 0.00 & 1.42 & 0.11 & 0.88 & 0.00 & 1.19 & 0.04 & 0.83 & 0.00 \\
\hline KN1 & 0.31 & 0.74 & 0.49 & 0.02 & 0.26 & 0.63 & 0.43 & 0.03 & 0.21 & 0.48 & 0.38 & 0.04 \\
\hline KN2 & 0.28 & 0.41 & 0.43 & 0.01 & 0.29 & 0.34 & 0.43 & 0.01 & 0.28 & 0.22 & 0.41 & 0.01 \\
\hline KN3 & 0.52 & 0.25 & 0.53 & 0 & 0.44 & 0.2 & 0.49 & 0 & 0.35 & 0.13 & 0.45 & 0.00 \\
\hline KN4 & 1.18 & 0.17 & 0.76 & 0 & 1.1 & 0.13 & 0.74 & 0 & 0.9 & 0.06 & 0.71 & 0.00 \\
\hline
\end{tabular}

